Chapman University

Chapman University Digital Commons

Education (PhD) Dissertations

Dissertations and Theses

Spring 5-2021

\title{
Mitigating Risks for Youth in At-Risk Living Conditions Through School-Based Protective Factors
}

\author{
Cora Palma \\ Chapman University, corpalma@chapman.edu
}

Follow this and additional works at: https://digitalcommons.chapman.edu/education_dissertations

Part of the School Psychology Commons

\section{Recommended Citation}

Palma, C. G. (2021). Mitigating risks for youth in at-risk living conditions through school-based protective factors [Doctoral dissertation, Chapman University]. Chapman University Digital Commons.

https://doi.org/10.36837/chapman.000267

This Dissertation is brought to you for free and open access by the Dissertations and Theses at Chapman University Digital Commons. It has been accepted for inclusion in Education (PhD) Dissertations by an authorized administrator of Chapman University Digital Commons. For more information, please contact laughtin@chapman.edu. 
Mitigating Risks for Youth in At-Risk Living Conditions Through

School-Based Protective Factors

A Dissertation by

Cora G. Palma

Chapman University

Orange, CA

Attallah College of Educational Studies

Submitted in partial fulfillment of the requirements for the degree of Doctor of Philosophy in Education, with an Emphasis in School Psychology

May 2021

Committee in charge:

Kelly Kennedy, PhD, Chair

Amy-Jane Griffiths, PhD

Emily Fisher, $\mathrm{PhD}$

Scot Danforth, PhD 
The dissertation of Cora G. Palma is approved.

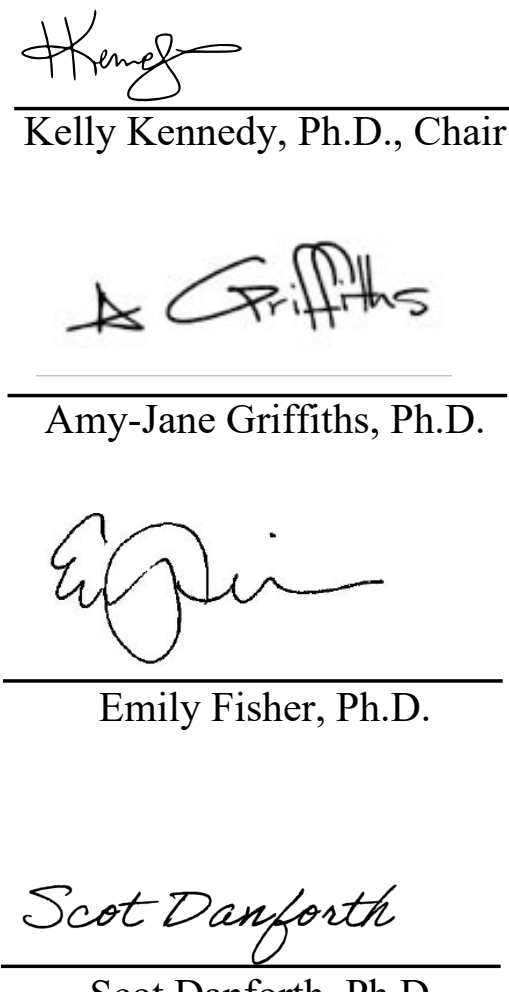

Scot Danforth, Ph.D.

March 2021 
Mitigating Risks for Youth in At-Risk Living Conditions Through

School-Based Protective Factors

Copyright (C) 2021

by Cora G. Palma 
For Luca, who lights the way. 


\section{ACKNOWLEDGEMENTS}

I must first and foremost thank those in my life who in some ways have laid the foundation for who I am. Dad—who taught me how to view mankind with compassion first, always - so much that I do in life is to honor your legacy. Mom, who taught me grit and strength. My quick-witted and highly intelligent brothers and sisters, Sky, Bethania, Nathaniel, Felicity,

Gabriel, and Agatha, with whom I would rather spend any given day-above anyone else — and who never fail to keep me humble and show me how little I actually know. Louise, Penny, and Leonard, who demonstrated a life of service to others and provided countless childhood memories. My mother-in-law, Etie, whose presence in my life was a lightning rod and whose encouragement alone would carry me for a mile - in so many ways, you have been with me through all of this. My son, my teacher, my reflection, and my inspiration, Luca, whose love is boundless and who has taught me endless patience and new heights of respect for all mothers. You are a model of true resilience. I hope you are always a life-long learner, continue to question everything you know, and, regardless of what path your life takes you on, always find ways to use your talents and gifts for the good of humanity. Finally, my friends, who have believed in my ability to do this — and do it well—-sometimes at levels higher than my own belief in myself.

I am deeply thankful to my professors and colleagues at Chapman who contributed in some way to the formulation of this research project and its eventual realization. I am above all thankful to my committee - especially my chair, Kelly_-for knowing exactly when to push me, for her encyclopedic brilliance that has always helped to elaborate my fragmented ideas, and for the relentless support which enabled me to pull myself through this tireless process, despite all things in life at constant odds with it. Thank you, Amy, for your ear and your wisdom, for being a model of resilience, grace under pressure, and grit. Thank you, Scot, for contributing to a 
sharp-left in both my thinking and approach to the field. Thank you, Emily, for your wisdom and support of this study. Additionally, I owe my gratitude to the many professors who allowed me to knock on their office door unannounced or hold them hostage after class to spin ideas, and to Dawn, whose compassion, patience, and encouragement have truly made this possible.

Finally, I am grateful to my husband, Kevin, whose own work ethic has inspired me as I have pursued this relentless and unforgiving life goal. Thank you for the sacrifices you have made and continue to make daily for your family, and for allowing me the space and ability to realize this dream. 


\begin{abstract}
Mitigating Risks for Youth in At-Risk Living Conditions Through

School-Based Protective Factors

by Cora G. Palma
\end{abstract}

Youth who are in foster care or are homeless - those who reside in at-risk living conditions - face increased risk for difficulties in school including poor grades and mental health issues such as suicidality and depression. Previous research has shown that youth who are in foster care or who are homeless have, by definition, experienced adverse childhood experiences or trauma, increasing their risks for poor outcomes. Protective factors in schools can have a significant and meaningful impact on reducing the rates of depression, suicidal ideation, and failing grades. Schools that provide environments in which caring relationships between students and adults are established, high expectations are held for the students, and students are given an opportunity for meaningful participation, are environments in which youth can thrive despite having faced adversity. There is a dearth of literature delineating school-specific risks and supports for students who have experienced the adverse childhood experiences related to residing in at-risk living conditions. This study examines the results of a large self-report survey on behaviors and resiliency of students in California, the California Healthy Kids Survey. Results of a hierarchical logistic regression model showed supportive relationships between adults and students and high expectations may significantly and profoundly reduce suicidal ideation, depressive symptoms, and failing grades in students residing in at-risk living conditions. This study provides evidence that students in foster care or homelessness are a unique population with distinct experiences and needs, and school practices that aim to support all students must consider the unique needs of this population. 


\section{TABLE OF CONTENTS}

$\underline{\text { Page }}$

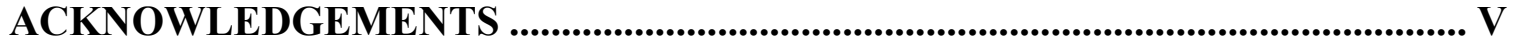

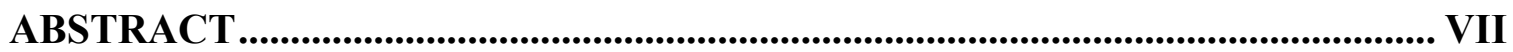

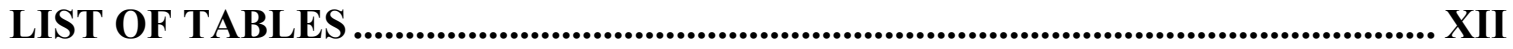

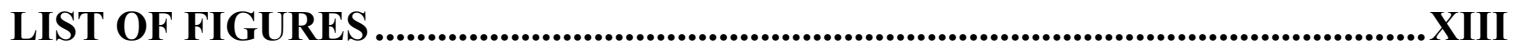

LIST OF ABBREVIATIONS .............................................................................XIV

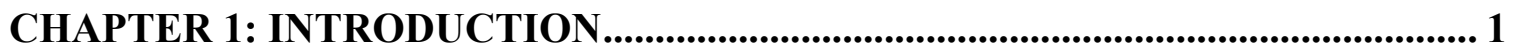

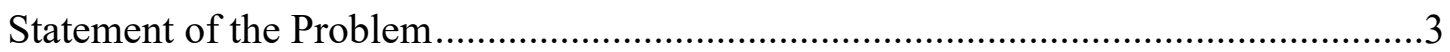

Purpose of the Present Study ...........................................................................

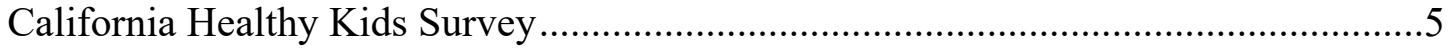

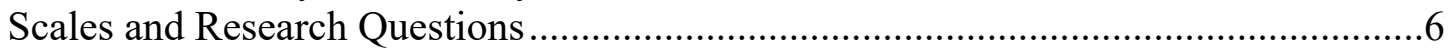

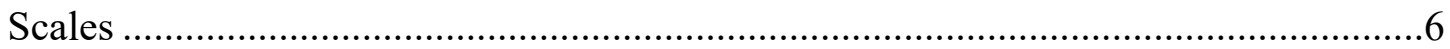

School-Based Protective Factors .............................................................6

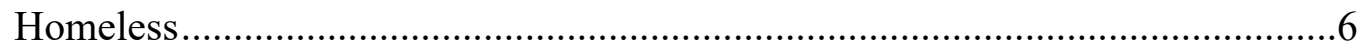

At-Risk Living Conditions..........................................................................6

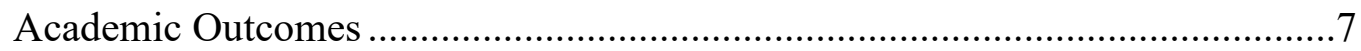

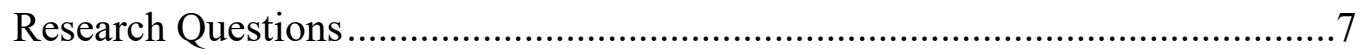

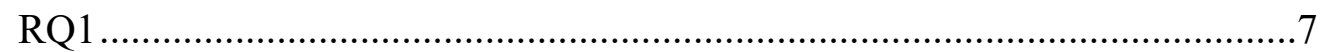

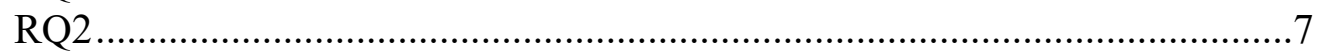

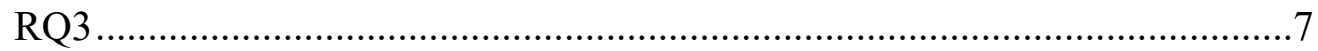

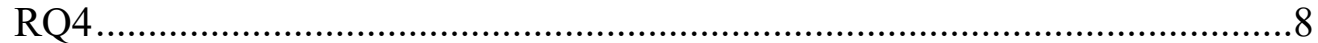

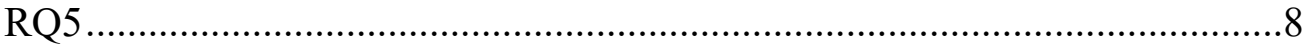

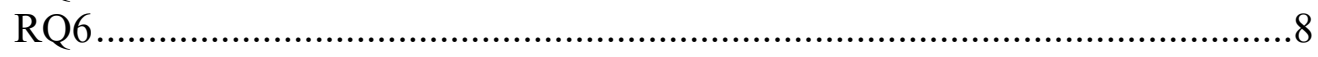

CHAPTER 2: LITERATURE REVIEW ............................................................... 9

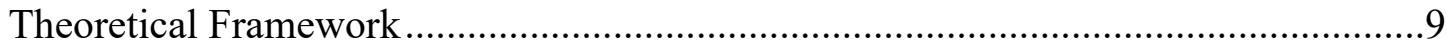

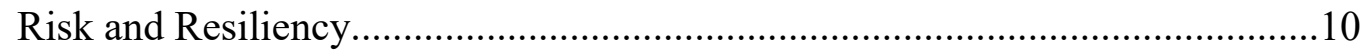

A Model of Resiliency ........................................................................ 11

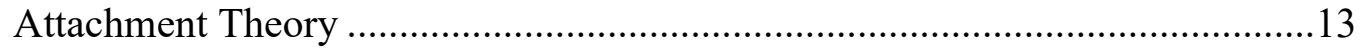

Adverse Childhood Experiences and Trauma.................................................. 15

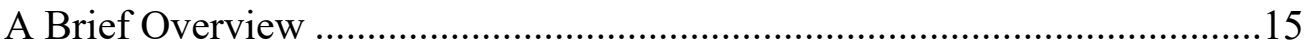

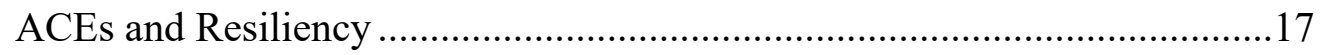

Trauma and Brain Development................................................................ 18

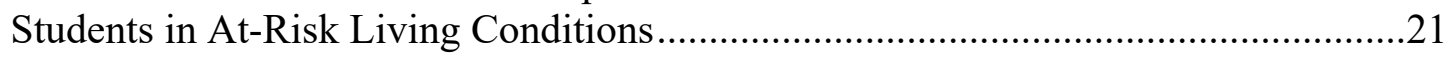

Overview of Students Living in Foster Care ...............................................21 
Overview of Students Who Are Homeless .....................................................23

ACEs and Students in ARLC .......................................................................26

Risk Factors for Students in ARLC .............................................................30

Developmental and Mental Health Risk Factors .......................................30

School-Based Risk Factors ..................................................................33

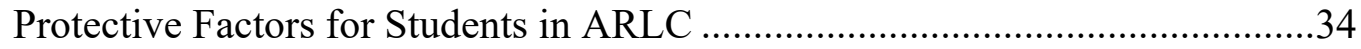

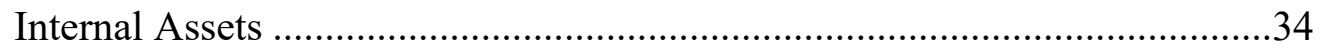

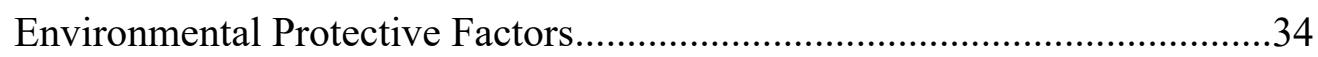

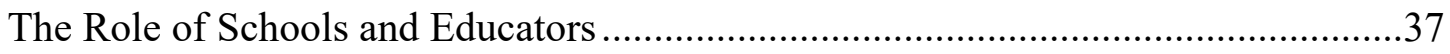

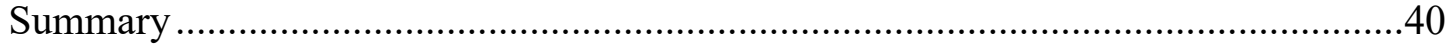

CHAPTER 3: RESEARCH METHODOLOGY .......................................................... 41

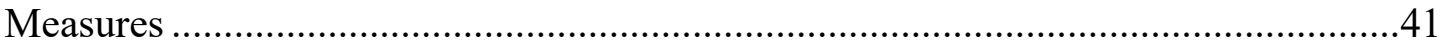

The California Healthy Kids Survey ......................................................... 41

School-Based Protective Factors .........................................................4 42

CHKS Development ...........................................................................44

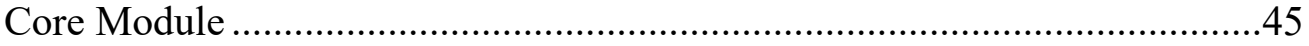

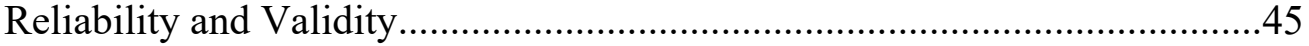

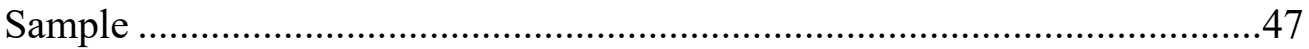

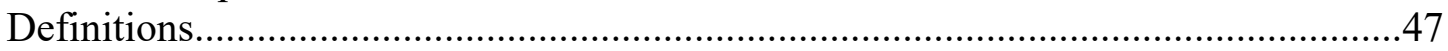

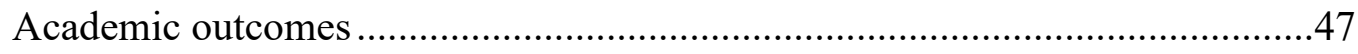

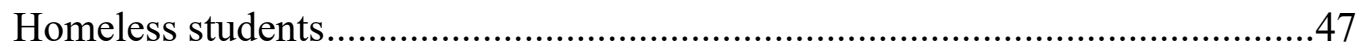

School-Based Protective Factors (SBPF) …...............................................47

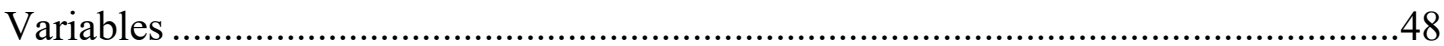

Measurement of Students Who Have Experienced Significant Adversities.......48

Measurement of Negative Outcomes..........................................................48

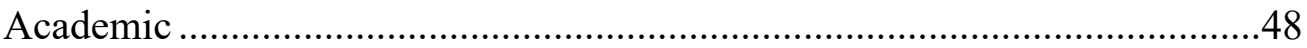

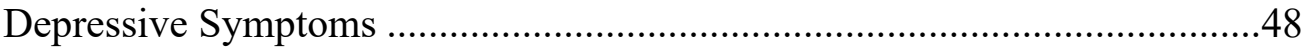

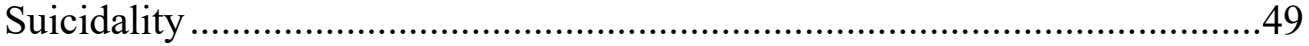

School-Based Protective Factors ................................................................49

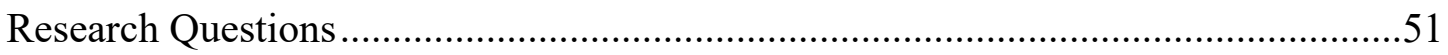

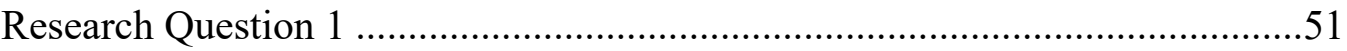

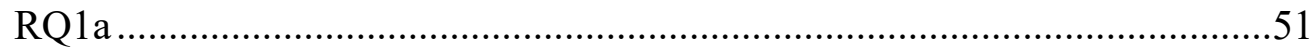

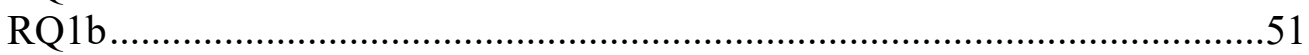

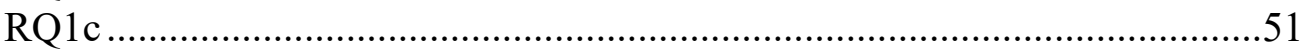

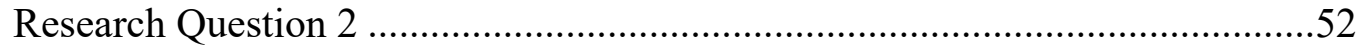

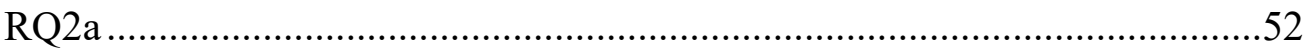

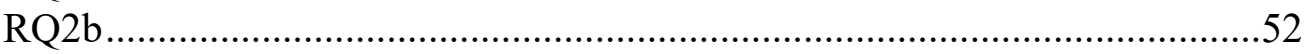

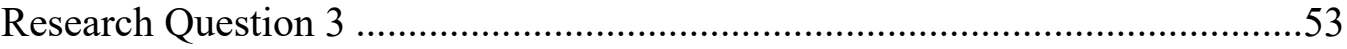

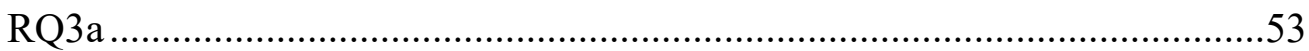

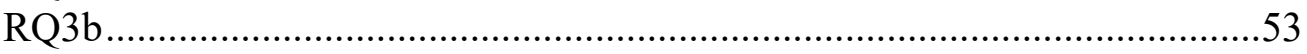

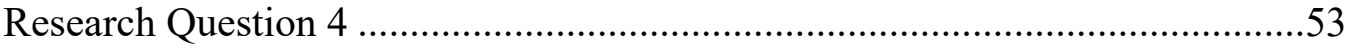

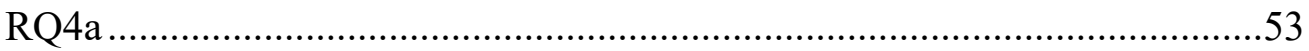

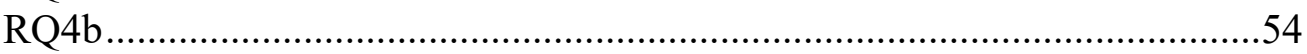


Research Question 5 ...................................................................................54

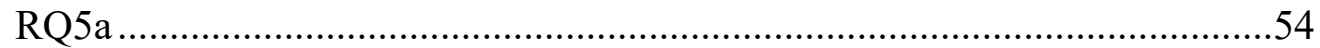

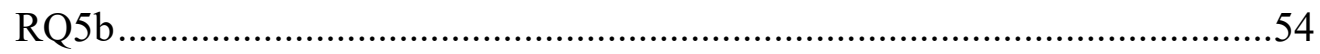

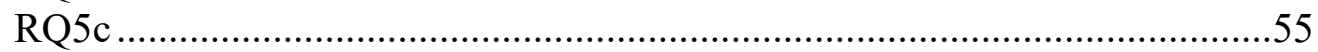

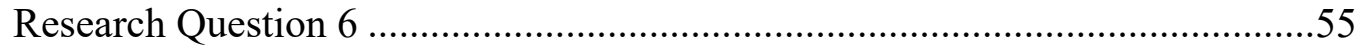

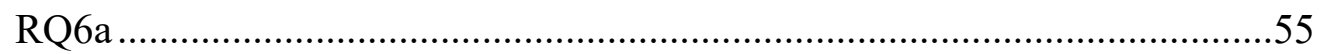

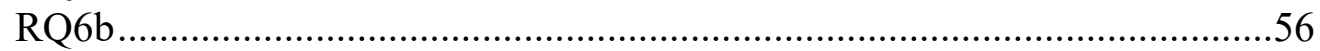

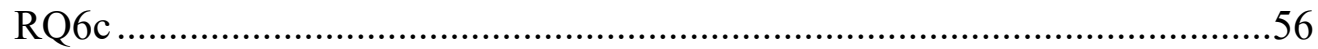

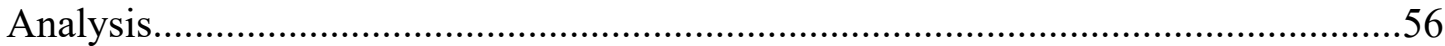

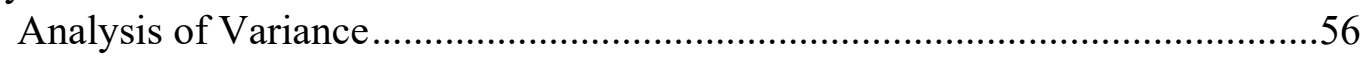

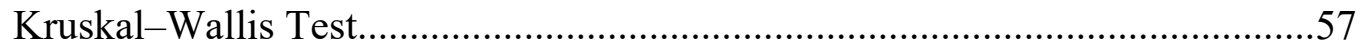

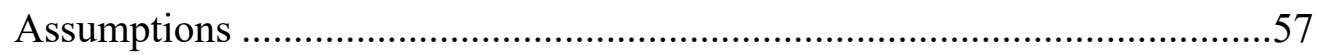

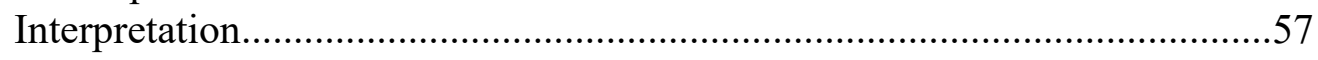

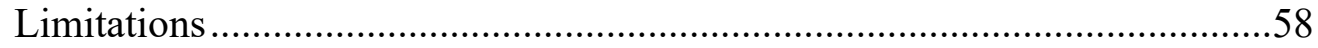

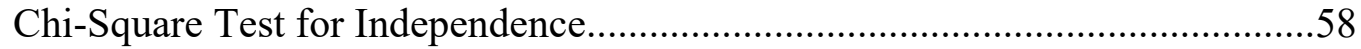

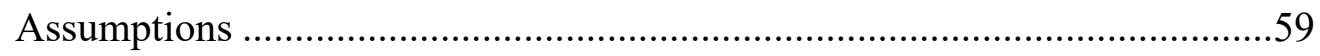

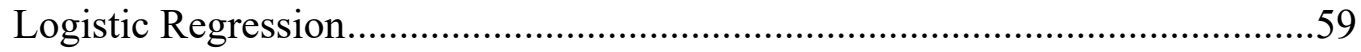

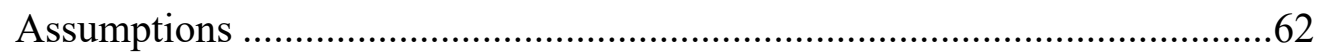

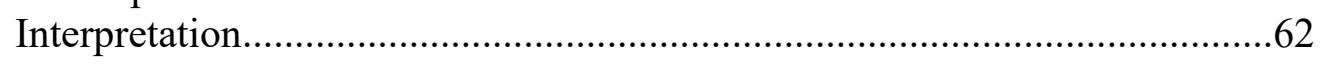

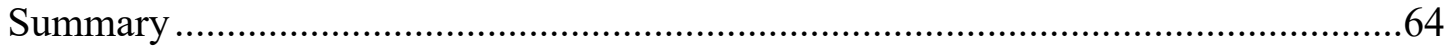

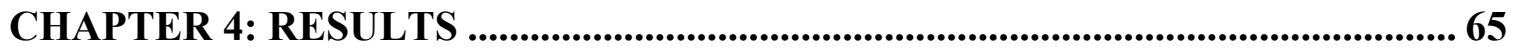

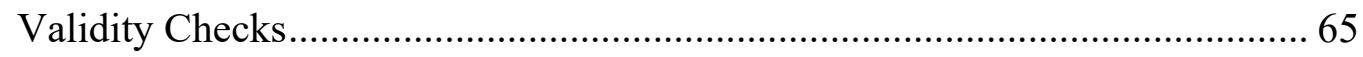

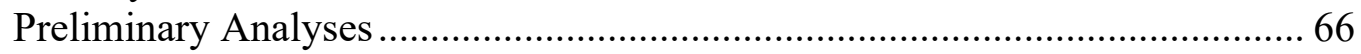

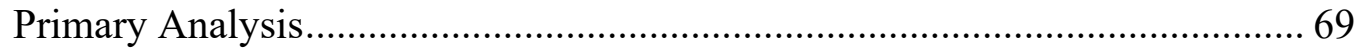

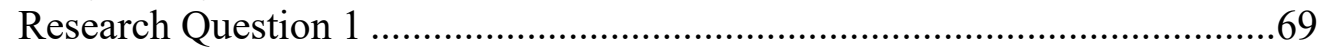

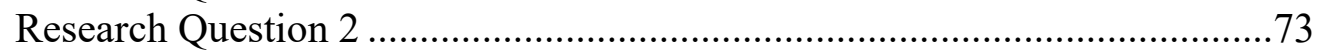

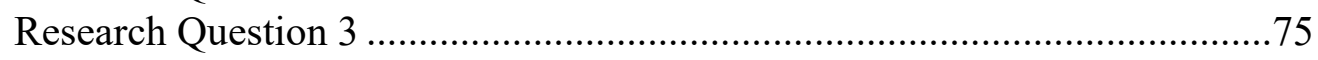

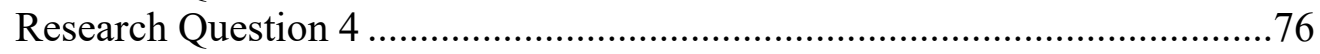

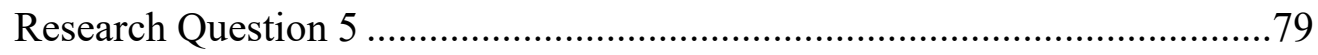

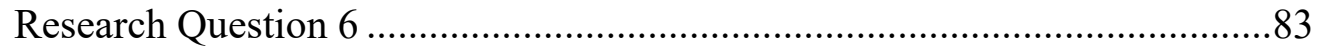

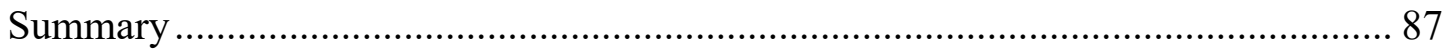

CHAPTER 5: DISCUSSION ................................................................................................ 88

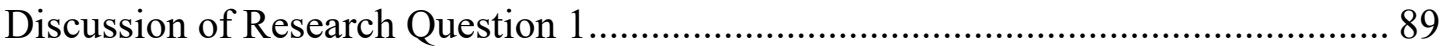

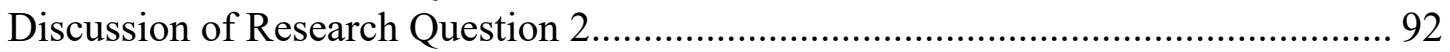

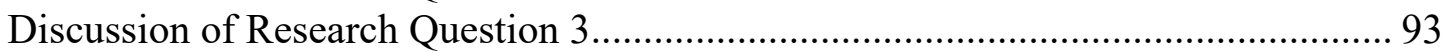

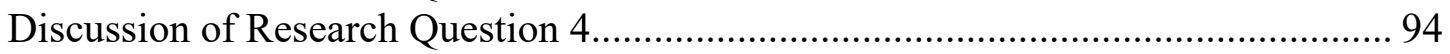

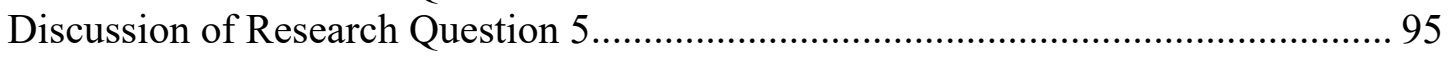

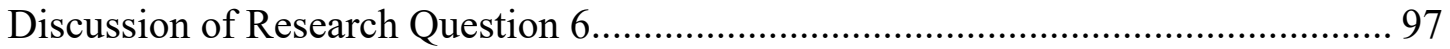

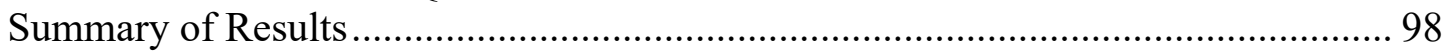

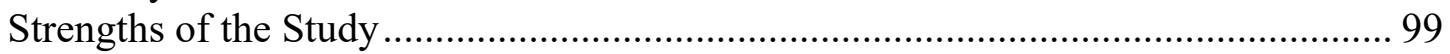

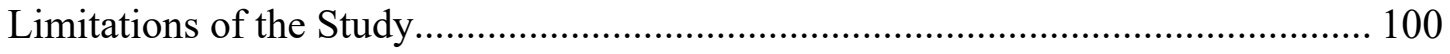

Implications and Directions for Future Research ........................................... 105

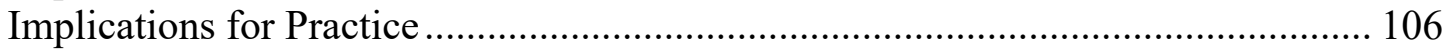

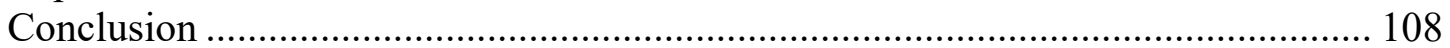


REFERENCES........................................................................................................................ 109

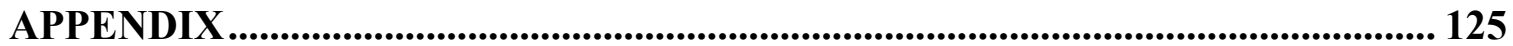




\section{LIST OF TABLES}

\section{$\underline{\text { Page }}$}

Table 1 ACEs Before and During Foster Care ........................................................ 27

Table 2 SBPF - Percentage of Respondents Categorized High, Moderate, and Low................................................................................ 44

Table 3 Secondary CHKS Core Module Confirmatory Factor Analysis Model ............. 47

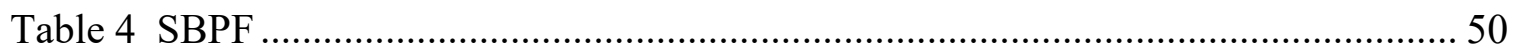

Table 5 Demographic Characteristics-Gender, Grade, Race, Gender Identity,

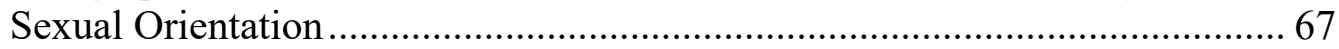

Table 6 Demographic Characteristics_-Socioeconomic Status and Language ............... 68

Table 7 Experiences of SBPF by Where a Student Resides ...................................... 71

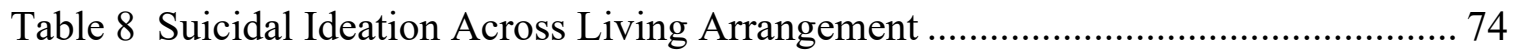

Table 9 Depressive Symptoms Across Living Arrangement........................................ 76

Table 10 Academic Outcomes Across Living Arrangement ..................................... 78

Table 11 Logistic Regression Predicting Suicidality Based on SBPF.......................... 80

Table 12 Logistic Regression Predicting Depressive Symptoms Based on SBPF ......... 81

Table 13 Logistic Regression Predicting Academic Outcomes Based on SBPF............ 83

Table 14 Logistic Regression Predicting Suicidality Based on Specific SBPF.............. 84

Table 15 Logistic Regression Predicting Depressive Symptoms

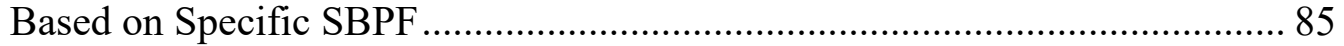

Table 16 Logistic Regression Predicting Self-Reported Grades Based on Specific SBPF. 


\section{LIST OF FIGURES}

$\underline{\text { Page }}$

Figure 1 School Protective Factors and the Related Youth Outcomes .......................... 43 


\section{LIST OF ABBREVIATIONS}

$\begin{array}{ll}\text { Abbreviation } & \text { Meaning } \\ \text { ACEs } & \text { Adverse Childhood Experiences } \\ \text { ARLC } & \text { At-Risk Living Conditions } \\ \text { CDE } & \text { California Department of Education } \\ \text { CHKS } & \text { California Healthy Kids Survey } \\ \text { NHCHC } & \text { National Health Care for the Homeless Council } \\ \text { SBPF } & \text { School-Based Protective Factors } \\ \text { WHO } & \text { World Health Organization }\end{array}$




\section{CHAPTER 1: INTRODUCTION}

Children who experience circumstances that call into question their most basic physiological needs, such as shelter, food, and safety, are among the most vulnerable members of society. These children include those who are in foster care and who reside in unstable housing circumstances (e.g., homeless shelters, hotels, and motels). Maslow (1943) asserted human needs are arranged in hierarchies of prepotency (Brenner, 2017), and each need rests on the prior satisfaction of another, more prepotent need (Brenner, 2017). Maslow's hierarchy of needs theory (1943) would thus indicate learning cannot take place during a time when more basic fundamental needs such as food, warmth, and safety are not met, yet all children, including those who are homeless and living in foster care, are expected to be ready to learn when they enter the classroom.

By definition, children who are in foster care or are homeless have experienced great adversity, such abuse, neglect, parental addiction, and domestic violence, to name a few. Additionally, many children who are homeless or reside in foster care are from impoverished backgrounds and have experienced erratic and insecure home environments lacking continuity and consistency in caregiving, all of which are associated with poorer developmental outcomes (Harden, 2004). Further, these young people often lack basic necessities such as food or access to showers or transportation and move between insecure housing arrangements and experiencing disruption in attachment from caregivers (Hyatt et al., 2014). Taken together, these experiences can make it challenging for children to stay in school and thrive in an educational environment, yet many do (Hyatt at al., 2014).

Understanding how these youth thrive despite these adverse experiences has far-reaching implications beyond just supporting these children in their educational environments. To truly 
support students who have experienced such adversity, a holistic and systemic approach is necessary; the focus must fall not only on the student and their microsystem but on their meso, exo, and macrosystem (Bronfenbrenner, 1977) as well. This study, however, focused on the risks and protective factors of students faced with significant adversities in such a way as to inform best practices in their educational settings.

Because children who are in foster care or are homeless have experienced significant adversity, understanding the research on adverse childhood experiences in general and for these populations specifically can help illuminate some of the processes involved in mitigating these risks and promoting resiliency to enhance life outcomes. Adverse childhood experiences (ACEs) are a well-researched (e.g., Babbel, 2012; Bruskas \& Tessin, 2013; Crouch et al., 2017; Felitti et al., 1998; Plumb et al., 2016) and important framework for understanding associations among family dysfunction, childhood maltreatment, and poor outcomes later in life. Despite adversity, there are many children who succeed in spite of the cumulative risks of their exposure to potentially traumatizing experiences: Reasearch has found that protective factors are more profoundly impactful on the life course of children who grow up under difficult or adverse conditions than are stressful life events or specific risk factors (Werner \& Smith, 1992). This remains true above and beyond socioeconomic, ethnic, historical, and geographic boundaries (Werner \& Smith, 1992).

This study had two goals given that (a) students who have experienced significant adversity are at greater risk for negative outcomes, (b) protective factors may be able to mitigate risk, and (c) students spend most of their time in schools and as such, schools are the de facto providers of mental health services to youth (Adelman \& Taylor, 2004). First, this study focused on understanding which school-based protective factors (SBPF), if any, may serve to mitigate the 
risk of negative outcomes for students in foster care and those who have experienced homelessness. Second, the aim of this study was to provide information that may increase positive academic outcomes for the youth studied.

\section{Statement of the Problem}

Although there is a recent push in the literature to identify trauma-informed practices to support students who have experienced significant adversity (Chafouleas et al., 2018; Plumb et al., 2016; Wolpow et al., 2009), there is little scientific evidence identifying which models are more successful than others. Additionally, due to lack of funding, competing priorities, or other logistical barriers, many schools may not be able to implement schoolwide interventions. However, there are typical day-to-day practices that many schools and teachers have used to support all students (e.g., providing caring relationships, having high expectations, and providing opportunities for meaningful participation) and research has shown these practices bolster more positive academic, social, emotional, and health outcomes (Benard, 2004; WestEd, 2017). Although there has been an abundance of research on the aforementioned protective factors (e.g., Benard, 1991, 2004; Masten, 2014; Werner \& Smith, 1992, 2001), there has been a gap in the research on, to what degree, if any, these common practices are more salient in building resilience with students who have experienced ACEs and trauma associated with living in foster care or homelessness—referred to in this study as "at-risk living conditions."

There are 10 different types of ACEs identified in the original study by Felitti et al. (1998) categorized into either abuse, neglect, or household dysfunction: (a) abuse: physical, sexual, emotional; (b) neglect: physical or emotional; or (c) household dysfunction: a household member with mental illness, witnessing mother treated violently, parental divorce or separation, substance abuse of a household member, or an incarcerated household member. Although there 
are 10 different types of ACEs and innumerous ways to experience trauma, there have been at least two identifiable and measurable groups of children in schools who have experienced certain ACEs. Specifically, on the California Healthy Kids Survey (CHKS; WestEd, 2011), respondents are asked to indicate the setting that best describes where they live, with foster care and unstable housing circumstances that would describe homelessness among the options. It has been well researched that students who are homeless or in foster care face increased risks and more negative outcomes than their peers (Babbel, 2012; Bruskas \& Tessin, 2013; Turney \& Wildeman, 2017). Although research exists on the benefits of resilience assets and protective factors in mitigating risk overall, little research exists on the salience of these factors for foster or homeless students, in particular.

\section{Purpose of the Present Study}

The purpose of the present study was to use a model of resiliency to better understand the factors related to mitigating risk and improving outcomes for students who have experienced the adverse childhood experiences leading to and associated with residing in at-risk living conditions. To address the problems and risks that foster and homeless youth face in schools, it is crucial to understand what sorts of protective factors have meaningful impact in mitigating these risks. Understanding the salience of different protective factors can allow schools to plan interventions and programs to ameliorate the presence of risks for this particular student population in their day-to-day activities, outside of adopting comprehensive trauma-informed models. By understanding and implementing protective factors, schools can reduce risks and thus improve outcomes for this population of students.

This study used data from the CHKS in combination with a review of the extant literature, to identify the SBPF that are the most powerful in increasing positive academic 
outcomes and reducing the risk of negative outcomes in students in foster care or who are homeless.

\section{California Healthy Kids Survey}

The CHKS is a survey developed by WestEd for the California Department of Education. The purpose of the CHKS is to understand the strengths and risks of students and schools, particularly from a perspective of positive youth development and risk and resiliency factors (Austin et al., 2018). It is an anonymous survey that assesses school climate and safety, student wellness, and youth resiliency. The CKHS enables schools to collect data on school climate, protective factors, and school connected among other youth health risks and behaviors (WestEd, n.d.).

Foundational to the CHKS is a core module that provides indicators to promote student achievement as well as school engagement, safety, health, positive development, and overall well-being (Austin et al., 2018). The CHKS is based on the notion that youth who experience high levels of environmental supports in three areas will develop the resilience, acquire the connection to school, and develop the motivation to learn that lead to positive outcomes in the areas of social, academic, and health (Constantine et al., 1999). Referred to as school developmental supports or school protective factors (Austin et al., 2018), the three environmental assets are high expectations from adults, caring relationships with adults, and opportunities for meaningful participation (Austin et al., 2018). According to Austin et al. (2018), when schools

provide these supports, students are more likely to experience benefits and report more positive outcomes in the areas of health, social-emotional, and academic well-being.

In California, an average of about 600,000 students have taken the CHKS every year (Mahecha \& Hanson, 2020). Since Fall 2003, the tool has been mandated by the California 
Department of Education for compliance with state Tobacco Use Prevention and Education (TUPE) grants and No Child Left Behind (Mahecha \& Hanson, 2020). For the purpose of this study, results of the core module of the 2017-2018, and 2018-2019 CHKS survey were analyzed.

\section{Scales and Research Questions}

To analyze the CHKS data, several new scales were developed and are defined here and discussed further in Chapter 3.

\section{Scales}

\section{School-Based Protective Factors}

The School-Based Protective Factors (SBPF) scale was created by combining the CHKS scales of School High Expectations, School Caring Relationships, and School Meaningful Participation.

\section{Homeless}

Item 8 of the survey asked, "What best describes where you live?” Respondents who indicated they reside either in a "hotel or motel," or "a shelter," "car," "campground," or "other transitional or temporary housing" was combined and referred to as homeless.

\section{At-Risk Living Conditions}

This term was used to refer to students who responded as either residing in foster care or are homeless on item 8 of the survey, which asked "What best describes where you live?" The responses (a) "foster home, group care, or waiting placement," (b) "hotel or motel," and (c) "shelter, car, campground, or other transitional or temporary housing" were combined and defined as at-risk living conditions (ARLC). 


\section{Academic Outcomes}

The term academic outcomes was used to describe responses to Item 18 on the survey:

"During the past 12 months, how would you describe the grades you mostly received in school?" For analysis purposes, responses were chunked into the following: (a) mostly As, As and Bs; mostly Bs, Bs and Cs; (b) mostly Cs, Cs and Ds; (c) mostly Ds, mostly Fs.

\section{Research Questions}

This study asked the following research questions (RQ):

RQ1

RQ1a. Is there a difference in how students experience School-Based Protective Factors (SBPF)?

RQ1b. Is there a difference in how students who are homeless experience SBPF as compared to students who live at home with one or more parent?

RQ1c. Is there a difference in how students who are in foster care experience SBPF as compared to students who live at home with one or more parent?

$R Q 2$

RQ2a. What is the rate of suicidal ideation in students who are homeless, and how does this compare with students living at home with one or more parent?

RQ2b. What is the rate of suicidal ideation for students who reside in foster care, and how does this compare with students living at home with one or more parent?

RQ3

RQ3a. What is the rate of depressive symptoms in students who are homeless, and how does this compare to students living with one or more parent? 
RQ3b. What is the rate of depressive symptoms in students who reside in foster care, and how does this compare to students living with one or more parent?

RQ4

RQ4a. What are the self-reported academic outcomes for students who are homeless, and how does this compare with students living at home with one or more parent?

RQ4b. What are the self-reported academic outcomes for students who reside in foster care, and how does this compare with students living at home with one or more parent?

RQ5

RQ5a. Do SBPF predict suicidality above and beyond where a student resides?

RQ5b. Do SBPF predict depression above and beyond where a student resides?

RQ5c. Do SBPF predict academic outcomes above and beyond where a student resides?

RQ6

RQ6a. Do specific SBPF significantly predict suicidality?

RQ6b. Do specific SBPF significantly predict depression?

RQ6c. Do specific SBPF significantly predict academic outcomes? 


\section{CHAPTER 2: LITERATURE REVIEW}

This chapter first presents the theoretical framework for this study: risk and resiliency. Next, it provides a brief description of youth in foster care and youth who have experienced homelessness, including demographics and rates. Although there is overlap in risk and protective factors between children who are in foster care and those who are homeless, there are also many differences between the groups. It was, thus, necessary to examine each individually before discussing them together in later chapters. Because of the body of evidence that has examined the significant adversities children who have been in foster care and children who have been homeless have faced, with many of these experiences being considered an adverse childhood experience (ACE) as initially identified in the seminal study by Felitti et al. (1998), an understanding of ACEs, then, is salient in interpreting the lifelong risks these children face and ways to support them. Thus, a brief background of ACEs is provided, then ACEs as they relate to youth in foster care and youth who are homeless are reviewed. This chapter then includes a summary of the current research on risk factors facing this populations of students. Finally, this chapter concludes with what is known about protective factors related to this population.

\section{Theoretical Framework}

Children who are in foster care or who are homeless are among the most vulnerable members of society. Such children are still expected to be enrolled in school and benefit from the educational curriculum. In essence, they are expected to attend to instruction, adhere to behavioral expectations, and thus, learn. Maslow (1943) asserted the satisfaction of human needs usually rest on the prior satisfaction of another, more prepotent need (Brenner, 2017). Maslow's (1943) hierarchy of needs theory would, thus, indicate learning cannot take place during a time 
when more basic fundamental needs are not met, and yet, all children are expected to be ready to learn when they enter the classroom.

Exacerbating the risk factors they experience, children who reside in foster care or are homeless are primarily from impoverished backgrounds (Harden, 2004). Moreover, home environments that lack continuity and consistency in caregiving and are insecure in nature are also associated with poor developmental outcomes (Harden, 2004) and call into question a student's readiness to learn. Experiencing adversities that may result in ones placement in foster care, or adversities associated with becoming or being homeless can all make it challenging to stay in school and thrive in an educational environment, yet many do (Hyatt at al., 2014).

\section{Risk and Resiliency}

There are several foundational tenets of risk and resilience research. First, resilience, by definition, is always linked to risk or adversity. Masten et al. (2015) defined resilience as "the capacity of a dynamic system to adapt successfully to disturbances that threaten system function, viability, or development" (p. 10). It is prominantly concluded by the most prominent resilience researchers (Benard, 1991, 2004; Masten, 2014; Werner \& Smith, 1992, 2001) that resilience is a universal capacity, evident in normal human development, rather than a trait or characteristic that some possess and others do not. Finally, resiliency comes from personal individual strengths or characteristics combined with environmental aspects (e.g., school, family, or community; Benard, 2004).

Longitudinal studies on children growing up in difficult circumstances and on factors that reduce risk in the process of children's development have provided a crucial foundation for a better understanding of resilience resources. Among these studies are the longitudinal study carried out on the Hawaiian island of Kauai (Werner, 2005) and the study on children at risk in 
Mannheim, Germany (Laucht et al., 2000). Results of studies such as these have reshaped our current understanding of children's capacity to overcome adversity (Sikorska, 2014).

\section{A Model of Resiliency}

The analysis of the ways in which resilience has been conceptualized and operationalized in the field of human development falls into four major waves of research on children and adolescents (Masten, 2007; Sikorska, 2014). In the first wave of research, the goal was to define, and subsequently measure, resilience and describe the situations in which a person overcame major adversity to have a successful outcome (Masten, 2014). In the second wave of research, the goal was to understand the processes of resilience and how resilience manifested itself in different situations (Masten, 2007, 2014). This wave of research viewed resilience differently, describing it as a "dynamic process whereby an interaction between risk factors and both external and internal protective factors" (Sikorska, 2014, p. 87) has taken place. Viewing resilience as a process, researchers regarded it as an internal attribute that develops as a result of the interaction between an individual and their environment (Masten, 2014; Sikorska, 2014). The third wave of research in the field of resilience emphasizes the application of knowledge, focusing on prevention, intervention, and creating a protective system around children living in conditions that may be detrimental to normal and typical development (Sikorska, 2014). These systems of prevention and intervention are regarded as playing a decisively important role in instilling resilience in children and adolescents (Sikorska, 2014). These three waves contributed to the current fourth wave of research on resilience. This approach aimed to integrate numerous fields of research, and has required the exchange of knowledge between genetics, neuroscience, and behavioral biology (Sikorska, 2014). It has centered on understanding the systems and the 
contexts in which resilience occurs (Masten, 2014) and has provided the study of resilience a more thorough understanding of all processes involved in resilience (Sikorska, 2014).

There are several processes by which environmental and individual factors help to mitigate the negative effects of trauma and risk factors. Researchers have described this in order to provide a framework for understanding the relationship between risks, protective factors, and outcomes (O'Leary, 1998). There are three resilience models described in the literature that essentially describe the way stress impacts positive adaptation: the challenge model, the compensatory model, and the protective factor model (O’Leary, 1998).

The challenge model regards risk factors with the potential to increase a person's resilience. In essence, a risk factor, provided it is not overly challenging or extreme, can actually increase a person's resilience, by preparing them for the next challenge (O’Leary, 1998). In this model, too little stress is not challenging enough, and very high levels result in dysfunction (O’Leary, 1998). Moderate levels of risk, however, provide a level of challenge that may strengthen functioning and competence. Masten (2014) has said that protection develops not through avoiding risk but through successfully engaging it.

The compensatory model regards resilience as an element that counteracts exposures to risk (O’Leary, 1998). Resilience, then, is viewed as having a direct and independent influence on the outcome of interest rather that operating within an interaction with the risk factor (O'Leary, 1998). Werner and Smith's (1992) landmark study illustrated the compensatory model. There were four main characteristics that emerged for the young adults who were labeled resilient. They possessed a proactive approach toward problem-solving, the ability to, even while suffering, perceive negative experiences in a positive light, the ability to gain positive attention 
from others, and maintain a positive life view through a strong reliance on faith (Werner \& Smith, 1992).

The protective factor indirectly influences outcomes, making it a model of resilience that stands apart from the compensatory or challenge model. In the protective factor model, there is an interaction between protection and risk factors which works in concert to reduce the probability of a negative outcome and moderate the effect of any exposure to risk (O'Leary, 1998). It is a protective mechanism that is an interactive process that helps identify "multiple interactions or synergistic effects in which one variable potentiates the effect of another" (Rutter, 1987, p. 106).

Using a model of resiliency allows for the testing of hypotheses and also serves as a guide for intervention (Masten, 2014). This study examined whether specific school supports have a direct and independent influence on the outcomes of interest and as such, it used a compensatory model as a framework for resilience.

\section{Attachment Theory}

As stated by Fosha (2009), "the roots of resilience are to be found in the sense of being understood by and existing in the mind and heart of a loving, caring, attuned, and self-possessed other" (p. 2). In other words, the roots of resilience lie in attachment. One of the key social determinants of health (i.e., physical, mental, and emotional) is the ability to form and maintain an attachment to a primary caregiver as well as sustain quality relationships with others (Bowlby, 1973). Bowlby (1969) also suggested a critical period for developing an attachment was from 05 years old, and if an attachment to a caregiver has not developed during that time, the child will "suffer from irreversible developmental consequences, such as increased aggression and reduced intelligence" (p. 84). Secure attachment is the emotional bond between a child and their 
caregiver, the foundation of trust and the capacity to build relationships throughout life, and the way in which children come to see the world and others as reliable and understand they are loveable (Gilligan, 2000; Masten et al., 2015; Strolin-Goltzman et al., 2016). Consequently, one of the single most traumatic experiences that can occur, especially for children, is the loss of a parent (Bowlby, 1998; Perry, 2007), whether through death, divorce, or removal from one's home- such as through a foster care placement.

Harden (2004) has said that child development is a process that is influenced by both biological and environmental processes. It is the maturation of cognitive, physical, emotional, and social development of human beings from conception to adulthood. According to Harden, of the environmental influences that impact the development of a child, family is arguably the most significant. Children develop attachments more readily with caregivers who are consistent, nurturing, and available, and trusting relationships with caregivers lead to several positive developmental outcomes in health, academics, and a child's social/emotional skills. Importantly, caregiving that is consistent, supportive, and positive has the potential to mitigate factors that have a negative impact on children (Harden, 2004).

Most children are securely attached. This means they look to their caregivers for comfort when distressed, and they feel confident exploring their environment because of how secure they feel with their caregivers (Harden, 2004; Siegel \& Bryson, 2020). Conversely, children who are raised by caregivers who do not provide consistent affection or attention, or who are uncertain about their relationships with their caregivers may become insecurely attached (Siegal \& Bryson, 2020) and are not adequately consoled by their caregivers nor do they feel confident to explore their environments (Siegel \& Bryson, 2020). They are more likely to be insecurely attached and have difficulty forming healthy attachments with others (Harden, 2004; Siegel \& Bryson, 2020). 
Foster children are more likely than nonfoster children to have insecure and disorganized attachments (Bruskas \& Tessin, 2013; Harden, 2004). This is especially true when they experience revictimization while in the child welfare system (Harden, 2004). Along with the unstable, unreliable, and traumatic family experiences leading to placement in foster care, children in foster care may experience continued attachment disruption and trauma by being removed from their families, being maltreated in foster care, and being in multiple foster care placements (Bruskas, 2008). Similar to the consequences of ACEs, attachment disorders and other mental health problems are associated with adversities during childhood such as maltreatment prior to or during foster care, parental loss, foster care placement, family disruptions, and other cumulative childhood adversities (Harden, 2004).

Offering a glimmer of hope to an otherwise grim outlook, although children may have disrupted attachment with their parents, they can form healthy attachments with others. For example, relatives, foster parents, peers, mentors, or teachers (Collins et al., 2008; Gilligan, 2000; Siegel \& Bryson, 2020) can serve as attachment figures for children. Notably for educators, these relationships may take on greater meaning for children in foster care, and such a social support system is an important factor in promoting resilience for children in foster care (Collins et al., 2008).

\section{Adverse Childhood Experiences and Trauma}

\section{A Brief Overview}

Since the publication of the seminal Adverse Childhood Experiences (ACEs) Study (Felitti et al., 1998), ACEs have provided a valuable framework for understanding the link between negative childhood experiences such as maltreatment and family dysfunction, and poor health and well-being outcomes in life (Plumb, et al., 2016; Radcliff et al., 2019). Since then, 
studies have confirmed the association between ACEs and later poor health and well-being outcomes (e.g., Crouch et al., 2017). The ACEs found in the original and subsequent studies included the following: abuse (e.g., psychological, physical, sexual), substance use of a household member, mental illness in the household, domestic violence toward the mother, criminal behavior of a household member, parental divorce, and emotional and physical neglect (e.g., Plumb et al., 2016). A graded dose-response effect was found between the number of ACEs and negative health and overall well-being across a lifetime. Approximately two thirds of Americans have had at least one ACE, as defined in this section. Additionally, a person with one ACE is approximately $85 \%$ more likely to have more ACEs (Centers for Disease Control, 2016). Though commonly used interchangeably, ACEs and trauma are not synonymous. ACEs are a clearly idenitified set of adverse situations that are highly correlated with poor physical and mental health outcomes later in life (Felitti et al., 1998). Trauma is one possible outcome to prolonged exposure to adversity, or a possible outcome of experiencing a sudden cataclysmic event. While traumatic events such as a serious car accident or a school shooting may qualify as an ACE, every individual responds to such an event differently; experiencing trauma is not a prescribed reaction. Every child is genetically unique, and due to their still-developing brain, are particularly vulnerable to significant levels of stress. However, the same event may be processed and responded to differently by each individual. There are certain types of childhood adversity more likely to result in trauma reactions (e.g., witnessing violence that results in death or serious injury) while others (e.g., parental divorce) result in a less predictable range. Resiliency acts as a buffer between ACEs and traumatic stress. 


\section{ACEs and Resiliency}

Understanding resilience is particularly relevant for foster care children and children who have experienced housing instability because it can explain the factors that help children who have been faced with extreme adversities to "beat the odds." As noted earlier, resilience has been defined in the literature as the ability of an individual to recover from adverse experiences, life stressors, and psychological trauma without great harm (Benard, 2004; Hunter \& Chandler, 1999; Masten, 1994). Benard (2004) described it as an innate self-righting mechanism that is accessible to everyone. Whether or not an individual is able to recover successfully from an extremely stressful or traumatic experience is dependent upon the availability of intrinsic (i.e., autonomy, social competence, self-efficacy, and problem-solving skills; Hunter \& Chandler, 1999) or extrinsic (i.e., support from family, school, community, and peers; Johnson \& Lazarus, 2014) protective factors that mitigate against risk (Masten, 1994). Resilience, then, is a process that uses assets and protective factors to overcome risks (Johnson \& Lazarus, 2014). It is based on research that has shown that despite being exposed to adversity, many children exhibit positive outcomes later in life (Benard, 2004; Masten, 1994). Many children who experience stressful, high-risk situations have positive long-term outcomes despite the odds (Masten, 1994). The term resilience generally describes individuals who, despite being exposed to multiple high risk or traumatic situations, have successfully overcome significant adversity (Fraser \& Richman, 1999).

There are several protective factors of both children and their environments that may serve to mitigate the impact of the adverse situations and lead to more positive outcomes. These characteristics include the child's IQ, their temperament, a supportive and warm relationship with caregivers, connectedness with school, and a supportive relationship outside of the family 
such as with a mentor (Harden, 2004). Children who demonstrate resilience despite adversity have high self-esteem, cognitive competence, and ego control (e.g., flexibility, reflection, and persistence; Cicchetti \& Lynch, 1993).

Educational resiliency, defined as the increased likelihood of educational success despite adverse experiences, is bolstered by family engagement and school relationships (Bryan, 2005). Notably, the presence of a consistent and supportive adult in the school environment in concert with an overall supportive school setting can serve as a protective factor (Strolin-Goltzman et al., 2016). Facilitators of educational resilience are described as "positive and supportive adult relationships, opportunities for meaningful student participation in their schools and communities, and high parent and teacher expectations regarding student performance and future success" (Bryan, 2005, p. 219).

Resilience is not synonymous with being invulnerable. Rather, it is a dynamic exchange between risk and protective factors (Strolin-Goltzman et al., 2016). Resilient individuals have managed to continue to function well despite adversity they have faced or continue to face, and often achieve positive outcomes (Strolin-Goltzman et al., 2016).

Specific areas of research are particularly relevant to understanding children who are in foster care or unstable housing, supporting their needs, fostering resilience, and bolstering positive outcomes. Although the following paragraphs are certainly not exhaustive, the research on brain development, resilience, and attachment is particularly germane to an understanding of children who have experienced significant adversities.

\section{Trauma and Brain Development}

Given the research on the prevalence of ACEs for youth in foster care and homelessness, understanding what ACEs and trauma can do to a child's brain and development are essential to 
fully understanding how to support children who have faced such adversities. Because the impetus of trauma is often in parent/guardian and child relationships, the developmental impact can be profound. ACEs are extremely stressful or traumatic events; Perry (2007) defined stress as any condition "that forces our regulating physiological and neurophysiologic systems to move outside their normal dynamic activity. Stress occurs when homeostasis is disrupted" (p. 2), and extreme forms of stress are referred to as traumatic stress. The effects of traumatic stress may be pervasive even when exposure does not meet established diagnostic criteria (Substance Abuse and Mental Health Services Administration [SAMHSA], 2014). This means a child does not need to meet the full criteria for posttraumatic stress disorder to experience serious and debilitating effects as a result of adverse and traumatic experiences.

In their original and subsequent studies, Felitti et al. $(1998,2006,2009,2019)$ found a strong dose-response relationship with more pervasive and long-reaching impacts associated with greater exposure to adverse experiences such as abuse or household dysfunction. Further, because a child's brain is more malleable than an adult's, trauma changes the actual chemistry and structure of a child's brain (Center for Youth Wellness, 2014; Van der Kolk, 2015). Changes in the brain functioning and the body's stress response that come with exposure to adverse events create greater sensitivity to stress later in development, thus making those exposed more vulnerable to later traumatic events (Center for Youth Wellness, 2014).

According to Van der Kolk (2014), there are seven domains governed by the brain that are impacted by early developmental trauma: somatic/sensory (governed by the brainstem); attachment, emotional regulation, and behavior regulation (limbic brain); and self-esteem, dissociation, and cognitive problems (cortical brain). The brain grows hierarchically from the bottom up (Perry \& Hambrick, 2008; Van der Kolk, 2015). From birth to adolescence, the brain 
develops in this order: brainstem/midbrain, limbic brain, and lastly, the cortical brain (Van der Kolk, 2015). The effects trauma has on a developing brain manifest differently during each stage of development (Plumb et al., 2016; Van der Kolk, 2015). For example, the limbic system regulates the fight or flight response. If trauma occurs during the time that this part of the brain is developing, a person's stress response may be affected. If trauma occurs during development of the cerebral cortex, an individual's ability to plan, problem solve, or use language may be impacted (Perry, 2007). Perry (2007) went on to explain if a child is subjected to prolonged, severe, and unpredictable stress, they may experience hyper- or hypo-arousal and be in constant fight, flight, or freeze mode. Higher-order functions, such as learning and demonstrating appropriate behavior, become difficult or impossible as the body is primarily concerned with survival. Additionally, the longer the time that children spend in lower orders of the brain, the more normalized it becomes (Van der Kolk, 2015).

Children who frequently experience abuse in their home are more likely to operate in a state of hyperarousal; in a classroom environment, they are more likely to act out or misbehave (Plumb et al., 2016). Perry (2007) stated youth who experience trauma will be in a persistent state of alarm, otherwise known as fight or flight, and may struggle with maintaining concentrating and focus when they enter classrooms. Due to this, they may pay more attention to a teacher's tone of voice, posture, or facial expressions, rather than to what the teacher is saying. Perry (2007) asserted unless teachers adopt regulating practices for those students, such as breathing exercises, meditation, or rhythmic activity, youth will remain in this fight or flight state - which impairs cognitive functioning, thus making it difficult or impossible to learn. Moreover, the effects of trauma on student learning may be associated with the achievement gap. Children who live in stressful environments do not process novel information at the same rate as 
children who are in a calm (ready to learn) state (Perry \& Hambrick, 2008). There is a perpetual cycle of traumatized students learning at slower rates, disengaging, falling behind, and often, dropping out of school (Perry \& Hambrick, 2008).

\section{Students in At-Risk Living Conditions}

\section{Overview of Students Living in Foster Care}

In the United States, foster care placement is a common occurrence, with estimates suggesting $6 \%$ of youth in the United States will be placed in foster care at some point before their 18th birthday (Turney \& Wildeman, 2017). There are three types of general placements in the foster system, with approximately half of youth placed in nonrelative family care, a quarter in kinship care (i.e., the care of children by relatives), and $16 \%$ in group homes or residential institutions (The Annie E. Casey Foundation, 2011). While the number of youth in foster care varies from year to year, in 2018, approximately 59,000 children were in foster care in California, with approximately 33,500 enrolled in school (Waters, 2020), accounting for roughly $14 \%$ of the foster care population in the nation. The degree of risk of children who are in foster care varies across the population, however, children living in poverty and those of racial or ethnic minority status are at a disproportionate risk. In the United States, $12 \%$ of African American children and $15 \%$ of Native American children are placed in foster care at some point during their childhood, compared with 5\% of White children (Wildeman \& Emanuel, 2014).

Several studies report the outcomes of youths who were in foster care. One such study is the Midwest Evaluation of the Adult Functioning of Former Foster Youth: Outcomes at Ages 23 and 24 (the Midwest Study; Courtney et al., 2010). The Midwest Study provided research outcomes for youth after aging out of the foster care system —otherwise known as emancipation. It is one of the largest longitudinal studies on this topic. The Midwest Study interviewed 732 
participants at age 17 to 18 , then subsequently interviewed the same individuals at ages 19,21 , 23, or 24 years, and at age 26 years (Courtney et al., 2011). Results indicated young adults from foster care have poorer outcomes compared with their non-foster care peers. For example, participants were more likely to experience financial hardship, and of those that had children, many were unable to parent them. Many participants were jobless, and participants were found likely to be suffering from persisting mental health disorders or substance abuse problems.

Bruskas and Tessin (2013) found the average age of foster care entry was 8 years old, with $33 \%$ of respondents reporting having entered the foster care system between the ages of $0-5$ years. Participants were in the foster care system for, on average, 7 years and lived in an average of six foster care placements during their time in care. The average number of school transfers was four, which was found to be associated with the number of foster care placements. Children most commonly resided in a foster care home (58\%) as opposed to the other types of foster care. Of the participants who lived in a foster care home, more than three fourths reported living with an unknown (not relative) foster care family. There were approximately $37 \%$ who reported living both in a foster care home and a group home, and 5\% reported living solely in a group home.

Bruskas and Tessin (2013) found results similar to that of the Midwest Study (Courtney et al., 2011) with regard to the experiences of youth in foster care. Both studies showed nearly half of respondents in foster care had visited the emergency room, with $24 \%$ being hospitalized. In both studies, illness and pregnancy were the most common reasons for hospitalization. In the Bruskas and Tessin (2013) study, depression was the most frequent diagnosis reported (43\%), followed by posttraumatic stress disorder (29\%).

Contrary to the benefits family stability provides, child maltreatment reflects an extreme form of family instability. Most children who enter the foster system experienced neglect, with 
the next largest group being due to physical abuse, and a smaller number entering foster care due to sexual abuse (NSCAW, 2013). Almost half of children who experience abuse or maltreatment experience more than one type (NSCAW, 2013). Although the goal of the U.S. foster care system is to provide a living environment that is safe for children who have faced abuse and neglect (Davis, 2006), transition from foster care to adulthood may come suddenly and without support, leaving foster youth vulnerable to a myriad of negative outcomes (Barrat \& Berliner, 2013).

\section{Overview of Students Who Are Homeless}

The McKinney-Vento Act defined homeless children and youth as "individuals who lack a fixed, regular, and adequate nighttime residence" (McKinney-Vento Homeless Education Assistance Improvements Act, 2004, para. 1). The term includes the following:

Children and youth who are: - sharing the housing of other persons due to loss of housing, economic hardship, or a similar reason (sometimes referred to as doubled-up); living in motels, hotels, trailer parks, or camping grounds due to lack of alternative adequate accommodations; - living in emergency or transitional shelters; - abandoned in hospitals; or - awaiting foster care placement; Children and youth who have a primary nighttime residence that is a public or private place not designed for, or ordinarily used as, a regular sleeping accommodation for human beings; Children and youth who are living in cars, parks, public spaces, abandoned buildings, substandard housing, bus or train stations, or similar settings; and Migratory children who qualify as homeless because they are living in circumstances described above. (McKinney-Vento Homeless Education Assistance Improvements Act, 2004, para. 1) 
The term homeless was used in this study to describe school-aged children who are homeless as defined by McKinney-Vento, including those residing in hotels, motels, shelters, cars, campgrounds, or other transitional or temporary housing due to the lack of alternative accommodations.

Homelessness is a notable indicator of poverty and deprivation (The Homelessness Research Institute [HRI], 2016). In the 2017-2018 academic year, there were 274,714 homeless students in California — accounting for $21 \%$ of the homeless students nationwide (California Department of Education, 2019). This is in stark contrast to the overall homeless student population of 3\% in the United States (NCHE, 2019). Additionally, the increasing rates of homelessness in the U.S., including family homelessness, have led to hotels increasingly being used as emergency accommodations (Nowicki et al., 2019).

Nationwide, approximately 1.36 million students in the public school system were homeless at some point during the 2016-2017 school year. As such, homeless students accounted for nearly 3\% of the student population (Meltzer et al., 2019; NCHE, 2019). In a 2019 Federal Data Summary Report by the National Center for Homeless Education (NCHE, 2019), this number accounted for a 7\% increase since 2014-2015. Other key findings in this report included the following statistics:

- A total of $20 \%$ of states experienced a growth in their homeless student populations of $10 \%$ or more during the 3 -year period covered in the report.

- The majority of students experiencing homelessness, $76 \%$, shared housing with others due to loss of housing or economic hardship.

- A total of $14 \%$ of homeless students resided in shelters, accounting for the second most common type of housing for the homeless population. 
- A total of $6 \%$ had a primary nighttime residence of hotels or motels.

- A total of $4 \%$ were identified as unsheltered.

- At the time of identification, the unsheltered category of primary nighttime residence grew the most since 2014-2015, seeing a 27\% increase in the number of unsheltered students.

- The use of hotels and motels increased by $10 \%$.

- The number of students staying in shelters increased by $3 \%$.

- Students experiencing homelessness who were also English language learners increased by $19 \%$, accounting for $16 \%$ of students who were homeless.

In addition, unaccompanied youth made up $10 \%$ or more of the homeless student population in over half the U.S. states. Additionally, although only $13 \%$ of all students had an identified disability, well over half of the states $(62 \%)$ reported a proportion of homeless students with a disability of $20 \%$ or more. Finally, approximately $30 \%$ of students experiencing homelessness achieved academic proficiency in language arts, and $25 \%$ were proficient in math. As noted earlier, California is home to $21 \%$ of the homeless students nationwide. Since 2014 , the rate has increased. In 2014-2015, there were 235,983 homeless students in California. In 2016-2017, there were 262, 935. In 2017-2018, there were 274,714 (NCHE, 2019).

Studies have suggested close links between child protective services (CPS) and homeless systems (e.g., Burt et al., 1999; Courtney et al., 2004; Rodriguez \& Shinn, 2016). Each system feeds into the other resulting in an overlap of individuals having been involved in both (Rodriguez \& Shinn, 2016). According to Rodriquez and Shinn (2016), families in homeless shelters have higher rates of CPS involvement compared others, controlling for income, and the risk of CPS involvement increases as shelter stays become longer or more frequent. 


\section{ACEs and Students in ARLC}

There are more than 400,000 children in the CPS system at any given time (Bruskas \& Tessin, 2013). Nearly $80 \%$ of children who entered foster care were from families in poverty (Bruskas \& Tessin, 2013; Davis, 2006). Although the purpose of foster care is to provide a safe and healthy environment for children at risk in their own homes, for many children, the very process of entering foster care is traumatic and abrupt in and of itself. Furthermore, children may experience anywhere from one to 15 foster care placements in the first year of entering foster care, creating increasing difficulties and challenges that may result in additional psychological burdens (Babbel, 2012; Bruskas \& Tessin, 2013).

Tragically, from $25 \%$ to as many as $40 \%$ of former foster care children report having been abused or neglected while in foster care (Babbel, 2012; English et al., 2015), indicating children who were already coping with the psychological and emotional ramifications of the maltreatment that caused them to be in foster care, experienced traumatic foster care experiences. When looking at the frequency of ACEs experienced by women who were in foster care as children before and during foster care placement, Bruskas and Tessin (2013) found notable differences, illustrated in Table 1. There were higher rates of ACEs before foster care compared with during, and physical abuse and living in a dysfunctional household (ACEs 6-10) were higher before foster care than during. However, the frequencies of emotional and physical abuse (ACEs 1-4) increased during time in foster care. 


\section{Table 1}

ACEs Before and During Foster Care

\begin{tabular}{|c|c|c|}
\hline \multirow{2}{*}{ Adverse childhood experiences } & \multicolumn{2}{|c|}{ Frequencies $\%$} \\
\hline & Before foster care & During foster care \\
\hline $\begin{array}{l}\text { 1. Intimidation: swearing, insults, put-downs, or } \\
\text { humiliation }\end{array}$ & 48 & 51 \\
\hline $\begin{array}{l}\text { 2. Physical abuse: pushed, grabbed, slapped, or } \\
\text { something thrown at a person }\end{array}$ & 39 & 43 \\
\hline $\begin{array}{l}\text { 3. Sexual abuse: touched or fondled or made to } \\
\text { touch abuser's body sexually }\end{array}$ & 34 & 55 \\
\hline $\begin{array}{l}\text { 4. Psychological abuse: did not feel loved, } \\
\text { important, special, or looked after }\end{array}$ & 55 & 64 \\
\hline $\begin{array}{l}\text { 5. Physical neglect: not enough to eat, had to wear } \\
\text { dirty clothes, or no one to protect or care for you }\end{array}$ & 46 & 30 \\
\hline $\begin{array}{l}\text { 6. Parental loss: parents/foster parents separated, } \\
\text { divorced, or lost to you }\end{array}$ & 43 & 22 \\
\hline $\begin{array}{l}\text { 7. Maternal abuse: mother/foster mother pushed, } \\
\text { grabbed, slapped, or ever had something thrown } \\
\text { at her }\end{array}$ & 41 & 16 \\
\hline $\begin{array}{l}\text { 8. Substance abuse: lived with a problem drinker or } \\
\text { alcoholic or drug abuser }\end{array}$ & 45 & 16 \\
\hline $\begin{array}{l}\text { 9. Mental illness: household member depressed, } \\
\text { mentally ill, or attempted suicide }\end{array}$ & 47 & 23 \\
\hline 10. Prison: household member in prison & 24 & 12 \\
\hline
\end{tabular}

Note. Adapted from "Adverse Childhood Experiences and Psychosocial Well-Being of Women

Who Were in Foster Care as Children," by D. Bruskas \& D. Tessin, 2013, The Permanente

Journal, 17(3), p. 136 (https://doi.org/10.7812/tpp/12-121). Copyright 2013 by The Permanente

Press.

It has been well known that children who have ever been placed in foster care are more

likely to come from unstable home lives, to experience poverty, and to live in poor

neighborhoods, all of which are risk factors for poor physical and mental health (Turney \&

Wildeman, 2017). Several studies have examined the history of ACEs experienced by youth in foster care (Bruskas \& Tessin, 2013; Garcia et al., 2017; Turney \& Wildeman, 2017). Garcia et al. (2017), for example, found neglect and domestic violence were among the most prevalent 
ACEs experienced by youth in foster care. Another study found a large percentage of children in foster care were exposed to ACEs: among children in foster care, 53.8\% experienced household member substance abuse, $45.4 \%$ experienced parental divorce or separation, $40.1 \%$ had parents who had been incarcerated, $34.2 \%$ experienced abuse, and $33.7 \%$ were exposed to violence. More than $75 \%$ of children in foster care experienced at least one ACE, and on average, experienced 2.5 ACEs (Turney \& Wildeman, 2017), as compared to the population of children as a whole, in which at least 38\% have experienced at least one ACE. Turney and Wildeman (2017) also found second ACEs were more common to children in foster care than children not in foster care. Yet another study found certain ACEs to be predictive of placement in foster care:

caregiver alcohol/drug use and maternal depression (English et al., 2015). Beyond the impact of the experienced maltreatment that precipitated the removal event, the removal and placement of a child in out-of-home care is considered a traumatic event in and of itself (English et al., 2015), likely causing further trauma to already traumatized youth. The Bruskas and Tessin (2013) study referenced earlier analyzed the psychosocial well-being of women who were in foster care as children. They found participants reported experiencing an average of 5.68 ACEs. Most respondents (97\%) experienced at least one ACE, with nearly $70 \%$ reporting more than five, $33 \%$ reporting eight or more, and $23 \%$ reporting nine or more. For comparative purposes, in the ACE study (Felitti et al., 1998), 64\% of respondents (regardless of housing circumstances) reported experiencing at least one ACE, and 11\% reported five or more ACEs. The Centers for Disease Control (2016) has reported on the frequency of ACEs in the general population, and found $41 \%$ of adults reported experiencing no ACEs, and $22 \%$ reported at least one.

ACEs are not only prevalent in children in foster care. In a recent study, $68.1 \%$ of adult respondents who reported being homeless at some point in childhood reported exposure to four 
or more ACEs. In comparison, of adults who did not experience homelessness in childhood, only 16.3\% reported exposure to ACEs (Radcliff et al., 2019). Notably, the chance of experiencing each adverse experience was significantly higher among adults who experienced childhood homelessness compared with those who did not (Radcliff et al., 2019). An intersection between being in foster care and homelessness also exists, as $25 \%$ of 23 - and 24 -year-old participants in one study reported becoming homeless subsequent to leaving foster care (Courtney et al., 2010). Radcliff et al. (2019) suggested homelessness may be an ACE in and of itself. They found high rates of ACEs among adults who experienced unstable and insecure housing circumstances in childhood. They went on to state the concept of homelessness could, with further research, meet the definition of the World Health Organization's (WHO, 2018) classification of ACEs, which requires the category (a) produce a biological stress response, (b) have sensitivity to policies, (c) be common across populations, (d) be easily measured, and (e) have similar associations as other identified ACEs.

In comparing where children lived to the total counts of ACE exposure, $37.2 \%$ of adults were never homeless in childhood reported having no ACE exposure. In contrast, only $2.7 \%$ of adults who were homeless at some point during childhood reported no ACE exposure (Radcliff et al., 2019). According to a report by the National Health Care for the Homeless Council (NHCHC, 2019), children who are homeless are more likely to have high numbers of ACEs, increasing their risk of emotional, psychological, and developmental challenges, as well as poor health outcomes. In fact, compared to those who live in financially stable households, children who live below the federal poverty line are 53 times more likely to have experienced four or more ACEs (NHCHC, 2019). The experience of housing insecurity, defined as poor housing quality, unstable neighborhoods, overcrowding, and homelessness (NHCHC, 2019) places 
children at risk of ACE exposure. Youth and families who are housing insecure report instances of abuse, sex-trafficking, and financial exploitation while staying in shelters or on the streets (NHCHC, 2019).

\section{Risk Factors for Students in ARLC}

To best support youth who have experienced significant adversity, it is essential to understand their current experiences and the risk factors they face. Unlike protective factors, risk factors are not easily categorized into internal or external factors and are more readily understood as factors that impact overall outcomes, health, and experiences of individuals (Benard, 2004). For the purposes of this study, they were categorized as developmental and mental health risk factors and school-based risk factors.

\section{Developmental and Mental Health Risk Factors}

Children who have ever resided in foster care or experienced homelessness are more likely to experience family instability, to be exposed to economic disadvantage, and to live in poor neighborhoods, all of which are risk factors for poor physical and mental health (Turney \& Wildeman, 2017). The literature on ACEs and risk and resilience has indicated children exposed to physical abuse often experience impairments in their physical health, cognitive development, academic achievement, mental health, and interpersonal relationships. Moreover, erratic and insecure home environments that lack continuity and consistency in caregiving are also associated with poor developmental outcomes (Harden, 2004). In addition, although some children may benefit from foster care services, those who have a history of being in foster care experienced disproportionate rates of psychiatric problems associated with ongoing or cumulative adversities (Bruskas, 2013). The prevalence of mental health problems for children involved with the child welfare system is high regardless of placement history; however, 
research has shown placement in foster care to be a strong predictor of negative outcomes. In a sample of 415 youth entering foster care, Newton et al. (2000) found children in foster care who experienced unstable placement histories faced an increased risk of internalizing and externalizing problems. Similarly, adolescents who had a history of out-of-home placement were 2.29 times more likely to report clinically significant depression symptoms compared to peers who were never placed out of home (Heneghan et al., 2013).

Research has shown that suicide rates are high for youth in foster care (Katz et al., 2011) and homelessness (Votta \& Manion, 2004). Youth in foster care were at greater risk of suicide attempts and suicide completions than those not in care (Katz et al., 2011). Katz et al. (2011) noted rates of suicide attempts and hospitalizations were at their highest before entry into the foster care system and decreased thereafter. Evans et al. (2017) conducted a systematic review and meta-analysis and found that youth in foster care were three times as likely to attempt or complete suicide than those not in care. Similarly, Votta and Manion (2004) found homeless youth experienced high levels of suicidal ideation and attempts, depressive symptoms, and internalizing and externalizing behaviors.

A large body of research, both on ACEs and risk and resilience, have documented various forms of maltreatment that are associated with adverse outcomes in brain development, health, cognition, language skills, and social-emotional functioning (Crittenden, 1998; Harden, 2004). For example, according to Crittenden (1998), neglect was associated with cognitive, language, and academic delays as well as poor peer relations and behavior issues. Physical abuse was associated with aggressive behavior, difficulties in social situations, cognitive delays, and behavior issues. Sexual abuse was associated with dissociation, depression, high-risk behaviors such as drug abuse, and low academic performance. Emotional maltreatment led to declines in 
cognitive and academic functioning and a variety of behavior problems. Harden (2004) asserted the diagnosis of "failure to thrive" is a particularly illuminating health outcome of an unstable and problematic family environment.

Foster care placements range from supportive and nurturing to neglectful and abusive, and everything in between (Fisher \& Kennedy, 2017). However, negative experiences while in foster care put children at further and more substantial risk for negative outcomes (Harden, 2004). In a qualitative study examining teacher perceptions of students in foster care, Zetlin et al. (2010) found student behavior was the biggest challenge noted by teachers. Many children exhibited "roller coaster" emotions ranging from explosive and unpredictable aggressive behaviors, such as tantrums, hitting, kicking and screaming, to shutting down, depression, clinging behaviors, and withdrawal. Teachers noted many children struggled the most shortly after contact with the birth parents, when students would become defiant and more physically aggressive. Conversely, other foster children exhibited needy or clingy behaviors and appeared sad; they did not trust adults and found it difficult to separate from one adult and transition to another.

Similarly, homelessness is associated with multiple stressors. This may include poverty, housing instability, substance abuse, community violence, and other risks related to safety and overall well-being (Masten et al., 2015). Homelessness can be particularly damaging to children and adolescents (American Academy of Pediatrics, 2020). Related to the significant stress associated with homelessness, studies have suggested it may be linked to developmental, academic, and behavioral problems (Fantuzzo \& Perlman, 2007; Grant et al., 2013).

Adding to the risks experienced by students in unstable housing, Nowicki et al. (2019) found children who spend long periods of time in hotels had stunted development, including 
speech and motor skills. They surmised this was likely due to the limited space in hotel rooms or the trauma of homelessness, limiting their ability to reach the usual developmental milestones on time. Nowicki et al. (2019) concluded that experiences of homelessness early in a child's life have long-term implications for young children who may have impaired physical and emotional development due to inadequate housing conditions.

\section{School-Based Risk Factors}

Not only are children in foster care and homelessness at risk for poor mental health outcomes, these populations are also at risk for low academic achievement and negative school outcomes. Foster youth tend to be disproportionately placed in special education and have high rates of poor academic and behavioral outcomes (Kirk \& Day, 2011). Additionally, Blome (1997) found children in foster care were significantly more likely to report more discipline problems at school, to change schools frequently, and ultimately, to drop out of high school.

Unquestionably, children raised in environments that are safe and stable have more positive adjustment, both in the short and long term, than children who are exposed to adverse experiences (Harden, 2004). Conversely, children exposed to violence in their homes experience the most deleterious outcomes. Obradović et al. (2009) found significant variability, not explained by demographics, in the achievement trajectories of students experiencing adversities (e.g., homelessness and foster care), with some students displaying academic resilience despite their challenges. Given that children spend more of their awake hours at school than at home, there is a true opportunity to create a positive environment, build relationships, foster trust, and potentially, to alter the trajectory for students who have experienced significant adversity. 


\section{Protective Factors for Students in ARLC}

Protective factors can be organized into two categories: internal (i.e., those that occur in a person) and those that are external or environmental. Internal protective factors are characteristics or competencies of an individual (Benard, 2004). External, or environmental, protective factors are factors that occur in environments or context outside of the individual. An individual may develop protective factors from various influences, but participation in meaningful activities in concert with emotionally responsive relationships with adults was found to be critical to students' academic success (Neal, 2017).

\section{Internal Assets}

Personal resilience strengths are the individual characteristics associated with healthy development and life success. They do not cause resilience, but rather are the positive developmental outcomes "demonstrating that this innate capacity is engaged" (Benard, 2004, p. 13). Personal strengths, or in this sense, the manifestations of resilience, can be categorized into four themes: problem-solving skills, autonomy, social competence, and a sense of purpose (Benard, 2004). These competencies appear to transcend cultures, genders, ethnicities, and locations (Benard, 2004; Werner \& Smith, 1992, 2001).

\section{Environmental Protective Factors}

As noted prior, resilience is a universal, developmental capacity of every human being. In order for positive developmental outcomes to emerge from one's environment, a nurturing environment must be present; whereby, a child can meet their inherent need for belonging, where they can develop a sense of competence and autonomy, and feel safe (Benard, 2004). Adversity and risk have been directly tied to factors that interfere with young people's abilities to satisfy these needs (Benard, 2004; Masten \& Reed, 2002) and highlighted specific environmental 
factors that protect children from risk (Benard, 2004): caring relationships, high expectation messages, and opportunities for participation and contribution. These factors were consistent across different environments, which, for youth, often include the family, the school, and the community (Benard, 2004). According to Austin et al. (2018), these protective factors, which in the California Healthy Kids Survey are called developmental supports or protective factors (used interchangeably), contributed to higher levels of school connectedness, which contributes to academic motivation and performance.

Caring Relationships. The concept of caring has emerged in the literature (Laursen \& Birmingham, 2003; Neal, 2017; Tronto, 1993). On the most general level it is viewed as: A species activity that includes everything that we do to maintain, continue, and repair our "world" so that we can live in it as well as possible. That world includes our bodies, ourselves, and our environment, all of which we seek to interweave in a complex, lifesustaining, web. (Tronto, 1993, p. 103)

Laursen and Birmingham's (2003) study of how unprotected youth perceived the care of adults found that when challenging experiences outweighed a student's protective environment, all students, even academically successful students, needed support. In addition, they found several characteristics of caring adults that were important in the relationships between adults and students in need. These characteristics included empathy, trust, availability, attention, and affirmation. Young persons who have experienced trauma and instability may, as a result of being met with these caring adults, feel important and worthy of others' time and remain resilient (Neal, 2017). Neal (2017) found an important connection between academic resilience and care; that when students who were considered vulnerable were facing challenges, especially those with involvement in the foster care system (and, arguably, those residing in unstable living 
conditions), those challenges needed to be met by a collective solution brought to them by caring adults.

The term caring relationships "conveys loving support — the message of being there for a youth, of trust, and of unconditional" support (Benard, 2004, p. 94). Benard (2004) noted resilient survivors described relationships characterized by "quiet availability," "fundamental positive regard," and "simple sustained kindness" (p. 44). Caring relationships were characterized by a sense of compassion, and by caregivers who were interested in and actively listened to the children and youth in their care (Benard, 2004).

High Expectations. Benard (2004) defined high expectations as "clear, positive, and youth-centered" (p. 45). Clear expectations refer to the guidance, structure, and safety through rules and discipline provided by caregivers. Positive and youth-centered expectations are those that communicate the adult's belief in the youth's innate self-righting capabilities (Benard, 2004). Benard (2004) stressed a subtlety of this sentiment is that the adult's high expectations were based on the strengths, interests, hopes, and dreams of the youth — not on what the adult wanted them to do or be. High expectations from adults serve as an exchange between persons through which young people internalize high expectations for themselves, "thus transforming them into an intra-personal attribute" (Benard, 2004, p. 46). In other words, the high expectations from the adult shift to be internalized by the youth.

Meaningful Participation. Benard (2004) categorized meaningful participation as "opportunities for participation and contribution" and posited it as a natural "outgrowth" (p. 46) of relationships based on caring and high expectations. Providing youth with the chance to participate in engaging, challenging, and interesting activities promotes the entire range of personal resilience strengths. Opportunities for participation in group or cooperative activities 
can help young people fulfill their strong psychological needs for belonging (Benard, 2004).

Werner and Smith (1992) found activities that allowed youth to be part of a "cooperative enterprise" (p. 205) such as being on school teams, connected them to a group that could serve as a surrogate family if needed (Benard, 2004).

Benard (2004) noted an important type of participation involves having opportunities for reflection and dialogue on issues that are meaningful to them, especially in a small group context. When caregivers provide youth with opportunities to dialogue about their beliefs, attitudes, and feelings, and critically question societal issues, they are empowered to be critical thinkers and decision makers about the important issues in their own lives. She added opportunities for creative expression through all forms, opportunities to problem solve, make decisions, and give back are vital components to youth participation.

\section{The Role of Schools and Educators}

The importance of a strong educational foundation for all youth, especially those who reside in at-risk living conditions, cannot be overstated as the experiences of success that a child has in school can impact their psychosocial functioning and overall well-being much later in life (Pecora, 2012). Particularly for students who have experienced significant adversities, being in school provides opportunities to build protective factors that may counter trauma-related challenges.

Although a child's educational environment is merely one aspect of a complex web of systems - supportive and inhibitive - that contribute to the physical, social, emotional, cognitive, academic, and mental health of a child, its role is profound. Where home, community, and societal environments may fail a child, schools must be prepared to meet their most basic needs including physiological, safety, and belonging. Similar to Maslow's (1943) hierarchy of needs 
theory, these must be met first to then move on to more complex needs such as self-esteem and self-actualization, which for students, manifest in their ability to learn (Neal, 2017; Tronto, 1993).

Benard (2004) has said a significant factor in fostering resilience in children is the role of the school. Schools must create supportive and nurturing environments; all children will benefit from this, especially those who have faced significant adversities such as students in foster care and unstable housing. Oddone (2002) argued that schools can emphasize protective factors by using a cohesive and systemic approach administrators, teachers, and school mental health professionals can apply a broad and systemic approach. For example, providing opportunities for meaningful participation at school; teaching and fostering skills for students to build prosocial relationships; setting clear, consistent expectations and boundaries, teaching life skills; and communicating high expectations for all students are all methods of promoting resilience (Johnson \& Lazarus, 2014).

School connectedness generally includes the sense of attachment and commitment a student feels as a result of perceiving that they are cared for by teachers and peers (Johnson \& Lazarus, 2014). Johnson and Lazarus (2014) found the feelings a student has towards school, the level of support from teachers, prosocial relationships, involvement in extra-curricular activities, and fair discipline processes were all strongly associated with positive student outcomes. Similarly, in a 2016 mixed-method analysis of educational well-being and resilience of youth in foster care, three themes were identified throughout the qualitative interviews: (a) school stability and structured transition, (b) positive relationships with adult mentors, and (c) the power of positive peer influence (Strolin-Goltzman et al., 2016). 
Bolstering the notion of peer influence on resilience, Taussig (2002) found social support from classmates, such as being liked and not being teased, has been found to predict fewer risktaking behaviors. Social support is frequently cited in the literature as a key component of resilience for youth who have ever resided in foster care (Strolin-Goltzman et al., 2016; Taussig, 2002).

Similar to Benard's $(1991,2004)$ work, Neal (2017) recommended the following approaches at school to facilitate resilience in youth in foster care, although the same recommendations can be generalized to all students who have experienced adversity, including homelessness:

- Ensure foster youth connect to a caring adult supporter at school whereby positive relationships with an adult can stimulate students' belief in themselves and the desire to change their academic outcomes.

- Establish a college-going culture in schools where foster youth are provided with dedicated academic advising with an emphasis on college and career paths, and social development opportunities through school's extracurricular activities.

- Ensure school leadership, teachers, and counselors are supported and trained in maintaining high academic expectations of their students where foster care students are shown encouragement and an explicit belief in their academic abilities.

Mota and Matos (2012) argued when students establish emotional relationships with educators, they may be better able to both express and regulate emotions, which promotes selfconfidence. Mota and Matos (2012) went on to emphasize that for young people who do not live with their biological family, these relationships are of particular importance. The trust established in the bonds formed with other adults promotes closeness and involvement, which 
may encourage the development of other personal and life skills beyond academic achievements (Mota \& Matos, 2012) or be seen as an extension or improvement of parental relationships (Riley, 2011).

\section{Summary}

Children who have been in foster care or who have experienced homelessness traverse a challenging journey through childhood, with many obstacles in their way toward optimal development. Many have experienced maltreatment, poverty, or disrupted attachments. With an understanding of the impact of resilience, supportive relationships, and meaningful participation on vulnerable students, educators can be more aware of adopting a holistic approach to servicing the needs of children who have faced significant adversities. When children who are considered vulnerable - especially those whose basic needs such as safety and attachment are called into question - are facing challenges, those challenges must be met by a collective solution. Of particular consideration is that the supports that are needed for the most vulnerable of children can reach any student, whether in foster care, homeless, or in another home setting.

Although protective factors can develop from various influences, the literature has indicated clearly that the most salient environmental influences are caring relationships with adults, high expectations, and opportunities to engage in meaningful participation. As a result of experiencing emotional and physical instability, youth in at-risk living conditions may become disconnected from supportive relationships that may help mitigate risk and bolster academic success and emotional well-being. Positive relationships with an adult, particularly an educator, can stimulate a child's belief in themselves and the desire to change their academic outcomes, resulting in a stronger, more academically resilient student (Neal, 2017). 


\section{CHAPTER 3: RESEARCH METHODOLOGY}

The purpose of this study was to better understand the factors related to mitigating risk and improving outcomes for students in foster care and students who are homeless. By understanding and implementing protective factors, schools may reduce risks and, thus, improve outcomes for these youth. This study used the California Healthy Kids Survey (CHKS) data in combination with a review of the extant literature on resilience, trauma, adverse childhood experiences (ACEs), foster care, and homeless youth to identify the school-based protective factors (SBPF) that improve resilience and, thus, increase positive outcomes. This study adds to the existing literature by examining risk and protective factors as they relate to students who have experienced significant adversities.

\section{Measures}

\section{The California Healthy Kids Survey}

The CHKS is a tool developed by WestEd for the California Department of Education (CDE) to understand the strengths and risks of students, particularly from a perspective of positive youth development and risk and resiliency factors (WestEd, 2017). The CHKS has been the largest statewide survey of students' perceptions of school climate, resiliency, and risk behaviors (Austin et al., 2011). The survey is a research-based, self-report tool administered to

students in Grades 5, 7, 9, and 11, and has focused on the five most foundational areas for school and student improvement (Mahecha \& Hanson, 2020): (a) learning engagement/motivation, school connectedness, and attendance; (b) school safety, school climate, culture and conditions; (c) physical and mental well-being; (d) social-emotional learning; and (e) student supports such as resilience-promoting developmental factors (i.e., caring relationships, high expectations, and meaningful participation; WestEd, 2020). 
A unique feature of the CHKS is its theoretical framework drawn from resilience and youth development research. The CHKS was created based on Benard's resiliency theory (Benard, 2004; WestEd, 2017). It employs the language of strengths outlined in Benard's work and designed questions to measure a student's positive development based on high expectations, caring relationships, and meaningful participation in the school. The Core Module contains specific scales for understanding these factors in the school environment. The CHKS is one of the few large-scale surveys to assess both risk and resilience (WestEd, 2018). It assesses three fundamental protective factors in the community, family, school, and peer group: positive adult relationships, high expectations (both academic and behavioral), and opportunities for meaningful participation and decision making (Mahecha \& Hanson, 2020). These supports are linked to positive outcomes in youth in academics, psychosocial factors, and health, even in high-risk environments. It also provides data on personal social-emotional assets linked with these factors (Mahecha \& Hanson, 2020). These are considered protective factors, in that they mitigate against the negative effects of trauma, stress, and other risk factors that youth may experience.

\section{School-Based Protective Factors}

The literature on CHKS uses SBPF and school-based developmental supports interchangeably. Research (Austin et al., 2018; Benard, 2004) has shown when schools (or communities or families) provide three developmental supports — caring adult relationships, high expectations, and opportunities for meaningful participation — students are more likely to report positive outcomes, including academic, social-emotional, and health (Austin et al., 2018).

Children and adolescents who attend schools that have an abundance of positive adult relationships, high expectations, and opportunities for meaningful participation, are more likely 
to have their basic developmental needs met. Aligned with Maslow's hierarchy of needs theory (1943), having their basic developmental needs met in schools leads to students being less likely to engage in risk behaviors, feeling more connected to school, and developing the socialemotional personal strengths that have been linked to success both in school and in life (Mahecha \& Hanson, 2020). This leads to youth that are more likely to have positive outcomes in academics, personal life, and health (Mahecha \& Hanson, 2020). School protective factors and the related youth outcomes are depicted in Figure 1.

\section{Figure 1}

School Protective Factors and the Related Youth Outcomes

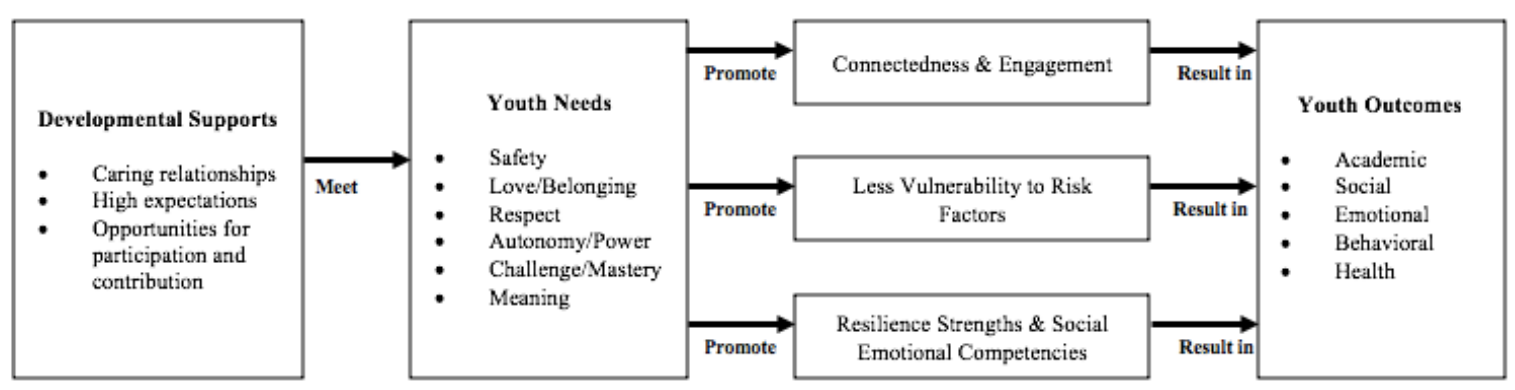

Note. Adapted from CalSCHLS by WestEd for the Department of Education (2021). Retrieved from https://calschls.org/about/the-surveys/\#chks.

Table 2 shows the average number of students reporting strongly agree or very much true on questions that make up the scale. 
Table 2

SBPF-Percentage of Respondents Categorized High, Moderate, and Low

\begin{tabular}{|c|c|c|c|c|c|c|}
\hline \multirow[b]{2}{*}{ SBPF Scale } & \multicolumn{2}{|c|}{ Grade 7} & \multicolumn{2}{|c|}{ Grade 9} & \multicolumn{2}{|c|}{ Grade 11} \\
\hline & $\begin{array}{l}2013- \\
2015 \\
(\%)\end{array}$ & $\begin{array}{l}2015- \\
2017 \\
(\%)\end{array}$ & $\begin{array}{l}2013- \\
2015 \\
(\%) \\
\end{array}$ & $\begin{array}{l}2015- \\
2017 \\
(\%)\end{array}$ & $\begin{array}{l}2013- \\
2015 \\
(\%)\end{array}$ & $\begin{array}{l}2015- \\
2017 \\
(\%)\end{array}$ \\
\hline \multicolumn{7}{|c|}{ Total school supports } \\
\hline High & 32.8 & 38.4 & 26.0 & 26.3 & 30.8 & 29.3 \\
\hline Moderate & 53.1 & 50.1 & 54.0 & 54.7 & 52.3 & 52.3 \\
\hline Low & 14.1 & 11.5 & 20.0 & 19.0 & 16.9 & 18.4 \\
\hline \multicolumn{7}{|l|}{ Caring adults } \\
\hline High & 32.7 & 38.1 & 27.0 & 27.3 & 33.9 & 32.0 \\
\hline Moderate & 52.8 & 50.6 & 54.8 & 56.5 & 53.0 & 54.0 \\
\hline Low & 14.5 & 11.3 & 18.1 & 16.2 & 13.2 & 13.9 \\
\hline \multicolumn{7}{|c|}{ High expectations } \\
\hline High & 52.6 & 56.4 & 41.3 & 40.9 & 43.8 & 41.1 \\
\hline Moderate & 39.4 & 37.2 & 47.2 & 49.2 & 46.5 & 48.7 \\
\hline Low & 8.0 & 6.4 & 11.6 & 9.9 & 9.8 & 10.2 \\
\hline $\begin{array}{l}\text { Meaningful } \\
\text { participation }\end{array}$ & 14.5 & 17.8 & 12.2 & 12.6 & 14.5 & 14.0 \\
\hline High & 54.0 & 53.2 & 49.8 & 49.9 & 48.4 & 47.8 \\
\hline $\begin{array}{l}\text { Moderate } \\
\text { Low }\end{array}$ & 31.4 & 29.0 & 38.0 & 37.5 & 37.2 & 38.2 \\
\hline
\end{tabular}

Note. $\mathrm{SBPF}=$ School-Based Protective Factors.

\section{CHKS Development}

The CHKS is a comprehensive health risk and resilience data collection system that relies on student self-reporting. The survey's core module tracks health risks and problem behaviors that are significant barriers to student learning (WestEd, n.d.). This section provides a brief background on how the survey was developed and is now used in California.

The CHKS is the largest effort in the nation to require school districts to assess student resilience and risk behaviors. The CDE requires all school districts with federal Title IV funding or with state Tobacco Use Prevention and Education grants to administer the survey every 2 years - the case for $85 \%$ of California school districts. In mandating the survey, the CDE has aimed to promote accountability and data-driven decision making and to improve health and 
prevention programs in schools (WestEd, n.d.). The survey was developed in 1997 and was funded by the $\mathrm{CDE}$ in response to federal requirements. The initial impetus for mandating the biennial administration of the survey, however, was meeting the requirements of the No Child Left Behind Act.

The CDE requires that districts administer the survey to 900 randomly selected students from each targeted grade $(5,7,9$, and 11). In districts with fewer than 900 students per grade (the case for $85 \%$ of California districts), all students in the targeted grades are surveyed. If a district has more than 10 schools per grade, at least $50 \%$ of schools are randomly sampled (WestEd, n.d.).

\section{Core Module}

The 2017-2018 and 2018-2019 versions of the Core Module of the CHKS survey contain 130 questions. A total of 13 demographic questions related to students' age, grade level, sex, race, housing situation, and parental education are asked at the beginning of the survey. The next sections include questions about students' attendance, drug and alcohol usage, feelings toward school, and victimization.

\section{Reliability and Validity}

In 2020, WestEd conducted a measurement analysis of the survey using a confirmatory factor analysis (CFA), differential item functioning (DIF), and Cronbach's alpha, pulling from the 2017-2018 to 2018-2019 administration of the survey (Mahecha \& Hanson, 2020). The secondary CHKS is administered in schools serving students in Grades 7-12. The Core Module consists of 77 questions about student perceptions and experiences related to school climate and safety, pupil engagement, developmental supports, positive behavior, parental involvement in school, and health-related and behavioral learning barriers. The secondary Core CHKS was 
administered to $70 \%$ of districts and $52 \%$ of schools in the California in 2017-2018 and 20182019.

The secondary CHKS Core Module survey questions reliably measure the purported dimensions of school climate and student well-being, which is consistent with previous psychometric analyses of the core items (Mahecha \& Hanson, 2020). Reliability for all nine of the constructs exceeded .70 for eight out of nine of the subgroups. All nine constructs demonstrated good internal consistency reliability. Only the reliability of the scales used in this study are presented here. Table 3 shows the items associated with each construct and standardized factor loadings from the CFA model. The higher the loading, the better the questionnaire item differentiates students with respect to their scores on the underlying factor. The average loading across all constructs is 0.81 , indicating the items are strongly correlated with the underlying factors. The analytic model indicates the CHKS Core Module measures the dimensions of school climate and student well-being that it is intended to measure. Internal consistency reliability estimates for the Secondary Core Module exceeded Nunnally’s (1978) threshold of .70 for subgroups School Caring Relationships (.90) and Student Meaningful Participation (.86). Due to high correlation between the two, high expectations and caring relationships were combined into one factor: caring staff-student relationships (referred to in this study as Supportive Relationships), while Meaningful Participation stood alone (Mahecha \& Hanson, 2020). 


\section{Table 3}

Secondary CHKS Core Module Confirmatory Factor Analysis Model

\begin{tabular}{clc}
\hline Item \# & Item & Loading \\
\hline & Factor 1: Caring Staff-Student Relationships & .81 \\
35. & Teacher or adult who really cares about me & .84 \\
36. & Teacher or adult who tells me when I do a good job & .74 \\
37. & Teacher or adult who notices when I'm not there & .87 \\
38. & Teacher or adult who wants me to do my best & .85 \\
39. & Teacher or adult who listens to me when I have something to say & .87 \\
40. & Teacher or adult who believes that I will be a successful student & \\
& Factor 2: Student Meaningful Participation & .76 \\
41. & At school, I do interesting activities & .85 \\
42. & At school, I help decide things like class activities or rules & .85 \\
43. & At school, I do things that make a difference & .84 \\
44. & At school, I have a say in how things work & .83 \\
45. & At school, I help decide school activities or rules &
\end{tabular}

\section{Sample}

As required by the CDE, the survey is administered in all schools that receive Title IV funding and those receiving federal money related to the Tobacco Use Prevention and Education grants (Hanson \& Kim, 2007). As noted earlier, approximately 85\% of schools in California meet this criterion (WestEd, 2017). There are roughly 600,000 California students who take the survey each year.

\section{Definitions}

Academic outcomes refers to self-disclosed grades (defined further in the next section). At-risk living conditions (ARLC) refers to an index of all students who responded they either reside in foster care or are homeless.

Homeless students refers to school-aged youth who have identified on the CHKS as living in hotels or motels, shelter, car, campground, or other transitional or temporary housing. School-Based Protective Factors (SBPF) are also known as school-based developmental supports, school-based resilience assets, and environmental resilience assets. This is an index 
comprised of three environmental factors: (a) Caring Adult Relationships, (b) High Expectations, and (c) Meaningful Participation. In the present study, caring relationships and high expectations were combined into one index: Supportive Relationships.

\section{Variables}

\section{Measurement of Students Who Have Experienced Significant Adversities}

To identify the population of students on the CHKS who have been exposed to significant adversities (which, in this study, are being measured by students who are in foster care or who are homeless), the variables used will be identifying students who are either in foster care, or who are homeless: (a) identification of living in "foster home, group care, or other waiting placement," or (b) identification of living in a "hotel or motel," or (c) identification of living in a "shelter, car, campground, or other transitional or temporary housing," in response to the survey question "What best describes where you live?" Response items b and c on the survey were combined and labeled as "homeless." Survey items used in this and the following measurements can be found in the Appendix.

\section{Measurement of Negative Outcomes}

\section{Academic}

To measure self-reported academic outcomes, the variable used was student responses to the following item: "During the past 12 months, how would you describe the grades you mostly received in school?"

\section{Depressive Symptoms}

To measure self-reported depressive symptoms, the variable used was student responses to the following item: "During the past 12 months, did you ever feel so sad or hopeless almost 
every day for 2 weeks or more that you stopped doing some usual activities?” Refer to Appendix, Item 124.

\section{Suicidality}

To measure self-reported suicidal thoughts or behaviors, the variable used was student responses to the following item: "During the past 12 months, did you ever seriously consider attempting suicide?" Refer to Appendix, Item 125.

\section{School-Based Protective Factors}

There are two different factors identified as school-based environmental resilience assets, or school-based protective factors (SBPF): Supportive Relationships (caring adults in school and high expectations in school) and Meaningful Participation at school. Table 4 shows the sum total of the responses on the nine different questions was used to create the dependent variable: SBPF. 


\section{Table 4}

SBPF

\begin{tabular}{|c|c|c|}
\hline SBPF & Questions & Responses \\
\hline \multirow[t]{3}{*}{ Caring adults in school } & $\begin{array}{l}\text { At school, there is a teacher or some other adult... } \\
\ldots \text { who really cares about me }\end{array}$ & $\begin{array}{l}\text { Not at all true } \\
\text { A little true } \\
\text { Pretty much true } \\
\text { Very much true }\end{array}$ \\
\hline & ... who notices when I'm not there & $\begin{array}{l}\text { Not at all true } \\
\text { A little true } \\
\text { Pretty much true } \\
\text { Very much true }\end{array}$ \\
\hline & ...who listens to me when I have something to say & $\begin{array}{l}\text { Not at all true } \\
\text { A little true } \\
\text { Pretty much true } \\
\text { Very much true }\end{array}$ \\
\hline \multirow[t]{3}{*}{ High expectations } & $\begin{array}{l}\text { At my school, there is a teacher or some other adult } \\
\ldots \text { who tells me when I do a good job }\end{array}$ & $\begin{array}{l}\text { Not at all true } \\
\text { A little true } \\
\text { Pretty much true } \\
\text { Very much true }\end{array}$ \\
\hline & ... who always wants me to do my best & $\begin{array}{l}\text { Not at all true } \\
\text { A little true } \\
\text { Pretty much true } \\
\text { Very much true }\end{array}$ \\
\hline & $\ldots$ who believes that I will be a success & $\begin{array}{l}\text { Not at all true } \\
\text { A little true } \\
\text { Pretty much true } \\
\text { Very much true }\end{array}$ \\
\hline \multirow[t]{3}{*}{ Meaningful participation } & $\begin{array}{l}\text { At school ... } \\
\ldots \text {. I do interesting activities }\end{array}$ & $\begin{array}{l}\text { Not at all true } \\
\text { A little true } \\
\text { Pretty much true } \\
\text { Very much true }\end{array}$ \\
\hline & ... I help decide things like class activities or rules & $\begin{array}{l}\text { Not at all true } \\
\text { A little true } \\
\text { Pretty much true } \\
\text { Very much true }\end{array}$ \\
\hline & ... I do things that make a difference & $\begin{array}{l}\text { Not at all true } \\
\text { A little true } \\
\text { Pretty much true } \\
\text { Very much true }\end{array}$ \\
\hline
\end{tabular}




\section{Research Questions}

There were six primary research questions (RQ) in this study.

\section{Research Question 1}

RQ1a

Is there a difference in how students experience School-Based Protective Factors (SBPF)?

Variables: Independent variable (IV): all students; dependent variable (DV): SBPF

Analysis: $\quad$ Because we compared the mean score of more than two groups with nonparametric data, a Kruskal-Wallis test was used to understand the rates at which students experience SBPF.

$R Q 1 b$

Is there a difference in how students who are homeless experience School-Based Protective Factors as compared to students who live at home with one or more parent?

Variables: IV: a) living at home with one or more parent, b) homeless DVs: 1) SBPF, 2) Supportive Relationships, 3) Meaningful Participation

Analysis: $\quad$ Because we compared the mean score of more than two groups with nonparametric data, a Kruskal-Wallis test was used to understand the rates at which students who live at home with one or more parent experience SBPF as a whole, as well as each individual protective factor, as compared to students who are homeless.

RQ1c

Is there a difference in how students who are in foster care experience School-Based Protective Factors as compared to students who live at home with one or more parent? 
Variables: IV: a) living at home with one or more parent, b) foster care DVs: 1) SBPF, 2) Supportive Relationships, 3) Meaningful Participation

Analysis: $\quad$ Because we compared the mean score of more than two groups with nonparametric data, a Kruskal-Wallis test was used to understand the rates at which students who live at home with one or more parent experience SBPF as a whole, and each individual protective factor, as compared to students who are living in foster care.

\section{Research Question 2}

$R Q 2 a$

What is the rate of suicidal ideation in students who are homeless, and how does this compare with students living at home with one or more parent?

Variables: IVs: a) homeless, b) at home with one or more parent DV: suicidal ideation

Analysis: $\quad$ To understand the frequencies of each response pattern, a chi square was used.

$R Q 2 b$

What is the rate of suicidal ideation for students who reside in foster care, and how does this compare with students living at home with one or more parent?

Variables: IVs: a) foster care, b) at home with one or more parent DV: suicidal ideation

Analysis: $\quad$ To understand the frequencies of each response pattern, a chi square was used. 


\section{Research Question 3}

RQ3a

What is the rate of depressive symptoms in students who are homeless, and how does this compare to students living with one or more parent?

Variables: IVs: a) homeless, b) at home with one or more parent

DV: depressive symptoms

Analysis: $\quad$ To understand the frequencies of each response pattern, a chi square was used.

$R Q 3 b$

What is the rate of depressive symptoms in students who reside in foster care, and how does this compare to students living with one or more parent?

Variables: IVs: a) foster care, b) at home with one or more parent DV: depressive symptoms

Analysis: To understand the frequencies of each response pattern, a chi square was used.

\section{Research Question 4}

$R Q 4 a$

What are the self-reported academic outcomes for students who are homeless, and how does this compare with students living at home with one or more parent?

Variables: IVs: a) homeless, b) at home with one or more parent DV: academic outcomes

Analysis: To understand the frequencies of each response pattern, a chi square was used. 
What are the self-reported academic outcomes for students who reside in foster care, and how does this compare with students living at home with one or more parent?

Variables: IVs: a) foster, b) at home with one or more parent DV: academic outcomes

Analysis: $\quad$ To understand the frequencies of each response pattern, a chi square was used.

\section{Research Question 5}

RQ5a

Do School-Based Protective Factors predict suicidality above and beyond where a student resides?

Variables: IV: a) where a student resides (foster, homeless, at home with one or more parent), b) SBPF

DV: suicidality

Analysis: $\quad$ A hierarchical logistic regression was used to answer whether SBPF predict the presence or absence of suicidality above and beyond where a student resides.

$R Q 5 b$

Do School-Based Protective Factors predict depression above and beyond where a student resides?

Variables: IV: a) where a student resides (foster, homeless, at home with one or more parent), b) SBPF

DV: depression 
Analysis: A hierarchical logistic regression was used to answer whether SBPF predict the presence or absence of depression above and beyond where a student resides.

RQ5c

Do School-Based Protective Factors predict academic outcomes above and beyond where a student resides?

Variables: IV: a) where a student resides (foster, homeless, at home with one or more parent), b) SBPF

DV: academic outcomes

Analysis: A hierarchical logistic regression was used to answer whether SBPF predict academic outcomes above and beyond where a student resides.

\section{Research Question 6}

RQ6a

Do specific School-Based Protective Factors significantly predict suicidality above and beyond where a student resides?

Variables: IV: a) where a student resides, b) Supportive Relationships, Meaningful Participation

DV: suicidality

Analysis: $\quad$ Similar to Research Question 5, a hierarchical logistic regression was used to answer whether specific SBPF predict suicidality above and beyond where a student resides. 
Do specific School-Based Protective Factors significantly predict depression above and beyond where a student resides?

Variables: IV: a) where a student resides, b) Supportive Relationships, Meaningful Participation

DV: depression

Analysis: A hierarchical logistic regression was used to answer whether specific SBPF predict depression above and beyond where a student resides.

RQ6c

Do specific School-Based Protective Factors significantly predict negative academic outcomes above and beyond where a student resides?

Variables: IV: a) where a student resides, b) Supportive Relationships, Meaningful Participation

DV: negative academic outcomes

Analysis: A hierarchical logistic regression was used to answer whether specific SBPF predict academic outcomes above and beyond where a student resides.

\section{Analysis}

\section{Analysis of Variance}

An ANOVA compares the mean scores across more than two groups. It compares the variance, or the variability in scores, between the different groups (i.e., believed to be due to the independent variable) with the variability within each of the groups (i.e., believed to be due to chance; Pallant, 2016). The ANOVA produces an $F$ ratio, which represents the variance between 
the groups divided by the variance within the groups (Pallant, 2016). A large $F$ ratio indicates there is more variability between groups, which is caused by the independent variable, than there is within each group. A significant $F$ test indicates the population means are equal. It does not, however, tell us which of the groups differ. For this, a post hoc test would be conducted.

\section{Kruskal-Wallis Test}

The Kruskal-Wallis test is the nonparametric alternative to a one-way between-groups ANOVA. It allows a comparison of the scores on some continuous variable for three or more groups. Scores are converted to ranks, and the mean rank for each group is compared. This is considered a "between groups" analysis (Pallant, 2016).

Research Question 1 addresses at what rates students experience SBPF. Because the data did not meet one of the assumptions, homogeneity of variance, for an ANOVA, a Kruskal-Wallis test was used to compare means.

\section{Assumptions}

The assumptions for a Kruskal-Wallis test are the same for all nonparametric statistics. These include random samples and independent observations (i.e., each person or case is counted only once, and the data from one participant cannot influence the other; Pallant, 2016). Nonparametric techniques are ideal for use when there is data that are measured on nominal (categorical) and ordinal (ranked) scales.

\section{Interpretation}

The main pieces of important information on the output are the chi-square value, the degrees of freedom $(d f)$, and the significance level (presented as asymp. sig.). If the significance value is less than .05 , it can be concluded that there is a statistically significant difference in the continuous variable across the groups. The mean rank for the groups is presented in the first 
output table, which shows which of the groups had the highest overall ranking that corresponded to the highest score on the continuous variable. If a statistically significant result is obtained on the Kruskal-Wallis test, it is not known which of the groups are different from one another, so doing a post hoc test such as comparing means allows comparison between groups. For each of the group comparisons, an effect size statistic can be calculated by calculating an approximate value of $r$ using the $z$ value (which is shown as the standardized test statistic) on the test summary table of the output. The calculation is: $=z$ /square root of $N$ where $N=$ total number of cases (Pallant, 2016).

\section{Limitations}

Despite not having stringent requirements about the normality of the data and not having assumptions about the underlying population distribution, there are disadvantages to using nonparametric types of tests. They tend to be less sensitive than the more powerful parametric alternatives and may, therefore, may fail to detect differences between groups that actually exist (Pallant, 2016).

\section{Chi-Square Test for Independence}

A chi square is a test used to determine the relationship between two categorical variables. These categorical variables can have two or more response categories. A chi square compares the observed frequencies or proportions of cases that occur in each of the categories, with the values that would be expected if there was no relationship or association between the variables being measured. A crosstabulation table is used to organize and classify the different categories of responses for each variable.

Research Questions 2, 3, and 4 address the rates of negative outcomes for students who are in foster care or who are homeless, as compared to those living at a home with one or more 
parent. Because the responses to the questions are categorical (e.g., considered suicide or not, and where the student resides) a chi-square analysis was the most appropriate statistic.

\section{Assumptions}

There is an assumption when using the chi-square test of independence that the lowest expected frequency for any square should be greater than five, or if a $2 \times 2$ table at least 10 in each square (Pallant, 2016). Because the sample size for this data set was large $(N=887,262)$, this assumption was met.

\section{Logistic Regression}

Logistic regression is a multivariate statistical model used to predict the probability of group membership based on a categorical dependent variable. It allows a researcher to test models to predict categorical outcomes with two or more categories. For logistic regression, the DV is categorical or dichotomous and may have as few as two values. For instance, the answer of "yes" or "no" to a question about thoughts of suicide. Because the goal is to predict values on a categorical DV, one is essentially trying to predict membership in one of two or more groups. Logistic regression specifies the probabilities of the particular outcomes (e.g., yes or no) for each participant or case involved. In other words, logistic regression analysis produces a regression equation that predicts the probability of whether an individual will fall into one category or the other (Mertler \& Vannatta, 2013).

An advantage to using logistic regression is that it requires no assumptions about the distributions of the predictor variables need to be made by the researcher (i.e., they do not have to be normally distributed, linearly related, nor have equal variances in the group). Another advantage is logistic regression can analyze predictor variables of all types—continuous, 
discrete, and dichotomous. Finally, logistic regression can be useful when the distribution of data on the DV is expected or known to be nonlinear with one or more IV (Wheelan, 2013).

The logit is the central mathematical concept that underlies logistic regression-the natural logarithm of an odds ratio. An odds ratio describes the likelihood of one variable occurring over another (e.g., how much more likely are boys to be placed in foster care than girls). In logistic regression, odds are calculated by dividing the probability that an event will occur by the probability that the event will not occur (Mertler \& Vannatta, 2013). This calculation is illustrated by the following equation:

$$
\text { Odds }=\frac{p(x)}{1-p(x)}
$$

where $p(x)$ is the probability of the event occurring, and $1-p(x)$ is the probability of the event not occurring. This equation will always yield a probability between 0 and 1 . From these probabilities, an odds ratio is calculated to determine the odds of one variable being classified into a group based on the presence of another variable. These probabilities are then used to compute the logit using an odds ratio. For example, if we know the odds of homeless students answering "yes" to a question about feelings of depression, we can use these odds to calculate whether these students are likely to answer "yes" to a question about depression depending on their responses to other questions.

The null hypothesis underlying logistic regression states that all $\beta$ s equal 0 . A rejection of this null hypothesis indicates that at least one $\beta$ does not equal 0 in the population. This means that the logistic regression equation predicts the probability of the outcome better than the mean of the dependent variable $Y$.

Research Questions 5a-5c address if where a student resides (i.e., foster care, unstable housing, at home with one or more parent) predicts negative outcomes. A logistic regression 
analysis was used to compute the odds ratios, which showed the likelihood of a student to indicate if they have ever experienced thoughts of suicide, felt depressed, or had poor grades, depending on where they live.

In hierarchical regression, the independent variables are entered into the model in the order specified by the researcher based on theoretical grounds (Pallant, 2016). If a researcher believes (based on the literature) that one variable may be more influential than others, that variable is entered into the analysis first. The researcher can specify the order in which variables are entered into the analysis. Subsequent variables are then added to determine the specific amount of variance they can account for, above and beyond what has been explained by any variables entered before.

Variables or sets of variables are entered in steps (or blocks), with each IV being assessed in terms of what it adds to the prediction of the DV after the previous variables have been controlled for. Research Question 5 addresses whether SBPF (and in Research Question 6, which SBPF) predict negative outcomes above and beyond where a student resides. In other words, how well SBPF predict negative outcomes after the effect of where a student resides is controlled for. In this study then, where a student resides was entered in Block 1, and then SBPF was entered in Block 2. In the first block, where a student resides was "forced" into the analysis, which had the effect of statistically controlling for this variable. In the second step, the other independent variables were entered into the model as a block. The difference, however, was that once the possible effect of where a student resides has been "removed," it was apparent whether the block of independent variables (SBPF) were still able to explain negative outcomes (i.e., suicidality, depression, and poor academic performance). 
Once all sets of variables were entered, the overall model was assessed in terms of its ability to predict the dependent measure, and the relative contribution of each block of variables was also assessed.

\section{Assumptions}

Logistic regression does not require adherence to any assumptions about the distribution of predictor variables. There are, however, several issues related to the use of logistic regression. The first is the ratio of cases to variables included in the analysis. Several problems may occur if too few cases relative to the number of predictor variables exist in the data. Second, logistic regression relies on a goodness of fit test as a means of assessing the fit of the model to the data. A goodness of fit test includes values for each cell's expected frequencies in the data matrix formed by combinations of discrete variables. If any of the cells have expected frequencies that are too small (typically, $f e<5$ ), the analysis may have little power. All cells should have expected frequencies greater than 1 , and no more than $20 \%$ have frequencies less than 5 (Mertler \& Reinhart, 2017). Third, logistic regression is sensitive to high correlations among predictor variables. This condition results in multicollinearity among predictor variables. Finally, logistic regression is very sensitive to outliers (Mertler \& Reinhart, 2017).

\section{Interpretation}

Results from a logistic regression analysis come in three main output components: the statistics for overall model fit, a classification table, and a summary of model variables. Several statistics for the overall model are presented in the first component of logistic regression output. The $-2 \log$ likelihood provides an index of model fit. A perfect model would have a $-2 \log$ likelihood of 0 . Consequently, the lower this value, the better the model fits the data (Mertler \& Reinhart, 2017). This value represents the sum of probabilities associated with the predicted and 
actual outcomes for each case. The next two values, Cox and Snell $R^{2}$ and Nagelkerke $R^{2}$, represent two different estimates of the variance in the DV accounted for by the model (Mertler $\&$ Reinhart, 2017). Chi-square statistics with levels of significance are also computed for the model, block, and step. Chi square for the model represents the difference between the constantonly model and the model generated. When using a stepwise method, the model generated will include only selected predictors. In contrast, the enter method generates a model with all IVs included (Mertler \& Vannatta, 2013). In general, a significant model chi square indicates the generated model is significantly better in predicting participant membership than the constantonly model. The second component of output is the classification table. This table applies the generated regression model for predicting group membership. These predictions are then compared to the actual participant values (Mertler \& Vannatta, 2013). The percentage of participants correctly classified is calculated and serves as another indicator of model fit. Finally, the third component of output is the summary of model variables. This summary presents several statistics: $B, S E$, Wald, $d f$, Significance, $R, \operatorname{Exp}(B)$ for each variable included in the model and the constant. As in multiple regression, $B$ represents the unstandardized regression coefficient and represents the effect the IV has on the DV. SE is the standard error of $B$. Wald is a measure of significance for $B$ and represents the significance of each variable in its ability to contribute to the model. Because Wald is conservative (Tabachnick \& Fidell, 2007), a liberal significance level (i.e., $p<.05$ or $p<.10$ ) should be used.

The output generated from hierarchical regression is similar to an output from a multiple regression but with some additional pieces. In the model summary box, there are two models listed. Model 1 refers to the first block of variables that were entered, and Model 2 includes all the variables that were entered in both blocks. The $R$ square explains the amount of variance 
after variables in Block 1 were entered, and then tells you what the model as a whole explains after Block 2 variables were entered. The column labeled $R$ square change is the overall variance explained by the variables of interest. The coefficients in the Model 2 row explained how well each of the variables contribute to the final equation.

\section{Summary}

The ultimate purpose of this study was to understand which SBPF may influence more positive outcomes for students who have experienced significant adversity. Research that adds to our understanding of the needs and protective factors of children who have faced significant adversities was necessary to inform educators' interpretations of children's cognitive and behavioral responses to trauma exposure and to develop effective trauma-informed school-based responses. The CHKS provided a comprehensive survey tool for analyzing these questions. Logistic regression was the ideal statistical tool for making this kind of prediction with this type of data. 


\section{CHAPTER 4: RESULTS}

This chapter presents results of the analyses of the California Healthy Kids Survey (CHKS) data. First, an explanation is provided of how the data were cleaned and how validity checks were performed to provide a more reliable and valid sample. Next, there were several preliminary analyses conducted to understand the demographics of the sample. Results of the primary analysis, followed by results of the research questions analysis, are presented.

\section{Validity Checks}

To provide a more valid and reliable data set, results of the survey were filtered. First, the data were filtered to remove any dishonest answers. Four items on the CHKS were used to identify potential dishonest responders and remove them from the sample: two questions that indicated the respondents' reliability and honesty and two questions that checked for inconsistencies in their responses (Robinson-Cimpian, 2014).

The CHKS has two main questions for understanding the honesty of the responses. One is a question asking respondents how many of the questions on the survey they answered honestly. The next item used is a less-direct honesty question, embedded in the section related to drug and alcohol use. In this section, there is one nonexistent drug listed called "Derbisol." This item is included in the scale to filter out responses that are not honest. The data were further cleaned to eliminate inconsistent responses.

There were two questions that were used to check for inconsistency. On Item 49, the question asked how many times in their life have they had "one full drink of alcohol." Item 71 asks on how many days in the last 30 days did they have "five or more drinks of alcohol in a row ... within a couple of hours." On Item 49, all respondents who indicated "0 times" were recoded as a 1 . On Item 71 , respondents who indicated "0 times" were recoded as a 0 and all 
other responses were recoded as a 1 . Anyone who earned 2 points earned a "strike" against them. Respondents were removed from the study if they met any two or more of the following criteria: (a) inconsistency in their responses, (b) exaggerated drug use (i.e., reporting a level or pattern of drug use that is improbably high), (c) responding "yes" to the question asking if they have used the drug "derbisol," or (d) endorsing that they did not respond honestly to all or most questions in the reliability questions. Refer to the Appendix for the survey questions. There were a total of $1,162,288$ subjects at the beginning of this process. Of those, 4,817 had two validity strikes against them, and 219 had three. An additional 176,643 had missing data on the validity checks, which were also removed. After removing dishonest or inconsistent responders, there were 980,609 participants. Lastly, the file was edited to include only the variables of interest on Item 8 of the survey, which asks "what best describes where you live." Only respondents who lived at "a home with one or more parent or guardian," "foster home, group care, or awaiting placement," "hotel or motel," or "shelter, car, campground, or other transitional or temporary housing" were included in the study. After applying these filters, the total $N=887,262$.

\section{Preliminary Analyses}

Before analyzing the research questions, preliminary analyses were conducted to better understand the demographics and characteristics of the sample. Table 5 shows gender, grade, race, gender identity, and sexual orientation broken into living arrangement categories. In this study, there were 879,032 students who lived at a home with one or more parent or guardian, 3,186 who lived in a foster home, and 5,044 who responded they resided either in (a) hotels or motels or (b) in shelters, campgrounds, or other transitional housing (referred to in this study as homeless). 


\section{Table 5}

Demographic Characteristics-Gender, Grade, Race, Gender Identity, Sexual Orientation

\begin{tabular}{|c|c|c|c|}
\hline Characteristic & $\begin{array}{c}\text { At home } \\
\text { n (\%) }\end{array}$ & $\begin{array}{c}\text { Foster } \\
\mathrm{n}(\%)\end{array}$ & $\begin{array}{c}\text { Homeless } \\
\mathrm{n}(\%)\end{array}$ \\
\hline \multicolumn{4}{|l|}{ Gender } \\
\hline Male & $415462(47.3)$ & $1460(45.8)$ & $2983(59.1)$ \\
\hline Female & $425398(48.4)$ & $1580(49.6)$ & $1731(34.3)$ \\
\hline Did Not Respond & $38172(4.3)$ & $146(4.6)$ & $4714(93.5)$ \\
\hline \multicolumn{4}{|l|}{ Grade } \\
\hline $6^{\text {th }}$ & $7754(.9)$ & $51(1.6)$ & $137(2.7)$ \\
\hline $7^{\text {th }}$ & $278336(31.7)$ & $901(28.3)$ & $1669(33.1)$ \\
\hline $8^{\text {th }}$ & $24018(2.7)$ & $115(3.6)$ & $161(3.2)$ \\
\hline $9^{\text {th }}$ & $263678(30)$ & $766(24.0)$ & $1336(26.5)$ \\
\hline $10^{\text {th }}$ & $34338(3.9)$ & $180(5.6)$ & $201(4.0)$ \\
\hline $11^{\text {th }}$ & $235617(26.8)$ & $900(28.2)$ & $1156(22.9)$ \\
\hline $12^{\text {th }}$ & $34114(3.9)$ & $243(7.6)$ & $256(5.1)$ \\
\hline other grade & $602(.1)$ & $13(.4)$ & $24(.5)$ \\
\hline ungraded & $248(.0)$ & $11(.3)$ & $100(2.0)$ \\
\hline \multicolumn{4}{|l|}{ Race } \\
\hline American Indian or Alaska Native & $31046(3.5)$ & $176(5.5)$ & $258(5.1)$ \\
\hline Asian & $104372(11.9)$ & $155(4.9)$ & $477(9.5)$ \\
\hline Black or African American & $33961(3.9)$ & $349(11.0)$ & $683(13.5)$ \\
\hline Native Hawaiian or Pacific Islander & $12724(1.4)$ & $72(2.3)$ & $182(3.6)$ \\
\hline White & $265263(30.2)$ & $679(21.3)$ & $1057(21.0)$ \\
\hline Mixed (two or more races) & $357030(40.6)$ & $1552(48.7)$ & $2090(41.4)$ \\
\hline System Missing & $74636(8.5)$ & $203(6.4)$ & $297(5.9)$ \\
\hline \multicolumn{4}{|l|}{ Transgender } \\
\hline No & $812691(92.5)$ & $2568(80.6)$ & $3633(72.0)$ \\
\hline Yes & $7118(.8)$ & $172(5.4)$ & $539(10.7)$ \\
\hline I'm not sure & $13297(1.5)$ & $126(4.0)$ & $359(7.1)$ \\
\hline Decline to Respond & $24985(2.8)$ & $208(6.5)$ & $368(7.3)$ \\
\hline \multicolumn{4}{|l|}{ Sexual Orientation } \\
\hline Straight & $712577(81.1)$ & $2059(64.6)$ & $3104(61.5)$ \\
\hline Gay or Lesbian & $13280(1.5)$ & $140(4.4)$ & $307(6.1)$ \\
\hline Bisexual & $46246(5.3)$ & $386(12.1)$ & $368(7.3)$ \\
\hline I am not sure yet & $38980(4.4)$ & $168(5.3)$ & $396(7.9)$ \\
\hline Something else & $12917(1.5)$ & $140(4.4)$ & $390(7.7)$ \\
\hline Decline to respond & $35098(4.0)$ & $192(6.0)$ & $359(7.1)$ \\
\hline Total & 879032 & 3186 & 5044 \\
\hline
\end{tabular}


The preliminary analysis provided some illuminating patterns of the population of students in this study. Of note is the disproportionate number of students who identified as Black or African American who lived in a foster home (1\%) or were homeless (2\%), as compared to the other races. By comparison, $0.1 \%$ of Asian students resided in foster care, and $0.5 \%$ were homeless. Of students who identified as White, $0.3 \%$ lived in foster care and $0.4 \%$ were homeless. No other race was as significantly overrepresented in foster care and homelessness as Black or African American students. Further, students who identified as transgender were significantly overrepresented in the foster care population (2.2\%). Transgender students represented $6.9 \%$ of the homeless population in this study, well surpassing any other demographic characteristic.

\section{Table 6}

Demographic Characteristics—Socio-Economic Status and Language

\begin{tabular}{lccc}
\hline \multicolumn{1}{c}{ Characteristic } & $\begin{array}{c}\text { At home } \\
n(\%)\end{array}$ & $\begin{array}{c}\text { Foster } \\
n(\%)\end{array}$ & $\begin{array}{c}\text { Homeless } \\
n(\%)\end{array}$ \\
\hline Parent Education & & & \\
$\quad$ Did not finish high school & $107686(12.3)$ & $628(19.7)$ & $1328(26.3)$ \\
Graduated from high school & $133559(15.2)$ & $484(15.2)$ & $722(14.3)$ \\
Did not complete college & $109536(12.5)$ & $344(10.8)$ & $539(10.7)$ \\
Graduated from college & $371198(42.2)$ & $679(21.3)$ & $1000(19.8)$ \\
Don't know & $152907(17.4)$ & $1025(32.2)$ & $1408(27.9)$ \\
Free \& Reduced Lunch & $366842(41.7)$ & $468(14.7)$ & $1175(23.3)$ \\
No & $385666(43.9)$ & $2186(68.6)$ & $2764(54.8)$ \\
Yes & $120958(13.8)$ & $488(15.3)$ & $1016(20.1)$ \\
Don't know & & & \\
Migrant Education Program & $683763(77.8)$ & $1881(59.0)$ & $2524(50.0)$ \\
No & $17646(2.0)$ & $241(7.6)$ & $756(15.0)$ \\
Yes & $173288(19.7)$ & $1027(32.2)$ & $1702(33.7)$ \\
Don't know & & & \\
Language at home & $564170(64.2)$ & $2118(66.5)$ & $2303(45.7)$ \\
English & $234646(26.7)$ & $706(22.2)$ & $1387(27.5)$ \\
Spanish & $78018(8.9)$ & $350(11.0)$ & $108(2.1)$ \\
Other & & & \\
\end{tabular}


With regard to students who identified as lesbian, gay, bisexual, transgender, questioning, or queer (LGBTQ), those who identified as transgender, gay, lesbian or bisexual were significantly overrepresented in the foster care and homeless population (see Table 5). It should be noted, however, this demographic breakdown does not provide the whole picture regarding where the students of interest reside, as responses on certain items on this question were removed from this study (e.g., other relative's home, a home with more than one family, friend's home, other living arrangement). Table 6 shows students of parents who did not finish high school were significantly overrepresented in the homeless population.

\section{Primary Analysis}

Each research question is designed to gather information to understand possible schoolbased interventions and solutions toward ameliorating negative outcomes of youth in foster care or homelessness. To reach this end, analyses were conducted to provide data regarding how foster or homeless students responded to questions about protective factors, suicidal ideation, depressive symptoms, and academic outcomes. These responses were compared to those of their peers who lived at a home with one or more parent or guardian ("at home"). Finally, predictive logistical and hierarchical logistic regression models were generated to determine the impact of risk and protective factors on suicidal ideation, depressive symptoms, and academic outcomes in youth in foster care or homelessness.

\section{Research Question 1}

Research Questions (RQ) 1a-c addressed the ways in which students experienced the different indexes that make up school-based protective factors (SBPF) as well as SBPF as a whole. RQ1a focused on all students (i.e., those who live at a home with one or more parent or guardian ("at home"), those who were in foster care, and respondents who were homeless), while 
RQs 1b-1c provided a deeper dive into the differences between students who were homeless versus those at home (RQ1b) and students who lived in foster care versus those at home (RQ1c). Upon initial analysis of the data, the SBPF variable was not normally distributed across the living arrangements. A one-way ANOVA analysis was planned to compare the means across groups. An ANOVA had several assumptions, which were discussed in Chapter 3. One of the assumptions were that there was homogeneity of variance. Using Levene's test for equality of variances, there was a $p<.001$, indicating there was not homogeneity of variance. Because the data did not meet the assumption of homogeneity of variance for an ANOVA analysis, a Kruskal-Wallis test was used.

RQ1a. Is there a difference in how students experience school-based protective factors?

Research Question 1a addressed if there was a difference in how students experienced SBPF, the index which combines High Expectations, Meaningful Participation, and Caring Relationships. Results are presented in Table 7. 


\section{Table 7}

Experiences of SBPF by Where a Student Resides

\begin{tabular}{clcccc}
\hline Residence & \multicolumn{1}{c}{ Scale } & $n$ & Median & Mean & Std. deviation \\
\hline \multirow{2}{*}{ At home } & SBPF & 873,036 & 7.80 & 7.79 & 2.04 \\
& Meaningful Participation & 875,255 & 1.80 & 1.99 & .77 \\
\multirow{5}{*}{ Foster } & Supportive Relationships & 875,127 & 6.00 & 5.80 & 3.03 \\
& SBPF & 3,135 & 7.53 & 7.43 & 2.39 \\
& Meaningful Participation & 3,155 & 1.80 & 2.00 & .85 \\
& Supportive Relationships & 3,151 & 5.67 & 5.43 & 1.84 \\
& SBPF & 4,978 & 6.87 & 6.80 & 2.53 \\
& Meaningful Participation & 4,996 & 1.60 & 1.87 & 1.97 \\
& Supportive Relationships & 5,000 & 5.00 & 4.92 & .993 \\
\hline
\end{tabular}

The Kruskal-Wallis test was used to understand the rates at which students who lived at home experienced SBPF as a whole, as well as each individual protective factor, as compared to students who were homeless. Table 7 shows the experiences of SBPF and the individual scales that comprise SBPF, for students who lived at home, those who were in foster care, and students who were homeless.

For overall SBPF, Group 1 (Gp1; at home) reported a median score of 7.80 and a mean of 7.79, indicating high experiences of SBPF. Group 2 ( $\mathrm{Gp} 2$; foster) reported a median score of 7.53 and a mean of 7.43, and Group 3 (Gp3; homeless) reported the lowest median score of 6.87 with a mean of 6.80 . Students who were in foster care and students who lived at home perceived experiencing Meaningful Participation relatively similarly $(\mathrm{Gp} 1, M=1.99, M d n=1.80 ; \mathrm{Gp} 2, M$ $=2.00, M d n=1.80)$, and students who were homeless experienced this significantly less $(M=$ $1.87, M d n=1.60$ ). Supportive Relationships (the index of caring relationships and high expectations) was experienced differently across the groups. Students who lived at home experienced Supportive Relationships at much higher rates $(M=5.80, M d n=6.00)$ than both other groups (Gp2, $M=5.43, M d n=5.67$; Gp3, $M=4.92, M d n=5.00)$. 
RQ1b. Is there a difference in how students who are homeless experience SBPF as compared to students who live at a home with one or more parent?

A Kruskal-Wallis test revealed a statistically significant difference in the rates at which students who were homeless experienced SBPF, $\chi^{2}(2, n=881,149: \mathrm{SBPF})=852.476, p<.001$. Additionally, students who were homeless experienced school Meaningful Participation and Supportive Relationships at significantly different rates than students who lived at home: $\chi^{2}(2, n$ $=883,275:$ Supportive Relationships $)=1057.87, p<.001 ; \chi^{2}(2, n=883,406$ : Meaningful Participation $)=225.021, p<.001$. Table 7 shows the median and mean scores for each of the categories for students who lived at home (Gp1) and students who were homeless (Gp3). Students who were homeless reported experiencing overall SBPF with a median score of 6.87, as compared to students who lived at home, who experienced SBPF with a significantly higher median score of 7.80. This trend was consistent across each of the subscales of the SBPF (Supportive Relationships: Gp1, $M=5.80, M d n=6.0 ; \mathrm{Gp3}, M=4.92, M d n=5.00$; Meaningful Participation: Gp1, $M=1.99, M d n=1.80 ; \mathrm{Gp} 3, M=1.87, M d n=1.60)$.

RQ1c. Is there a difference in how students in foster care experience SBPF as compared to students who live at a home with one or more parent?

Similar to the previous research question, because we were comparing the mean score of more than two groups, a Kruskal-Wallis test was used to understand the rates at which students who lived at home experience SBPF as a whole, and each individual protective factor, as compared to students who were living in foster care. A Kruskal-Wallis test revealed a statistically significant difference in the rates at which students in foster care experienced SBPF, $\chi^{2}(2, n=881,149: \mathrm{SBPF})=852.476, p<.001$. Additionally, students who lived in foster care experienced Supportive Relationships and Meaningful Participation at significantly different 
rates than students who lived at home: $\chi^{2}(2, n=883,275$ : Supportive Relationships $)=1057.866$, $p<.001 ; \chi^{2}(2, n=883,406:$ Meaningful Participation $)=225.021, p<.001$. Table 7 shows the median scores for each of the categories for students who lived at home (Gp1) and students who lived in foster care (Gp2). Students who lived at home reported experiencing overall SBPF with a median score of 7.80, as compared to students who lived in foster care who experienced SBPF with a significantly lower median score of 7.53. Across the other categories, students who were in foster care experienced Supportive Relationships and Meaningful Participation at significantly lower rates (Supportive Relationships: Gp1, $M=5.80, M d n=6.00 ; \mathrm{Gp} 2, M=5.43, M d n=5.67$; Meaningful Participation: Gp1, $M=1.97, M d n=1.80 ; \mathrm{Gp} 2, M=2.00, M d n=1.80$ ).

\section{Research Question 2}

Research Question 2 focused on if there are differences in thoughts of suicide among the different groups of students. RQ2a addressed students who were homeless, as compared to those who lived at a home with one or more parent or guardian ("at home"), and RQ2b focused on students who were in foster care versus those at home.

RQ2a. What is the rate of suicidal ideation in students who are homeless, and how does this compare with students living at home with one or more parent?

This question addressed the relationship between where a student resides (at home versus homeless) and suicidal ideation. A chi-square test for independence (with Yates' continuity correlation) was used to explore the relationship between these variables. As illustrated in Table 8, most students who lived at home reported not ever considering suicide in the past 12 months $(84.2 \%)$, with $15.8 \%$ reporting they had considered suicide in that time period. Of students who were homeless, $67.4 \%$ reported they had not considered suicide during the past 12 months, and $32.6 \%$ reported they had. A significant association was found between where a student resides 
(at home versus homeless) and thoughts of suicide, $\chi^{2}(1, n=707,086)=835.054, p<.001$, phi $=.034$.

\section{Table 8}

Suicidal Ideation Across Living Arrangement

\begin{tabular}{lcccc}
\hline Residence & Count $/ \%$ & No & Yes & Total \\
\hline At home & Count & 592,016 & 111,106 & 703,122 \\
& $\%$ & $84.2 \%$ & $15.8 \%$ & $100.0 \%$ \\
Homeless & Count & 2,670 & 1,294 & 3,964 \\
& $\%$ & $67.4 \%$ & $32.6 \%$ & $100.0 \%$ \\
Foster & Count & 1,816 & 769 & 2,585 \\
& $\%$ & $70.3 \%$ & $29.7 \%$ & $100.0 \%$ \\
\hline
\end{tabular}

Note. Question asked was "During the past 12 months, did you ever seriously consider attempting suicide?"

RQ2b. What is the rate of suicidal ideation for students who reside in foster care, and how does this compare with students living at home with one or more parent?

This question addressed the relationship between where a student resides (at home versus foster care) and suicidal ideation. A chi-square test for independence (with Yates' continuity correlation) was used to explore the relationship between these variables. As illustrated in Table $8,84.2 \%$ of students who lived at home with their parent(s) reported not ever considering suicide in the past 12 months, with $15.8 \%$ reporting they had considered suicide in that time period. Of students who were in foster care, $70.3 \%$ reported they had not considered suicide during the past 12 months, and $29.7 \%$ reported they had. A significant association was found between where a student resides (at home versus foster care) and thoughts of suicide, $\chi^{2}(1, n=705,707)=$ 374.502, $p<.000$, phi $=.023$. 


\section{Research Question 3}

Research Question 3 focused on understanding if there are differences in symptoms of depression among the different groups of students. RQ3a addressed students who were homeless, as compared to those who lived at a home with one or more parent or guardian ("at home"), and RQ3b focused on students who were in foster care versus those at home.

RQ3a. What is the rate of depressive symptoms in students who are homeless, and how does this compare to students living with one or more parent?

This question focused on students who were homeless as compared to living at a home with one or more parent or guardian and the relationship to depressive symptoms. A chi-square test for independence (with Yates' continuity correlation) was used to explore the relationship between these variables. As illustrated in Table 9, the majority of students who lived at home with their parent(s) reported not ever feeling depressive symptoms over the past 12 months (68.9\%), with $31.1 \%$ reporting they had experienced depressive symptoms in that time period. Of students who were homeless, 55.5\% reported they had not experienced depressive symptoms during the past 12 months, and $44.5 \%$ reported they had. A significant association was found between where a student resides (at home versus homeless) and depressive symptoms, $\chi^{2}(1, n=$ $875,782)=416.39, p<.001, \mathrm{phi}=.022$.

RQ3b. What is the rate of depressive symptoms in students who reside in foster care and how does this compare to students living with one or more parent?

This question addressed students who lived in foster care as compared to living at home with one or more parent, and the relationship to depressive symptoms. A chi-square test for independence (with Yates' continuity correlation) was used to explore the relationship between these variables. As illustrated in Table 9, 68.9\% of students who lived at home with their 
parent(s) reported not ever feeling depressive symptoms over past 12 months, with $31.1 \%$ reporting they had experienced depressive symptoms in that time period. Of students who were in foster care, $54.8 \%$ reported they had not experienced depressive symptoms during the past 12 months, and $45.2 \%$ reported they had. A significant association was found between where a student resides (at home versus foster care) and depressive symptoms, $\chi^{2}(1, n=873,946)=$ 287.921, $p<.001, \mathrm{phi}=.018$.

\section{Table 9}

Depressive Symptoms Across Living Arrangement

\begin{tabular}{lcccc}
\hline Residence & Count $/ \%$ & No & Yes & Total \\
\hline At home & Count & 600,234 & 270,583 & 870,817 \\
& $\%$ & $68.9 \%$ & $31.1 \%$ & $100.0 \%$ \\
Homeless & Count & 2,754 & 2,211 & 4,965 \\
& $\%$ & $55.5 \%$ & $44.5 \%$ & $100.0 \%$ \\
Foster & Count & 1,716 & 1,413 & 3,129 \\
& $\%$ & $54.8 \%$ & $45.2 \%$ & $100.0 \%$ \\
\hline
\end{tabular}

Note. The question asked was "During the past 12 months, did you ever

feel so sad or hopeless almost every day for 2 weeks or more that you stopped doing some usual activities?"

\section{Research Question 4}

Research Question 4 addressed if there were differences in self-reported academic outcomes among the different groups of students. RQ4a focused on students who were homeless, as compared to those who lived at a home with one or more parent or guardian ("at home"), while RQ4b focused on students who were in foster care versus those at home. For the purposes of this analysis, response options for grades were grouped into the following three groups: Group 
1: mostly A's, A's and B's, mostly B's, B's and C's; Group 2: mostly C's, C's and D's; Group 3: Mostly D’s, Mostly F’s.

RQ4a. What are the self-reported academic outcomes for students who are homeless, and how does this compare with students living at home with one or more parent?

This question addressed students who were homeless as compared to living at home with one or more parent and the relationship to self-reported academic outcomes, as illustrated in Table 10. A chi-square test for independence was used to explore the relationship between these variables and indicated there was a significant association between where a student resides (at home versus foster care) and academic outcomes, $\chi^{2}(2, n=881,615)=4872.353, p<.001$, phi $=.074$. Of students who lived at home, $85.5 \%$ reported earning grades in Group 1 (ranging from "mostly A's" to "B's and C's") as opposed to $64.2 \%$ of homeless students. Of students who lived at home, $11.5 \%$ reported earning grades in Group 2 ("mostly C's" and "C's and D's"), and $16.0 \%$ of homeless students reported these grades. Only $3.0 \%$ of students living at home received grades in Group 3 of "mostly D's" or "mostly F's," in contrast with $19.8 \%$ of students who were homeless reporting these grades. 


\section{Table 10}

Academic Outcomes Across Living Arrangement

\begin{tabular}{lcccc}
\hline & \multicolumn{3}{c}{ Group 1 } & \\
Residence & Mostly A's & Group 2 & Group 3 \\
& Count/\% & A's and B's & Mostly C's & Mostly D's \\
& & Mostly B's & C's and D's & Mostly F's \\
& & B's and C's & & \\
\hline At home & Count & 749,424 & 100,850 & 26,328 \\
& $\%$ & $85.5 \%$ & $11.5 \%$ & $3.0 \%$ \\
Homeless & Count & 3,220 & 802 & 991 \\
& $\%$ & $64.2 \%$ & $16.0 \%$ & $19.8 \%$ \\
Foster & Count & 2202 & 661 & 364 \\
& $\%$ & $69.3 \%$ & $19.2 \%$ & $11.5 \%$ \\
\hline
\end{tabular}

Note. The question was "During the past 12 months, how would you describe the grades you mostly received?"

RQ4b. What are the self-reported academic outcomes for students who reside in foster care, and how does this compare with students living at home with one or more parent?

This question addressed students who were in foster care as compared to living at home with one or more parent and the relationship to self-reported academic outcomes. A chi-square test for independence was used to explore the relationship between these variables and indicated there was a significant association between where a student resides (at home versus foster care) and academic outcomes, $\chi^{2}(2, n=879,779)=1006.603, p<.001$, phi $=.034$. Of students who lived at home, $85.5 \%$ reported earning grades in Group 1 as opposed to $69.3 \%$ of students in foster care. Of students who lived at home, $11.5 \%$ reported earning grades in Group 2, and $19.2 \%$ of students in foster care reported these grades. Of students who lived at home, $3.0 \%$ received grades in Group 3 of “mostly D's" or "mostly F's," in contrast with $11.5 \%$ of students who were in foster care reporting these grades. 


\section{Research Question 5}

The relationship between negative outcomes and where a student resides has been clearly established in the preceding research questions. Research Question 5 asked whether SBPF had a mitigating relationship on negative outcomes such as suicidality, depression, and academic outcomes, above and beyond where a student resides.

RQ5a. Do SBPF predict suicidality above and beyond where a student resides?

Question 5a focused on suicidality as a negative outcome. A logistic regression analysis was created to predict the likelihood of an individual answering "yes" to the suicidal ideation question based on their responses to the different developmental-support questions. The suicidal ideation question was entered as the dependent variable, with two independent variables in Block 1: foster and homeless, with 'living at home' being the comparison group. SBPF was entered in Block 2. The model was statistically significant $\chi^{2}(1, n=705,478)=17,248.89, p<.001$, indicating the model was able to distinguish between respondents who reported and did not report suicidal ideation. The model explained between 2.6\% (Cox and Snell $R^{2}$ ) and 4.4\% (Nagelkerke $R^{2}$ ) of the variance in suicidal ideation and correctly classified $84 \%$ of cases. With a large $N$, the Hosmer and Lemeshow test is expected to be significant (Demidenko, 2006), as it was $(p<.001)$, and thus can be ignored (W. Donald, IBM, personal communication, January 26, 2021). As shown in Table 11, all of the independent variables made statistically significant contributions to the model. However, with such a large $N$, interpretation should focus on the beta weight, $\operatorname{Exp}(B)$. The strongest predictor of suicidal ideation was residing in foster care, with an odds ratio of 2.13-indicating for those who reside in foster care, the likelihood of experiencing suicidal ideation increased by a factor of 2.13. Alternatively put, living in foster care increased the odds of suicidal ideation by $113 \%$ [(2.13 - 1) x 100]. Living in homelessness was also a 
strong predictor of suicidality $(O R=2.08)$, increasing the odds of suicidality by $108 \%$ [(2.08 -1$)$

$\mathrm{x} 100]$. Students who resided in foster care or were homeless were significantly more likely to have considered suicide in the past 12 months than students who resided at a home with one or more parent. SBPF played a mitigating role. The odds ratio of .81 is less than 1, indicating for every 1 unit of increase in school-based protective factor, there was a 19\% [(1- .81) x 100] decrease in suicidal ideation.

Table 11

Logistic Regression Predicting Suicidality Based on SBPF

\begin{tabular}{|c|c|c|c|c|c|c|c|c|}
\hline \multirow[b]{2}{*}{ IV } & \multirow[b]{2}{*}{$B$} & \multirow[b]{2}{*}{ S.E. } & \multirow[b]{2}{*}{ Wald } & \multirow[b]{2}{*}{$d f$} & \multirow[b]{2}{*}{$p$} & \multirow[b]{2}{*}{$\begin{array}{l}\text { Odds Ratio } \\
\operatorname{Exp}(B)\end{array}$} & \multicolumn{2}{|c|}{$\begin{array}{c}\text { 99\% C.I. for } \\
\text { Odds Ratio }\end{array}$} \\
\hline & & & & & & & Lower & Upper \\
\hline Foster & .757 & .045 & 288.937 & 1 & .000 & 2.132 & 1.954 & 2.327 \\
\hline Homeless & .734 & .035 & 432.196 & 1 & .000 & 2.083 & 1.943 & 2.232 \\
\hline SBPF & -.211 & .002 & 16654.786 & 1 & .000 & .810 & .807 & .812 \\
\hline Constant & -.105 & .012 & 75.513 & 1 & .000 & .900 & & \\
\hline
\end{tabular}

RQ5b. Do SBPF predict depression above and beyond where a student resides?

Question $5 b$ focused on depression as a negative outcome. A logistic regression analysis was created to predict the likelihood of an individual answering "yes" to the depressive symptoms question based on their responses to the different protective-factors questions. The depressive symptoms question was entered as the dependent variable, with two independent variables in Block 1: foster and homeless, with 'living at home' being the comparison group. SBPF was entered in Block 2. The model was statistically significant $\chi^{2}(3, n=873,138)=$ $33,528.77, p<.001$, indicating the model was able to distinguish between respondents who reported and did not report depressive symptoms. The model explained between 3.8\% (Cox and Snell $R^{2}$ ) and 5.3\% (Nagelkerke $R^{2}$ ) of the variance in depressive symptoms and correctly 
classified $69 \%$ of cases. With a large $N$, the Hosmer and Lemeshow test is expected to be significant (Demidenko, 2006), as it was at $p<.001$, and thus can be ignored (W. Donald, IBM, personal communication, January 26, 2021). As shown in Table 12, all of the independent variables made statistically significant contributions to the model. However, with such a large $N$, interpretation should focus on the beta weight, $\operatorname{Exp}(B)$. The strongest predictor of depressive symptoms was residing in foster care, with an odds ratio of 1.73 -indicating that those who resided in foster care were $73 \%$ more likely $[(1.73-1)$ x 100] to report experiencing depressive symptoms than those who lived at home. Living in homelessness was also a strong predictor of depressive symptoms, with an odds ratio of 1.47 . Students who resided in foster care were $47 \%$ more likely to have felt depressive symptoms than students who resided at a home with one or more parent. SBPF played a mitigating role. The odds ratio of .81 is less than 1, indicating for every 1 degree of increase in SBPF, there was a 19\% [(1 - .81) x 100] decrease in depressive symptoms.

\section{Table 12}

Logistic Regression Predicting Depressive Symptoms Based on SBPF

\begin{tabular}{lccccccccc}
\hline & & & & & & & & \multicolumn{2}{c}{$\begin{array}{c}9 \% \text { C.I. for } \\
\text { Odds Ratio }\end{array}$} \\
\cline { 7 - 10 } \multicolumn{1}{c}{ IV } & & & & & & & & & \multicolumn{2}{c}{$\begin{array}{c}\text { Odds Ratio } \\
\operatorname{Exp}(B)\end{array}$} & Lower & Upper \\
\hline Foster & .547 & .037 & 214.200 & 1 & .000 & 1.728 & 1.606 & 1.859 \\
Homeless & .385 & .030 & 166.769 & 1 & .000 & 1.469 & 1.386 & 1.557 \\
SBPF & -.209 & .001 & 31437.154 & 1 & .000 & .811 & .809 & .813 \\
Constant & .802 & .009 & 7699.655 & 1 & .000 & 2.229 & & \\
\hline
\end{tabular}


RQ5c. Do SBPF predict academic outcomes above and beyond where a student resides?

Research Question 5c used self-reported academic outcomes as the dependent variable. To capture "poor academic outcomes" for the purpose of this analysis, self-reported grades on the survey item were grouped into those who indicated they received "mostly D's" or "mostly F's." All other grades were removed from the analysis. A logistic regression analysis was created to predict the likelihood of individuals reporting grades of mostly D's or mostly F's. The recoded self-reported grades question was entered as the dependent variable, with two independent variables in Block 1: foster and homeless, with 'living at home' being the comparison group. SBPF was entered in Block 2. The model was statistically significant $\chi^{2}(3, n=878,955)=$ $12,540.09, p<.001$, indicating the model was able to distinguish between respondents who reported receiving D's and F's and those who did not. The model explained between 1.4\% (Cox and Snell $R^{2}$ ) and 5.8\% (Nagelkerke $R^{2}$ ) of the variance in self-reported grades and correctly classified $97 \%$ of cases. With a large $N$, the Hosmer and Lemeshow test is expected to be significant (Demidenko, 2006), as it was at $p<.001$, and thus can be ignored (W. Donald, IBM, personal communication, January 26, 2021). As shown in Table 13, all of the independent variables made statistically significant contributions to the model. However, with such a large $N$, interpretation should focus on the beta weight, $\operatorname{Exp}(B)$. The strongest predictor of receiving D's and F's was homelessness, with an odds ratio of 5.940 - indicating those who were homeless were nearly 6 times more likely to report receiving D's and F's than those who lived at home. Living in foster care was also a strong predictor of poor grades, with an odds ratio of 3.683, being more than 3.5 times as likely to report poor grades. SBPF played a mitigating role. The odds ratio of .739 is less than 1, indicating for every 1 unit of increase in SBPF, there was a $26 \%$ $[(1-.739) \times 100]$ decrease in the likelihood of receiving poor grades. 


\section{Table 13}

Logistic Regression Predicting Academic Outcomes Based on SBPF

\begin{tabular}{|c|c|c|c|c|c|c|c|c|}
\hline \multirow[b]{2}{*}{ IV } & \multirow[b]{2}{*}{$B$} & \multirow[b]{2}{*}{ S.E. } & \multirow[b]{2}{*}{ Wald } & \multirow[b]{2}{*}{$d f$} & \multirow[b]{2}{*}{$p$} & \multirow[b]{2}{*}{$\begin{array}{l}\text { Odds Ratio } \\
\operatorname{Exp}(B)\end{array}$} & \multicolumn{2}{|c|}{$\begin{array}{l}\text { 99\% C.I. for } \\
\text { Odds Ratio }\end{array}$} \\
\hline & & & & & & & Lower & Upper \\
\hline Foster & 1.304 & .058 & 504.629 & 1 & .000 & 3.683 & 3.172 & 4.277 \\
\hline Homeless & 1.782 & .038 & 2215.528 & 1 & .000 & 5.940 & 5.388 & 6.549 \\
\hline SBPF & -.302 & .003 & 9521.832 & 1 & .000 & .739 & .734 & .745 \\
\hline Constant & -1.30 & .021 & 3689.592 & 1 & .000 & .272 & & \\
\hline
\end{tabular}

\section{Research Question 6}

This research question builds upon the last and addressed if specific SBPFs predicted negative outcomes above and beyond where a student resides.

RQ6a. Do specific SBPF significantly predict suicidality?

Question 6a focused on suicidality as a negative outcome. To understand the salience of each protective factor, a logistic regression model was created using a forward stepwise procedure. The suicidal ideation question was entered as the dependent variable, with two independent variables in Block 1: foster and homeless, with 'living at home' being the comparison group. Supportive Relationships and Meaningful Participation were entered in Block

2. The model was statistically significant $\chi^{2}(4, n=705,478)=18,236.53, p<.001$, indicating the model was able to distinguish between respondents who reported suicidal ideation and those who did not. The model explained between 2.6\% (Cox and Snell $\left.R^{2}\right)$ and 4.4\% (Nagelkerke $R^{2}$ ) of the variance in suicidal ideation and correctly classified $84 \%$ of cases. With a large $N$, the Hosmer and Lemeshow test is expected to be significant (Demidenko, 2006) and thus can be ignored (W. Donald, IBM, personal communication, January 26, 2021). As shown in Table 14, all of the independent variables made statistically significant contributions to the model. 
However, with such a large $N$, interpretation should focus on the beta weight, $\operatorname{Exp}(B)$. Supportive Relationships and Meaningful Participation both played a statistically significant role in mitigating suicidal ideation, although there was little difference between them. Supportive Relationships and Meaningful Participation each individually decreased the likelihood of suicidal ideation by approximately $19 \%$ to $20 \%$, respectively, for every 1 unit increase in the scale.

\section{Table 14}

Logistic Regression Predicting Suicidality Based on Specific SBPF

\begin{tabular}{|c|c|c|c|c|c|c|c|c|}
\hline \multirow[b]{2}{*}{ IV } & \multirow[b]{2}{*}{$B$} & \multirow[b]{2}{*}{ S.E. } & \multirow[b]{2}{*}{ Wald } & \multirow[b]{2}{*}{$d f$} & \multirow[b]{2}{*}{$p$} & \multirow[b]{2}{*}{$\begin{array}{c}\text { Odds } \\
\text { Ratio } \\
\operatorname{Exp}(B)\end{array}$} & \multicolumn{2}{|c|}{$\begin{array}{l}99 \% \text { C.I. for Odds } \\
\text { Ratio }\end{array}$} \\
\hline & & & & & & & Lower & Upper \\
\hline Foster & .759 & .045 & 290.438 & 1 & .000 & 2.137 & 1.905 & 2.397 \\
\hline Homeless & .737 & .035 & 435.680 & 1 & .000 & 2.090 & 1.908 & 2.289 \\
\hline Supportive Relationships & -.205 & .002 & 7707.09 & 1 & .000 & .814 & .811 & .818 \\
\hline Meaningful Participation & -.228 & .005 & 1806.23 & 1 & .000 & .796 & .788 & .805 \\
\hline
\end{tabular}

RQ6b. Do specific SBPF significantly predict depression?

Research Question $6 \mathrm{~b}$ focused on depression as a negative outcome. To understand the salience of each protective factor, a logistic regression model was created using a forward stepwise procedure. The depressive symptoms question was entered as the dependent variable, with two independent variables in Block 1: foster and homeless, with 'living at home' being the comparison group. Supportive Relationships and Meaningful Participation were entered in Block 2. The model was statistically significant $\chi^{2}(4, n=873,138)=34,976.86, p<.001$, indicating the model was able to distinguish between respondents who reported and did not report symptoms of depression. The model explained between 3.8\% (Cox and Snell $\left.R^{2}\right)$ and 5.4\% (Nagelkerke $R^{2}$ ) of the variance in depressive symptoms and correctly classified $68.8 \%$ of cases. 
With a large $N$, the Hosmer and Lemeshow test is expected to be significant (Demidenko, 2006) and thus can be ignored (W. Donald, IBM, personal communication, January 26, 2021). As shown in Table 15, all of the independent variables made statistically significant contributions to the model. However, with such a large $N$, interpretation should focus on the beta weight, $\operatorname{Exp}(B)$. Supportive Relationships and Meaningful Participation both played a statistically significant role in mitigating depressive symptoms. Supportive Relationships reduced the likelihood of depressive symptoms by $16 \%$. Meaningful Participation, however, offered a $22 \%$ decrease in the likelihood of a student reporting depressive symptoms.

\section{Table 15}

Logistic Regression Predicting Depressive Symptoms Based on Specific SBPF

\begin{tabular}{|c|c|c|c|c|c|c|c|c|}
\hline \multirow[b]{2}{*}{ IV } & \multirow[b]{2}{*}{$B$} & \multirow[b]{2}{*}{ S.E. } & \multirow[b]{2}{*}{ Wald } & \multirow[b]{2}{*}{$d f$} & \multirow[b]{2}{*}{$p$} & \multirow[b]{2}{*}{$\begin{array}{c}\text { Odds } \\
\text { Ratio } \\
\operatorname{Exp}(B)\end{array}$} & \multicolumn{2}{|c|}{$\begin{array}{c}\text { 99\% C.I. for } \\
\text { Odds Ratio }\end{array}$} \\
\hline & & & & & & & Lower & Upper \\
\hline Foster & .559 & .037 & 224.049 & 1 & .000 & 1.750 & 1.750 & 1.589 \\
\hline Homeless & .403 & .030 & 182.799 & 1 & .000 & 1.496 & 1.385 & 1.615 \\
\hline Supportive Relationships & -.18 & .002 & 11048.48 & 1 & .000 & .835 & .832 & .838 \\
\hline Meaningful Participation & -.291 & .004 & 6123.392 & 1 & .000 & .747 & .742 & .753 \\
\hline
\end{tabular}

RQ6c. Do specific SBPF significantly predict negative academic outcomes?

Research Question 6c addressed self-reported grades, specifically for those students indicating they received mostly D's or mostly F's. To understand the salience of each protective factor, a logistic regression model was created using a forward stepwise procedure. The selfreported grades question was entered as the dependent variable, with two independent variables in Block 1: foster and homeless, with 'living at home' being the comparison group. Supportive Relationships and Meaningful Participation were entered in Block 2. The model was statistically 
significant $\chi^{2}(4, n=878,955)=13,331.48, p<.001$, indicating the model was able to distinguish between respondents who received mostly D's or F's and those who did not. The model explained between 1.5\% (Cox and Snell $R^{2}$ ) and 6.2\% (Nagelkerke $R^{2}$ ) of the variance in poor grades and correctly classified $96.9 \%$ of cases. With a large $N$, the Hosmer and Lemeshow test is expected to be significant and thus can be ignored (W. Donald, IBM, personal communication, January 26, 2021). As shown in Table 16, all of the independent variables made statistically significant contributions to the model. However, with such a large $N$, interpretation should focus on the beta weight, $\operatorname{Exp}(B)$. As shown in Table 16, students who were in foster care were 3.8 times as likely to report D's and F's than students who lived at home. Students who were homeless were over 6 times as likely to report D's and F's than students who lived at home. Both Supportive Relationships and Meaningful Participation reduced that likelihood. Increasing the value of Supportive Relationships by 1 unit decreased the likelihood of being in the DV target group (D's and F's) by a factor of approximately .81, or it decreased the odds by about $19 \%[(1-0.81) \times 100]$. Increasing the value of Meaningful Participation by 1 unit decreased the likelihood of receiving D's and F's by a factor of approximately 0.54 , or it decreased the odds by about $46 \%[(1-0.54) \times 100]$. 


\section{Table 16}

Logistic Regression Predicting Self-Reported Grades Based on Specific SBPF

\begin{tabular}{|c|c|c|c|c|c|c|c|c|}
\hline \multirow[b]{2}{*}{ IV } & \multirow[b]{2}{*}{$B$} & \multirow[b]{2}{*}{ S.E. } & \multirow[b]{2}{*}{ Wald } & \multirow[b]{2}{*}{$d f$} & \multirow[b]{2}{*}{$p$} & \multirow[b]{2}{*}{$\begin{array}{c}\text { Odds } \\
\text { Ratio } \\
\operatorname{Exp}(B)\end{array}$} & \multicolumn{2}{|c|}{$\begin{array}{c}\text { 99\% C.I. for } \\
\text { Odds Ratio }\end{array}$} \\
\hline & & & & & & & Lower & Upper \\
\hline Foster & 1.34 & .058 & 531.090 & 1 & .000 & 3.81 & 3.40 & 4.27 \\
\hline Homeless & 1.83 & .038 & 2323.726 & 1 & .000 & 6.23 & 5.78 & 6.71 \\
\hline Supportive Relationships & -.216 & .004 & 2482.81 & 1 & .000 & .81 & .799 & .812 \\
\hline Meaningful Participation & -.610 & .012 & 2702.69 & 1 & .000 & .54 & .531 & .556 \\
\hline
\end{tabular}

\section{Summary}

Students who lived in at-risk living conditions (ARLC) had very high rates of suicidal ideation, depressive symptoms, and poor grades. Students who were in foster care had significantly greater chances of considering suicide or having feelings of depression than both of the other groups. Students who were homeless were significantly more likely to consider suicide or have depressive symptoms than those who lived at home. With regard to grades, homeless students had by far the poorest outcomes, being over 6 times as likely to report D's and F's than students who lived at home. Students in foster care also had very poor grades, being approximately 3.8 times as likely to report poor grades than those who lived at home. Confounding the results of this analysis was the disproportionate number of Black or African American, American Indian or Alaska Native, and LGBTQ students who were over-represented in at-risk living conditions. SBPF can significantly and profoundly alter the outcomes for these students. 


\section{CHAPTER 5: DISCUSSION}

This study used the California Healthy Kids Survey (CHKS) data, in combination with a review of the extant literature on youth in foster care, homelessness, adverse childhood experiences (ACEs) and resilience, to identify the school-based protective factors (SBPF) that were most salient in reducing risks of negative outcomes for students who lived in at-risk living conditions (ARLC). The data were first analyzed to understand the rates of suicide, depression, and self-reported academic outcomes for students who resided in ARLC, as compared to those who lived at a home with one or more parent ("at home"). The data were then analyzed to understand the ways in which SBPF moderated the risks associated with living in ARLC.

In Chapter 4, the preliminary analyses looked at, among other factors, the intersection of race and where a student resided and the intersection of sexual preference and gender identity and where a student resided. When comparing the rates of different races in ARLC, Black students were the most significantly overrepresented in foster care and homelessness. While accounting for $4 \%$ of the overall population in this study, they make up $11 \%$ of the foster care population, and $13.5 \%$ of the homeless population. Transgender students were also significantly overrepresented in ARLC. While they account for $1 \%$ of the overall population in the study, they represent $5.4 \%$ of the foster care, and $10.7 \%$ of the homeless population. Students who identify as gay or lesbian account for $1.5 \%$ of the overall population in the study, they make up $4.4 \%$ of the foster care and $6.1 \%$ of the homeless population. Similarly, students who identify as bisexual are $12.1 \%$ of the foster care population and $7.3 \%$ of the homeless population, while only representing $5.3 \%$ of the overall sample. When interpreting the results of the following research questions, it is important to keep in mind the overrepresentation of Black students and LGBTQ students in these living conditions, and the associated implications. 
As noted in Chapter 2, ACEs were linked to poor mental health outcomes, including depression, suicidal thoughts, and learning difficulties (Bruskas \& Tessin, 2013; Center for Youth Wellness, 2017; Crouch et al., 2017; Felitti et al., 1998; Katz et al., 2011; Perry, 2007; Porche et al., 2016; Radcliff et al., 2019). Furthermore, as the link between ACEs and residing in ARLC was made clear in previous chapters, it is important to recognize the potential role ACEs play in the findings of this study. The ACE experienced by the majority of children who are in the foster care system was neglect by their primary caregivers, with the next largest group being in foster care due to physical abuse (NSCAW, 2013). Radcliff et al. (2019) found 68.1\% of adults who had been homeless in childhood were exposed to four or more ACEs, and housing insecurity in and of itself may be an ACE. Students who reside in ARLC have, by definition, experienced numerous adverse childhood experiences.

\section{Discussion of Research Question 1}

RQ1a. Is there a difference in how students experience school-based protective factors (SBPF)?

RQ1b. Is there a difference in how students who are homeless experience SBPF as compared to students who live at home with one or more parent?

RQ1c. Is there a difference in how students in foster care experience SBPF as compared to students who live at a home with one or more parent?

Before addressing and analyzing protective factors that may mitigate the risk of negative outcomes for youth in foster care or experiencing homelessness, one must first understand the problem. Research Questions 1a, 1b, and 1c provided more information regarding how students who resided in ARLC experienced SBPF as compared to those who lived at a home with one or more parent. Although one might expect risk factors and outcomes are poorer for students in ARLC, one may hope the degree to which SBPF were experienced by students would be the 
same across all youth. This was not the case. Research Question 1 illustrated students who lived at a home with one or more parent had a vastly different perception of the ways they experienced SBPF as compared to students in ARLC. For overall SBPF, students who lived at home reported a median score of 7.80 and a mean of 7.79 indicating higher experiences of SBPF (range $=3.00$ 12.00), students who were in foster care reported a median score of 7.53 and a mean of 7.43 , and students who were homeless reported the lowest median score of 6.87 with a mean of 6.80 . Students in foster care and students who lived at home perceived experiencing Meaningful Participation (range $=1.00-4.00)$ relatively similarly (At home, $M=1.99, M d n=1.80 ;$ Foster, $M$ $=2.00, M d n=1.80)$, while students who were homeless experienced this significantly less $(M=$ $1.87, M d n=1.60$ ) than their peers. Supportive Relationships (the index of caring relationships and high expectations) were also experienced differently across the groups. Students who lived at home experienced Supportive Relationships (range $=2.00-8.00$ ) with adults in school settings at higher rates $(M=5.80, M d n=6.00)$ than both other groups (Foster, $M=5.43, M d n=5.67$; Homeless, $M=4.92, M d n=5.00)$.

Across all indexes, students who were homeless experienced the resilience-building supports at significantly different rates. Although this may well be due to the transient nature of homelessness, resulting in the possibility of children having multiple different schools in any given year (NCHE, 2019), thereby less opportunities to form connections, this nevertheless provides an illuminating path forward to providing this at-risk population of students more intensive and immediate supports. Students in foster care children may experience on average four school transfers in their first year of entering the system (Bruskas \& Tessin, 2013). As a result, they may struggle with the same transient nature of their living arrangements as homeless students. Nevertheless, foster care students experienced these school protective factors at higher 
rates than homeless students while Meaningful Participation was experienced at about the same rate as students who lived at home.

WestEd (n.d.) defined Meaningful Participation as, in part, “autonomy-supportive learning environments" (p. 1) that provide the opportunities for students to participate in interesting and relevant activities that require their own responsibility and contribution (Mahecha \& Hanson, 2020). The idea of autonomy was prevalent in the literature as well and discussed in Chapter 2. Benard (2004), for example, stated that autonomy (as well as problem-solving skills, social competence, and a sense of purpose) is a personal attribute, that if apparent, demonstrates that resiliency traits are engaged. The CHKS survey asks questions such as "(at school) I do interesting activities," or "I have a say in how things work." Students who do not feel a sense of autonomy are more likely to be dissatisfied or alienated from school (WestEd, n.d., p. 1). In examining the differences in how students in foster care and students who are homeless experienced Meaningful Participation, as noted earlier, it was found that students in foster care experienced this support at similar rates to students who lived at home, while students who were homeless experienced it significantly less. Studies have shown that individuals who are homeless may experience a significant lack of autonomy due to their circumstances and the resources available to them (Van Leeuwen \& Merry, 2019), which may account for a sense of disconnectedness to their school, potentially resulting in lower experiences of Meaningful Participation.

The CHKS was built on the well-researched premise that resiliency comes from a combination of personal individual strengths or characteristics, combined with environmental aspects in the school, family, and community (Benard, 2004). Chapters 1-3 discussed the risks children who reside in foster care or homelessness face, as well as the implicit protective factors 
that exist simply by residing at home. Knowing some of the most at-risk students do not experience the very things in schools that can bolster their resilience and improve outcomes at the same rates as their peers is foundational for future research and immediate and practical recommendations.

To further understand the differences among groups of students depending on where they live, Research Questions 2-4 examined the rates of negative outcomes (i.e., suicidal ideation, depressive symptoms, poor grades) for students in ARLC, as compared to students who live at home.

\section{Discussion of Research Question 2}

RQ2a. What is the rate of suicidal ideation in students who are homeless, and how does this compare with students living at home with one or more parent?

RQ2b. What is the rate of suicidal ideation for students who reside in foster care, and how does this compare with students living at home with one or more parent?

Research Questions 2a and 2b addressed the rates of suicidal ideation among students who lived at home, compared with those who lived in ARLC. A significant difference was found among the groups. For students who lived at a home with one or more parent, $15.8 \%$ had considered suicide over the past 12 months. This was significantly lower than the other groups: $29.7 \%$ of students in foster care and $32.6 \%$ of students who were homeless reported seriously considering suicide over the past 12 months. Previous studies have shown rates of suicidal thoughts for homeless students were approximately 21\% (Haskins, 2018) and that students in foster care were 3 times more likely to consider suicide than those not in care (Pilowsky \& Wu, 2006). Although the present study examined thoughts of suicide, it did not provide insight into suicide attempts. The aforementioned studies reported suicide attempt rates at $9 \%$ for homeless 
students and that foster care students are four times as likely to consider suicide compared to other students.

Findings from past literature were clear that students who resided in ARLC were more likely to face significantly greater mental health risks than their counterparts and more negative outcomes (Babbel, 2012; Bruskas \& Tessin, 2013; Katz et al., 2011; Turney \& Wildeman, 2017), including suicide (Katz et al., 2011). This was confirmed by the present study. Youth in foster care or homelessness were found to be at greater risk of suicide than those who were not residing in ARLC. Further, similar to the present study, research has shown links between experiencing ACEs and suicidal behavior. Choi et al. (2017) showed participants who had experienced at least two ACEs were significantly more likely to attempt suicide at least once, as compared to individuals who had not experienced ACEs.

\section{Discussion of Research Question 3}

RQ3a. What is the rate of depressive symptoms in students who are homeless, and how does this compare to students living with one or more parent?

RQ3b. What is the rate of depressive symptoms in students who reside in foster care, and how does this compare to students living with one or more parent?

Depressive symptoms were analyzed across groups in Research Questions 3a and 3b. In examining rates of depression across groups, $31.1 \%$ of students who lived at home reported feeling so sad or hopeless for 2 weeks or more over the past 12 months that they stopped doing usual activities. Although this is a concerning number, it is significantly lower than the other groups. Nearly half of students who were homeless $(44.5 \%)$ and in foster care (45.2\%) reported depressive symptoms. This is unsurprising, as children in foster care experience poor mental and physical health when compared to children in the general population controlling for specific 
family types and economic disadvantage (Turney \& Wildeman, 2016). Homelessness amplifies poor mental health (Meltzer et al., 2019; NCHE, 2019) and the stress of the experience of homelessness may exacerbate already existing mental illness (NCHE, 2019). As noted earlier, ACEs are linked to poor mental health outcomes, including depression (Felitti et al., 1998).

\section{Discussion of Research Question 4}

RQ4a. What are the self-reported academic outcomes for students who are homeless, and how does this compare with students living at home with one or more parent?

RQ4b. What are the self-reported academic outcomes for students who reside in foster care, and how does this compare with students living at home with one or more parent?

Self-reported academic outcomes across the groups were examined in Research

Questions $4 \mathrm{a}$ and $4 \mathrm{~b}$. Students who lived at a home with one or more parent reported earning the highest grades, with $85.5 \%$ of them earning between "mostly A's" and "B's and C's." Only $3 \%$ of this student group reported receiving "mostly D's" or "mostly F's." Homeless students reported the worst academic outcomes, with $19.8 \%$ of them receiving "mostly D's" or "mostly F's." Students in foster care had slightly better outcomes, with more of them (19.2\%) reporting "Mostly C's" or "C's and D's" than D's or F's (11.5\%). The findings of the literature are clear on possible reasons for the discrepancy in grades between students who lived at home and those who resided in ARLC. As was illustrated in Chapter 2, children who resided in ARLC are likely to have experienced trauma as a result of the ACEs they have faced. The link between trauma and learning has been made clear (Harden, 2004; Perry, 2007; Van der Kolk, 2015). As noted in Chapter 2, Perry (2007) said to intervene with students who are in the alarm state, teachers should use regulating practices in their classrooms such as meditative breathing or rhythmic activity. If students remain in the alarm state, their cognitive functioning is impaired, thus, 
making it very difficult, if not impossible, to learn. The findings of the present study are also consistent with Perry and Hambrick's (2008) conclusion that the effects of trauma on student learning may be associated with the achievement gap. Perry and Hambrick (2008) asserted children who live in stressful environments may not internalize information as quickly as children who are in a calm, and ready to learn, state. They went on to state there is a perpetual cycle of students impacted by trauma learning at slower rates, falling behind, and often, dropping out of school. Although self-reported grades are a limited and perhaps even misleading measure of a child's learning (discussed further in the limitations section), nevertheless, the results of the present study are consistent with the literature, painting a clear picture of the academic needs of students who reside in ARLC.

\section{Discussion of Research Question 5}

RQ5a. Do SBPF predict suicidality above and beyond where a student resides?

RQ5b. Do SBPF predict depression above and beyond where a student resides?

RQ5c. Do SBPF predict academic outcomes above and beyond where a student resides?

Research Question 5 focused on predicting negative outcomes and determined whether SBPF offered a mitigating effect. For these questions, a hierarchical logistic regression model was created to determine the predictive value of protective factors on suicidal ideation, depression, and academic outcomes above and beyond the predictive factors of where a student resides. Because where a student resides is significantly linked to suicidality, depressive symptoms, and academic outcomes as shown in the results of previous research questions, overcoming the likelihood of experiencing these would indicate that SBPF have a meaningful and real impact on reducing these risks for students in ARLC. 
Regression results indicated protective factors did have a statistically significant impact on suicidal ideation above and beyond where a student resides. Homelessness was a strong predictor of suicidality - in fact, students experiencing homelessness were 2.10 times as likely to consider suicide in the past 12 months than a student who resided at home. Students in foster care expressed similar results - they were 2.13 times as likely to consider suicide than those living at home. As alarming as these findings are, the presence of SBPF can reduce these risks significantly — by $19 \%$ for every lunit increase. These data reinforce the concept that SBPF are not only a powerful source that mitigates risk for all students, this is especially true for students who are in foster care and homelessness.

Similar to suicidal ideation, SBPF had a significant impact on depressive symptoms above and beyond where a student resides. The strongest predictor of depressive symptoms was residing in foster care: Students who lived in foster care were 1.73 times more likely to report experiencing depressive symptoms than those who lived at home. A homeless student was nearly 1.50 times as likely to report depressive symptoms than those who lived at home. SBPF once again proved to be a strong mitigator of risks, reducing the likelihood of depressive symptoms by $19 \%$, for every 1 unit increase of SBPF. The index of SBPF has a range of scores from $3-12$, with the possibility of scores being a score of 3 (not at all true on all three scales that comprise SBPF) to 12 (very much true on all three scales that comprise SBPF). If, for example, a student indicated a score of 3 , indicating not at all true to their experience of all the variables on the SBPF measure, but after intervention indicated that their experience of SBPF was a little true (score of 6), the 19\% reduction in the likelihood of depressive symptoms would become $57 \%$ (an increase of SBPF by a rate of 3). 
SBPF also played a significant role in self-reported academic outcomes. The strongest predictor of receiving D's or F's was homelessness, indicating that those who were homeless were nearly 6 times more likely to report D's and F's than those who lived at home. Students who lived in foster care were nearly 4 times more likely to report D's and F's than students who lived at home. Similar to the other negative outcomes measured in this analysis, SBPF once again significantly reduced the likelihood of receiving poor grades by $26 \%$ for every 1 unit increase in SBPF. These findings are consistent with the literature. For example, Neal (2017) found a critical connection between academic resilience and care; when students who are vulnerable are facing challenges, those challenges must be met by support brought to them by caring adults. Bryan (2005) described educational resilience as being bolstered by positive and supportive adult relationships, opportunities for meaningful participation, and high expectations by teachers regarding their performance and future endeavors - in essence, the SBPF studied here.

\section{Discussion of Research Question 6}

RQ6a. Do specific SBPF significantly predict suicidality?

RQ6b. Do specific SBPF significantly predict depression?

RQ6c. Do specific SBPF significantly predict academic outcomes?

Research Question 6 built upon Research Question 5 to understand which, if any, of the protective factors are most salient in reducing the risk of suicidal ideation, depressive symptoms, or poor academic outcomes in youth in ARLC. Supportive Relationships and Meaningful Participation both played a statistically significant role in mitigating negative outcomes. With regards to suicidality, the two indexes played relatively similarly predictive roles. This changed, however, when examining depression and academic outcomes: Meaningful Participation played 
a stronger mitigating role for depressive symptoms and academic outcomes than did Supportive Relationships. The results of this analysis indicate that the presence of just one support, whether it be Meaningful Participation or Supportive Relationships plays a powerful role in supporting all students, including those with the odds stacked against them, such as students residing in ARLC. Neal (2017) discussed when challenging experiences outweigh a youth's protective environment, all students need support. This may indicate the potential for these protective factors to be even more important for the students who reside in at-risk living conditions. As noted in Chapter 2, although children in foster care may have disrupted attachment with their parents, they can form positive and healthy attachment with others, such as relatives, foster parents, mentors, and notably, teachers (Collins et al., 2008; Gilligan, 2000; Siegel \& Bryson, 2020). A pertinent and salient finding from Collins et al. (2008) showed these relationships may take on even greater meaning for children in foster care, and this support system is an important factor in promoting resilience.

\section{Summary of Results}

Students who experience at-risk living conditions are among the most at-risk populations in schools. Students who are Black or African American or identify as LGBTQ are significantly overrepresented in foster care and homelessness. Compared to students who live at a home with one or more parent, students residing in ARLC were significantly more likely to consider suicide, experience depressive symptoms, and have poor academic outcomes. Further, this study has shown if a student resides in ARLC, this significantly increased the risk for suicidal ideation, depressive symptoms, and poor grades. SBPF can have a profound impact on reducing the rates of negative outcomes for youth who live in foster care or are homelessness. In the present study, SBPF reduced the risk of suicidal ideation and depression by $19 \%$ and reduced the risk of poor 
grades by $26 \%$. Meaningful Participation played a more powerful in mitigating the risks of depression and poor grades, than did Supportive Relationships.

\section{Strengths of the Study}

Although no study is without its imperfections, there were notable strengths in the present study. First, the CHKS provided a very large and diverse sample across California. The sample size for ARLC $(n=8,230)$ and for students who lived at home $(n=879,032)$ was large and captured a range of students who reported residing in these housing arrangements across different cities and districts in California. California is home to approximately $14 \%$ of the foster students in the United States, and homeless students in California make up $21 \%$ of the homeless student population nationwide (CDE, 2019). As such, data that speaks to the needs of this population of students are particularly pertinent in California. Additionally, the large sample size allows for more complex and nuanced statistical analyses which can be generalized to a larger group. The population was not self-selecting, meaning that the results include a broad sample of youth who may not otherwise have access to resources that would distribute such a study.

Another notable strength of the CHKS survey is that the construct of SBPF is well researched and empirically sound. There is a wealth of research supporting the concepts of Supportive Relationships and Meaningful Participation as they relate to risk and resilience. Further, there have been numerous studies, as discussed in Chapter 3, which examined the validity of the CHKS survey.

As mentioned earlier, African American or Black students and LGBTQ students were significantly overrepresented in the foster care and homeless populations. There is no known literature that examines the educational significance of these overrepresentations in ARLC and the implications therein. This study provides illuminating data on the ways in which students in 
ARLC are at risk of negative outcomes and the ways in which they experience school supports. Considering the overrepresentation of Black and LGBTQ students in these housing circumstances, future studies should address the relative impact of the interaction between demographics such as race, gender identity, and ARLC.

In addition to the strengths of the survey and sample itself, this study provides practitioners and educators with concrete information they can apply and implement in their schools without additional training or resources. As noted in Chapter 2, there is a push in the educational field to be "trauma-informed" in practices in the classroom, systemically as a school, and in mental health therapies. There is an abundance of literature on trauma-informed practices but none that make clear the one best-practice approach. Furthermore, schools are at increasing odds with competing initiatives: teachers are taxed, professional development time is scarce, funding is limited. There are many districts - especially those where these findings might be most relevant—which would struggle the most with implementing such a framework. This study provides indications of school practices that are either already being implemented, or are readily available, which can make profound improvements for students who have experienced ACEs without adopting a trauma-informed framework or curriculum.

\section{Limitations of the Study}

There are several issues that exist in this study because of the nature of the measure used. Using a large-scale survey such as the CHKS can provide strengths; however, the same components can also present limitations. Due to participants neglecting to answer all questions, the CHKS data has a large amount of missing data, which poses an issue to generalizability and validity. Furthermore, due to the particular population being studied, there may be significant attendance issues of the populations in question, thus rendering the possibility of missing data 
from students absent on the day the measure was administered. This is an issue because this data may not necessarily give a true picture of the population. All of this should be taken into consideration when interpreting the results of this study.

Additionally, the CHKS is a self-report survey, meaning that participants are to selfidentify their belonging to the variables in question. The validity of the survey relies on the honesty of the participants. Though preliminary analyses were run to clean the data and weed out dishonest responses, the possibility exists that some data in the survey were derived from participants who responded dishonestly or inaccurately. Self-report surveys are prone to bias or omissions (Rosenman et al., 2014), particularly with sensitive questions such as the ones of interest in the present study.

With an $N$ as large as 887,262 , the size of the sample studied presented a risk of reporting false-significant findings (Biau et al., 2008), indicating a potential threat to the statistical conclusion validity of this study. This risk holds true when running predictive analyses such as a logistic regression, and this should be taken into consideration when interpreting the results of the logistic regression analysis.

Internal validity refers to changes in the dependent variable due to extraneous variables or alternate explanations as opposed to the contribution of the independent variable (Mertler \& Vanatta, 2013). In a large-scale survey such as the CHKS, there are inherent threats to the internal validity. Although the authors reported acceptable reliability on the SBPF measures (noted in Chapter 3), they were shown to be correlated with each other (also discussed in Chapter 3). This threat is related to the validity of the measure.

In addition to the sample size limitation noted earlier, another limitation exists with the sample size. Comparing unequal sample sizes $(n=887,262$ vs. $n=8,230)$ can lead to a loss of 
power and increased possibility of Type I error (Mertler \& Vannatta, 2013). Having equal-sized groups maximizes the statistical power of an analysis. Further, there may be issues with confounding variables, or unaccounted-for variables that may contribute to the effect the independent variables have on the dependent variables (Mertler \& Vannatta, 2013). Further study is warranted to tease apart any contributions to negative outcomes that might be related to other factors beyond where a student resides.

Construct validity refers to the degree that the survey is able to measure what it intends to measure. In the CHKS, the school protective factors being measured include a 3 to 6 item question addressing each construct, providing a limited scope to the ways in which participants experienced each. Further, the question regarding suicidal ideation only allowed for a dichotomous response (yes or no). Limited response options such as this should be considered when interpreting results. Additionally, there was a notable weakness in the way academic outcomes were measured in this study, relying solely on student's self-reported grades. The selfreported nature holds the same limitations as previously mentioned, but in addition, grades are merely one part of numerous factors that actually define academic outcomes. For example, performance on state testing, attendance (and the impact thereof on grades), work completion, participation, and graduation rates are only a few of the many elements that one would consider when looking at the whole picture of a child's educational outcomes. Further, students in foster care and homelessness are likely to be in special education (California Department of Education, 2012), and any modifications and accommodations to the child's learning environment would need to be taken into consideration when comparing their grades to grades of students not in special education. Using this variable as a dependent variable, and operationalizing academic outcomes as such indicates a threat to the construct validity of this portion of the study. 
There are some theoretical limitations of the study as well. Resilience theory emphasizes the importance of an individual's environment and protective factors working in concert to create resiliency. Protective factors may come from a variety of influences outside of a child's school and may impact their experience of protective factors in school. Examining protective factors only in a school setting provides a limited scope and understanding of what a child may have working for (or against) them, as protective factors from all environments—school, home, community, peer group — work in harmony.

Beyond the limitations of the survey itself and the analyses, there are inherent limitations when using a quantitative research method to examine something as personal and nuanced as risk and resilience, especially for such a vulnerable population. Although this study did capture thematic and big-picture information, what is missing are the voices and lived experiences of the populations of interest. A qualitative study might ask respondents questions such as, "what are the biggest barriers you face in school," and "what can teachers do to better form connections with you?" Without data from these lived experiences of the students, there is much that is impossible to be captured in a study such as this. For example, Strolin-Goltzman et al. (2016) conducted a mixed-methods analysis of educational well-being and resilience of youth who had experienced adversity, and three themes were identified through the qualitative interviews: (a) school stability and structured transition, (b) positive relationships with adult mentors, and (c) the power of positive peer influence. Although it is reassuring that interviews elicited similar results to this statistical analysis with regard to positive relationships with adult mentors, it is that confirmation of findings from individuals that is missing from the present study. Further, the Strolin-Goltzman et al. (2016) study is just one example of qualitative analysis illuminating other 
pathways to bolstering student success not identified in the present study: transition and peer influence.

Additionally, there is a potential concern regarding the implications of the results of this study. Although the general recommendations discussed later in this chapter will highlight the need to identify students who reside in foster care or homelessness, this raises the concern of misuse of this information or misinterpretation of the associated risks and causes by educators. It would not be prudent to label all students who have resided in ARLC as "traumatized students" and treat them as such in lieu of a holistic understanding of their strengths, internal assets, and individual history. Further, viewing children as traumatized or having experienced significant ACEs may lead to unintentional bias against a child's capability and ability to persevere. The overrepresentation of Black or LGBTQ students in these living arrangements cannot be ignored when considering the aforementioned concerns. Any subsequent recommendations or dissemination of results of this study or similar studies should hold at the forefront ways to reduce bias, deficit mindset, or misconceptions about these youth.

Lastly, the CHKS does not query how long students have been at their school. This is a significant limitation of a survey that looks at school-supports that bolster resiliency because the time a student has been in a school would likely significantly impact their ability to form connections with teachers and be involved meaningfully with the school. Without this key piece of information, findings that indicate students experience protective factors at lower rates without taking into consideration their length of time at a school would limit what can be deduced as potential causes of the lower experience of SBPF. 


\section{Implications and Directions for Future Research}

This study used a quantitative approach to understanding risks and protective factors for youth who reside in at-risk living conditions. Future studies should use a mixed-methods or qualitative approach, which would allow for a deeper understanding of ways to bolster resilience and mitigate negative outcomes. Future studies examining SBPF should include analysis of the amount of time a child has been at the given school and attendance rates and determine how that relates to their experience of SBPF. An important implication for future studies would be to examine the potential influence of confounding variables, such as race, socio-economic status and gender identity, on the results. Studies should also examine academic outcomes by broadening the variables used to determine said outcomes, such as state testing, attendance (and the impact thereof on grades), work completion, participation, and graduation rates. Furthermore, there are a collection of evidence-based interventions that schools use to increase school connectedness or connections with adults at school. Future studies should examine these interventions in terms of their effectiveness with increasing Supportive Relationships and Meaningful Participation as defined in this study, specifically on the population of students in ARLC. For example, upon entering a new school, would implementing an intervention that requires a student check in and check out with a designated adult each day increase students' connection with adults in such a way that it decreases risks, and would such an intervention be more salient for those in ARLC?

Although the present study and extant literature make clear the need for youth to establish emotional connections with teachers or other school professionals, what is not clear is the impact that the natural severance of these relationships upon matriculation or moving schools will have on youth who may already have experienced disrupted attachments with their caregivers. 
Furthermore, students who are homeless or in foster care may move schools frequently, which may hinder their ability, or even their willingness, to form connections. If connections are successfully formed and then severed upon matriculation or moving schools, it is unclear what impact this will have on these youth; thus, future studies should consider the potential implications of this.

\section{Implications for Practice}

One of the most compelling strengths of this study is the immediate applicability to the ways educators practice in schools. Students spend much of their time in schools, and as such, schools offer ample opportunity for intervention by providing an environment where steady and meaningful support can take place. Particularly for students who have experienced ACEs, being in school provides opportunities to build protective factors that may counter trauma-related struggles. Where home, community, and societal environments may fail a child, schools must be prepared to meet their most basic needs including physiological, safety, and belonging. Similar to Maslow's (1943) hierarchy of needs theory, these basic needs must be met first to then move on to more complex needs.

Results of this study, in tandem with extant literature, suggest to improve outcomes for youth who have faced ACEs, administrators, teachers, and school mental health professionals can apply a broad and systemic approach to enhancing resilience in schools by meeting the students' basic needs and emphasizing protective factors. Primarily, the basic needs of students should be addressed first and foremost upon entering the classroom. Often, students' first period of the day is homeroom or a similar class, and a class such as this provides prime opportunity to conduct a daily check-in to determine if students are arriving to school hungry, thirsty, sleepdeprived, and so on. Second, schools should focus on promoting opportunities that foster a 
student's sense of belonging, positive feelings toward school, and connections with school staff. Upon a child in foster care or homelessness entering a new school, schools should immediately implement interventions such as eliciting student engagement in school decisions and functions, providing leadership opportunities, using a buddy-teacher or mentor program, and hosting a variety of inclusive school clubs and activities. Many schools have already adopted curriculums or programs that promote such strategies, but it is important for educators to realize the salience of such programs for students who have faced adversity and as such, reach out directly to these students to elicit their participation.

Beyond this, it is crucial for administrators, teachers, counselors, and school mental health professionals to be aware of the students who are in foster care or living in homelessness in order to immediately and intensively implement strategies to form connections with these students. Resilient individuals have described Supportive Relationships as being characterized by quiet availability, fundamental positive regard, and simple sustained kindness (Benard, 2004). Neal (2017) has described characteristics of Supportive Relationships as ones that exhibit attention, trust, empathy, availability, and affirmation. When adults provide youth who have experienced adversity with these supports, the students feel important and worthy of others' time. Benard (2004) has described meaningful participation as opportunities for reflection and dialogue in ways that are meaningful to the students. Such dialogue should leverage their beliefs, attitudes, and feelings and allow them to critically engage with societal issues (Benard, 2004).

When youth establish emotional connections with educators, these relationships are of particular importance (Mota \& Matos, 2012) for students who reside in ARLC. Protective factors are more profoundly impactful on the life course of children who grow up in adverse conditions than the stressful life events or risk factors they have faced (Werner \& Smith, 1992). Such 
protective factors are intuitive strategies already employed by many caring educators. Empowering educators with the knowledge that simple connections with students and opportunities for meaningful participation can impart profound change in some of the most atrisk students' lives should be an immediate and accessible goal for educational leaders.

\section{Conclusion}

Students who reside in ARLC are among the most at-risk populations in schools. Research has consistently shown increased risks and deleterious outcomes for these students. Research has also shown some students "beat the odds" and are able to succeed in life despite the significant adversities they have faced. There is a great deal of literature on resilience: on what causes resilience and what bolsters resilience, but there is little research on specific resiliencebuilding elements for students who have faced significant adversity. Schools can provide a powerful environment for preventing the risks that these children are susceptible to, specifically the risks of suicide attempts or thoughts, depression, and failing grades. This study demonstrates the importance of both identifying and implementing school-based supports that will reduce risks and promote resiliency. Although a child's educational environment is merely one aspect of a complex web of systems - supportive and inhibitive - that contributes to the physical, social, emotional, cognitive, academic, and mental health of a child, its role is profound. Where home, community, and societal environments may fail a child, schools must be prepared to meet their most basic needs including physiological, safety, and belonging. 


\section{REFERENCES}

American Academy of Pediatrics. (2020). Healthy foster care America. https://www.aap.org/enus/advocacy-and-policy/aap-health-initiatives/healthy-foster-careamerica/Pages/default.aspx

Austin, G., Bates, S., \& Duerr, M. (2011). Guidebook to the California healthy kids survey. West Ed. https://calschls.org/docs/chks_guidebook_3_datause.pdf

Austin, G., Hanson, T., Polik, J., \& Zheng, C. (2018). School climate, substance use, and student well-being in California, 2015-17. Results of the sixteenth biennial statewide student survey, grades 7,9 , and 11. WestEd. https://data.calschls.org/resources/Biennial_State_1517.pdf

Babbel, S. (2012). The foster care system and its victims: Part 2. Psychology Today. https://www.psychologytoday.com/us/blog/somatic-psychology/201201/the-foster-caresystem-and-its-victims-part-2

Barrat, V. X., \& Berliner, B. (2013). The invisible achievement gap: Education outcomes of students in foster care in California's public schools. WestEd.

https://www.wested.org/resources/the-invisible-achievement-gap-education-outcomes-ofstudents-in-foster-care-in-californias-public-schools-part-1/

Benard, B. (1991). Fostering resiliency in kids: Protective factors in the family, school, and community. Northwest Regional Educational Laboratory.

Benard, B. (1995). Fostering resilience in children (Report No. EDO-PS-95-9). ERIC Clearinghouse on Elementary and Childhood Education. https://files.eric.ed.gov/fulltext/ED386327.pdf

Benard, B. (2004). Resiliency: What have we learned? WestEd. 
Benard, B., \& Slade, S. (2009). Listening to students: Moving from resilience research to youth development practice and school connectedness. In R. Gilman, E. S. Huebner, \& M. J. Furlong (Eds.), Handbook of positive psychology in the schools (pp. 353-370). Routledge.

Benzies, K., \& Mychasiuk, R. (2009). Fostering family resiliency: A review of the key protective factors. Child \& Family Social Work, 14(1), 103-114. https://doi.org/10.1111/j.13652206.2008.00586.x

Biau, D. J., Kereneis, S., \& Porcher, R. (2008). Statistics in brief: The importance of sample size in planning and interpretation of medical research. Clinical Orthopaedics and Related Research, 466(9), 2282-2288. https://doi.org/10.1007/s11999-008-0346-9

Blome, W. W. (1997). What happens to foster kids: Educational experiences of a random sample of foster care youth and a matched group of non-foster care youth. Child and Adolescent Social Work Journal, 14, 41-53. https://doi.org/10.1023/A:1024592813809

Bowlby, J. (1969). Attachment and loss. Hogarth Press.

Bowlby, J. (1973). Attachment and loss / anxiety and anger. Basic Books.

Bowlby, J. (1998). Attachment and loss. sadness and depression. Pimlico.

Brenner, G. H. (2017). What does self-actualization really mean? Decoding self-actualization reveals a surprising finding. Psychology Today. https://www.psychologytoday.com/us/blog/experimentations/201707/what-does-selfactualization-really-mean

Bronfenbrenner, U. (1977). Toward an experimental ecology of human development. American Psychologist, 32(7), 513-531. https://doi.org/10.1037/0003-066x.32.7.513 
Bruskas, D. (2008). Children in foster care: A vulnerable population at risk. Journal of Child and Adolescent Psychiatric Nursing, 21(2), 70-77. https://doi.org/10.1111/j.17446171.2008.00134.x

Bruskas, D., \& Tessin, D. (2013). Adverse childhood experiences and psychosocial well-being of women who were in foster care as children. The Permanente Journal, 17(3), 131-141. https://doi.org/10.7812/tpp/12-121

Bryan, J. (2005). Fostering educational resilience and achievement in urban schools through school-family-community partnerships. Professional School Counseling, 8(3), 219-227.

Burt, M. R., Aron, L. Y., Douglas, T., Valente, J., Lee, E., \& Iwen, B. (1999). Homelessness: Programs and the people they serve: Findings of the National Survey of Homelessness Assistance Providers and Clients. U.S. Interagency Council on Homelessness and The Urban Institute. https://www.urban.org/sites/default/files/publication/66286/310291Homelessness-Programs-and-the-People-They-Serve-Findings-of-the-National-Surveyof-Homeless-Assistance-Providers-and-Clients.PDF

California Department of Education. (2012). Foster children now eligible for free meals/milk. https://www.cde.ca.gov/ls/nu/sn/mbusdasnp252012.asp

California Department of Education. (2019). Foster youth services. https://www.cde.ca.gov/ls/pf/fy/

California Department of Education. (2019). Homeless education. https://www.cde.ca.gov/sp/hs/ Center for Youth Wellness. (2017). Adversity and toxic stress are so pervasive, they affect us all. https://centerforyouthwellness.org/ace-toxic-stress/

Centers for Disease Control. (2016). https:/www.cdc.gov/violenceprevention/aces/ 
Chafouleas, S. M., Koriakin, T. A., Roundfeld, K. D., \& Overstreet, S. (2018). Addressing childhood trauma in school settings: A framework for evidence-based practice. School Mental Health, 11, 40-53. https://doi.org/10.1007/s12310-018-9256-5

Child Welfare Information Gateway. (n.d.). Foster care. https://www.childwelfare.gov/topics/outofhome/foster-care/

Choi, N. G., Dinitto, D. M., Marti, C. N., \& Segal, S. P. (2017). Adverse childhood experiences and suicide attempts among those with mental and substance use disorders. Child Abuse \& Neglect, 69, 252-262. https://doi.org/10.1016/j.chiabu.2017.04.024

Cicchetti, D., \& Lynch, M. (1993). Toward an ecological/transactional model of community violence and child maltreatment: Consequences for children's development. Psychiatry Interpersonal \& Biological Processes, 56(1), 96-118. https://doi.org/10.1080/00332747.1993.11024624

Collins, M. E., Paris, R., \& Ward, R. L. (2008). The permanence of family ties: Implications for youth transitioning from foster care. American Journal of Orthopsychiatry, 78(1), 54-62. https://doi.org/10.1037/0002-9432.78.1.54

Constantine, N., Benard, B., \& Diaz, M. (1999). Measuring protective factors and resilience traits in youth: The healthy kids resilience assessment [Paper presentation]. The Seventh Annual Meeting of the Society for Prevention Research, New Orleans, LA.

Courtney, M. E., Dworsky, A. L., Lee, J. A. S., \& Raap, M. (2010). Midwest evaluation of the adult functioning of former foster youth: Outcomes at ages 23 and 24. Chapin Hall at the University of Chicago. 
Courtney, M. E., Dworsky, A., Brown, A., Cary, C., Love, K., \& Vorhies, V. (2011). Evaluation of the adult functioning of former foster youth: Outcomes at age 26. Chapin Hall at the University of Chicago.

Crittenden, P. M. (1998). Dangerous behavior and dangerous contexts: A 35-year perspective on research on the developmental effects of child physical abuse. In P. K. Trickett \& C. J. Schellenbach (Eds.), Violence against children in the family and the community (pp. 1138). American Psychological Association. https://doi.org/10.1037/10292-001

Crouch, E., Strompolis, M., Bennett, K. J., Morse, M., \& Radcliff, E. (2017). Assessing the interrelatedness of multiple types of adverse childhood experiences and odds for poor health in South Carolina adults. Child Abuse \& Neglect, 65, 204-211. https://doi.org/10.1016/j.chiabu.2017.02.007

Demidenko, E. (2006). Sample size determination for logistic regression revisited. Statistics in Medicine, 26(18), 3385-3397. https://doi.org/10.1002/sim.2771

English, D. J., Thompson, R., \& White, C. R. (2015). Predicting risk of entry into foster care from early childhood experiences: A survival analysis using LONGSCAN data. Child Abuse \& Neglect, 45, 57-67. https://doi.org/10.1016/j.chiabu.2015.04.017

Evans, R., White, J., Turley, R., Slater, T., Morgan, H., Strange, H., \& Scourfield, J. (2017). Comparison of suicidal ideation, suicide attempt and suicide in children and young people in care and non-care populations: Systematic review and meta-analysis of prevalence. Children and Youth Services Review, 82, 122-129. 
Fantuzzo, J., \& Perlman, S. (2007). The unique impact of out-of-home placement and the mediating effects of child maltreatment and homelessness on early school success. Children and Youth Services Review, 29(7), 941-960. https://doi.org/10.1016/j.childyouth.2006.11.003

Felitti, V., Anda, R., Nordenberg, D., Williamson, D., Spitz, A., Edwards, V., Koss, J., \& Marks, J. (1998). Relationship of childhood abuse and household dysfunction to many of the leading causes of death in adults: The adverse childhood experiences (ACE) study. American Journal of Preventative Medicine, 14(4), 245-258. https://doi.org/10.1016/S0749-3797(98)00017-8

Fisher, E. S., \& Kennedy, K. S. (2017). Counseling special populations in schools. Oxford University Press.

Fosha, D. (2009). The healing power of emotion: Affective neuroscience. In D. E. Fosha, D. J Siegel, \& M. F. Solomon (Eds.), The healing power of emotion: Affective neuroscience, development \& clinical practice (p. 24). WW Norton \& Company.

Fraser, M., \& Richman, J. (1999). Risk, protection, and resilience: Toward a conceptual framework for social work practice. Social Work Research, 23(3), 131-143. https://doi.org/10.1093/swr/23.3.131

Furlong, M., Ritchey, K., \& O’Brennan, L. (2009). Developing norms for the California Resilience Youth Development Module: Internal assets and school resources subscales. The California School Psychologist, 14, 99-114. 
Garcia, A. R., Gupta, M., Greeson, J. K., Thompson, A., \& Denard, C. (2017). Adverse childhood experiences among youth reported to child welfare: Results from the national survey of child \& adolescent wellbeing. Child Abuse \& Neglect, 70, 292-302. https://doi.org/10.1016/j.chiabu.2017.06.019

Gilligan, R. (2000). Adversity, resilience and young people: The protective value of positive school and spare time experiences. Children \& Society, 14(1), 37-47. https://doi.org/10.1111/j.1099-0860.2000.tb00149.x

Hanson, T. L., \& Kim, J. O. (2007). Measuring resilience and youth development: The psychometric properties of the Healthy Kids Survey. (Issues \& Answers Report, REL 2007-No. 034). U. S. Department of Education, Institute of Education Sciences, National Center for Education Evaluation and Regional Assistance, Regional Educational Laboratory West. http://ies.ed.gov/ncee/edlabs

Harden, B. (2004). Safety and stability for foster children: A developmental perspective. The Future of Children, 14(1), 31-47. https://doi.org/10.2307/1602753

Haskins, J. (2018). Teens who are homeless at higher risk for suicide attempts, self-harm. The Nation's Health, 48(4), E19. https://www.thenationshealth.org/content/48/4/E19

Heneghan, A., Stein, R. E., Hurlburt, M. S., Zhang, J., Rolls-Reutz, J., Fisher, E., Landsverk, J., \& Horwitz, S. M. (2013). Mental health problems in teens investigated by U.S. child welfare agencies. Journal of Adolescent Health, 52(5), 634-640.

https://doi.org/10.1016/j.jadohealth.2012.10.269

Hunter, A. J., \& Chandler, G. E. (1999). Adolescent resilience. IMAGE: Journal of Nursing Scholarship, 31(3), 243-247. https://doi.org/10.1111/j.1547-5069.1999.tb00488.x 
Hyatt, S., Walzer, B., \& Julianelle, P. (2014). California's homeless students: A growing population. California Homeless Youth Project. https://cahomelessyouth.library.ca.gov/docs/pdf/CaliforniasHomelessStudents_AGrowin gPopulation.pdf

Katz, L. Y., Au, W., Singal, D., Brownell, M., Roos, N., Martens, P. J., Chateau, D., Enns, M. D., Kozyrski, A. L., \& Sareen, J. (2011). Suicide and suicide attempts in children and adolescents in the child welfare system. CMAJ, 183(17), 1977-1981. https://doi.org/10.1503/cmaj.110749

Kirk, R., \& Day, A. (2011). Increasing college access for youth aging out of foster care: Evaluation of a summer camp program for foster youth transitioning from high school to college. Children and Youth Services Review, 33(7), 1173-1180. https://doi.org/10.1016/j.childyouth.2011.02.018

Laucht, M., Schmidt, M. H., \& Esser, G. (2004). The development of at-risk children in early life. Educational and Child Psychology, 21(1), 20-31.

Laursen, E. K., \& Birmingham, S. M. (2003). Caring relationships as a protective factor for atrisk youth: An ethnographic study. Families in Society: The Journal of Contemporary Social Services, 84(2), 240-246.https://doi.org/10.1606/1044-3894.101

Mahecha, J., \& Hanson, T. (2020). Measurement structure of the California school climate, health, and learning surveys: Student, staff, and parent surveys. WestEd. https://calschls.org/docs/measurementstructurecalschls_final.pdf

Maslow, A. H. (1943). A theory of human motivation. Psychological Review, 50(4), 370396. https://doi.org/10.1037/h0054346 
Masten, A. (2007). Resilience in developing systems: Progress and promise as the fourth wave rises. Development and Psychopathology, 23, 141-154.

https://doi.org/10.1017/S0954579407000442

Masten, A. (2014). Ordinary magic: Resilience in development. The Guilford Press.

Masten, A. S., Fiat, A. E., Labella, M. H., \& Strack, R. A. (2015). Educating homeless and highly mobile students: Implications of research on risk and resilience. School Psychology Review, 44(3), 315-330. https://doi.org/10.17105/spr-15-0068.1

Masten, A. S., \& Reed, M.-G. J. (2002). Resilience in development. In C. R. Snyder \& S. J. Lopez (Eds.), Handbook of positive psychology (pp. 74-88). Oxford University Press.

McKinney-Vento Homeless Education Assistance Improvements Act of 2001, 42 U.S.C. $\S$ 11431 et seq. (2004). https://www2.ed.gov/policy/elsec/leg/esea02/pg116.html

Meltzer, A., Quintero, D., \& Valant, J. (2019, October 24). Better serving the needs of America's homeless students. Brookings Institution. https:/www.brookings.edu/blog/brown-centerchalkboard/2019/10/24/better-serving-the-needs-of-americas-homelessstudents/\#: :text=The\%20homeless\%20student\%20population $\% 20$ has, the $\% 202016 \% 2 \mathrm{D}$ $17 \% 20$ school $\% 20$ year

Mertler, C., \& Reinhart, R. (2017). Advanced and multivariate statistical methods: Practical application and interpretation (6th ed.). Routledge.

Mertler, C., \& Vannatta, R. (2013). Advanced and multivariate statistical methods (5th ed.). Pyrczak.

Mota, C. P., \& Matos, P. M. (2012). Peer attachment, coping, and self-esteem in institutionalized adolescents: The mediating role of social skills. European Journal of Psychology of Education, 28(1), 87-100. https://doi.org/10.1007/s10212-012-0103-z 
National Center for Homeless Education. (2019). Data and statistics on homelessness. https://nche.ed.gov/data-and-stats/

National Survey of Child and Adolescent Well Being. (2013). National survey of child and adolescent well-being (NSCAW), 1997-2014 and 2015-2022. https://www.acf.hhs.gov/opre/research/project/national-survey-of-child-and-adolescentwell-being-nscaw

Neal, D. (2017). Academic resilience and caring adults: The experiences of former foster youth. Children and Youth Services Review, 79, 242-248. https://doi.org/10.1016/j.childyouth.2017.06.005

Newton, R. R., Litrownik, A. J., \& Landsverk, J. A. (2000). Children and youth in foster care: Disentangling the relationship between problem behaviors and number of placements. Child Abuse \& Neglect, 24(10), 1363-1374. https://doi.org/10.1016/s01452134(00)00189-7

Nowicki, M., Brickell, K., \& Harris, E. (2019). The hotelisation of the housing crisis: Experiences of family homelessness in Dublin hotels. The Geographical Journal, 185(3), 313-324. https://doi.org/10.1111/geoj.12307

Nunnally, J. C. (1978). Psychometric theory (2nd ed.). McGraw-Hill.

Obradović, J., Long, J. D., Cutuli, J. J., Chan, C.-K., Hinz, E., Heistad, D., \& Masten, A. S. (2009). Academic achievement of homeless and highly mobile children in an urban school district: Longitudinal evidence on risk, growth, and resilience. Development and Psychopathology, 21(2), 493-518. https://doi.org/10.1017/s0954579409000273

Oddone, A. (2002). Promoting resilience in an "at risk" world. Childhood Evaluation, 78(5), $274-277$. 
O'Leary, V. E. (1998). Strength in the face of adversity: Individual and social thriving. Journal of Social Issues, 54(2), 425-446. https://doi.org/10.1111/0022-4537.751998075

Pallant, J. (2016). SPSS survival manual (6th ed.). McGraw Hill Education.

Pecora, P. J. (2012). Maximizing educational achievement of youth in foster care and alumni: Factors associated with success. Children and Youth Services Review, 34(6), 1121-1129. https://doi.org/10.1016/j.childyouth.2012.01.044

Pecora, P. J., Williams, J., Kessler, R. C., Hiripi, E., O’Brien, K., Emerson, J., Herrick, M., Torres, D. (2006). Assessing the educational achievements of adults who were formerly placed in family foster care. Child Family Social Work, 11(3), 220-231. https://doi.org/10.1111/j.1365-2206.2006.00429.x

Perry, B. (2007). Stress, trauma and post-traumatic stress disorders in children: An introduction. The Child Trauma Academy. https://childtrauma.org/wpcontent/uploads/2013/11/PTSD_Caregivers.pdf

Perry, B. D., \& Hambrick, E. P. (2008). The neurosequential model of therapeutics. Reclaiming Children and Youth, 17(3), 38-43.

Perry, B. D., \& Szalavitz, M. (2017). The boy who was raised as a dog: And other stories from a child psychiatrist's notebook: What traumatized children can teach us about loss, love, and healing. Basic Books.

Pilowsky, D., \& Wu, L. (2006). Psychiatric symptoms and substance use disorders in a nationally representative sample of American adolescents involved with foster care. Journal of Adolescent Health, 38(4), 351-358.

Plumb, J., Bush, K., \& Kersevich, S. (2016). Trauma-sensitive schools: An evidence-based approach. School Social Work Journal, 40(2), 37-60. 
Porche, M., Costello, D., \& Rosen-Reynoso, M. (2016). Adverse family experiences, child mental health, and educational outcomes for a national sample of students. School Mental Health, 8, 44-60.

Radcliff, E., Crouch, E., Strompolis, M., \& Srivastav, A. (2019). Homelessness in childhood and adverse childhood experiences (ACEs). Maternal and Child Health Journal, 23, 811820.

Riley, P. (2011). Attachment theory and the teacher-student relationship: A practical guide for teachers, teacher educators and school leaders. Routledge.

Robinson-Simpian, J. P. (2014). Inaccurate estimation of disparities due to mischievous responders: Several suggestions to assess conclusions. Educational Researcher, 43(4), 171-185. https://doi.org/10.3102/0013189X14534297

Rodriguez, J. M., \& Shinn, M. (2016). Intersections of family homelessness, CPS involvement, and race in Alameda County, California. Child Abuse \& Neglect, 57, 41-52. https://doi.org/10.1016/j.chiabu.2016.06.004

Rosenman, R., Tennekoon, V., \& Hill, L. G. (2011). Measuring bias in self-reported data. International Journal of Behavioral Healthcare Research, 2(4), 320-332. https://doi.org/10.1504/IJBHR.2011.043414

Siegel, D. J., \& Bryson, T. P. (2020). The power of showing up: How parental presence shapes who our kids become and how their brains get wired. Ballantine Books.

Sikorska, I. (2014). Theoretical models of resilience and resilience measurement tools in children and young people. In T. M. Ostrowski \& I. Sikorska (Eds.), Health and resilience (pp. 85-100). Jagiellonian University Press. 
Strolin-Goltzman, J., Woodhouse, V., Suter, J., \& Werrbach, M. (2016). A mixed method study on educational well-being and resilience among youth in foster care. Children and Youth Services Review, 70, 30-36. https://doi.org/10.1016/j.childyouth.2016.08.014

Substance Abuse and Mental Health Services Administration. (2014). Trauma and violence. https://www.samhsa.gov/trauma-violence

Tabachnick, B. G., \& Fidell, L. S. (2007). Using multivariate statistics (5th ed.). Allyn \& Bacon/Pearson Education.

Taussig, H. N. (2002). Risk behaviors in maltreated youth placed in foster care: A longitudinal study of protective and vulnerability factors. Child Abuse \& Neglect, 26(11), 1179-1199. https://doi.org/10.1016/s0145-2134(02)00391-5

Taylor, L., \& Adelman, H. S. (2004). Advancing mental health in schools-Guiding frameworks and strategic approaches. In K. E. Robinson (Ed.), Advances in school-based mental health interventions: Best practices and program models (pp. 1-23). Civic Research Institute.

The Annie E. Casey Foundation. (2011). More children in foster care raised by relatives in 2011. https://www.aecf.org/blog/more-children-in-foster-care-raised-by-relatives-in2011/

The Homelessness Research Institute. (2016). 2016 continuum of care resources. https://endhomelessness.org/resource/2016-continuum-of-care-resources/

Tronto, J. C. (1993). Moral boundaries: A political argument for an ethic of care. Routledge.

Turney, K., \& Wildeman, C. (2016). Mental and physical health of children in foster care. Pediatrics, 138(5), Article e2016118. https://doi.org/10.1542/peds.2016-1118 
Turney, K., \& Wildeman, C. (2017). Adverse childhood experiences among children placed in and adopted from foster care: Evidence from a nationally representative survey. Child Abuse \& Neglect, 64, 117-129. https://doi.org/10.1016/j.chiabu.2016.12.009

Van der Kolk, B. A. (2005). Developmental trauma disorder: Toward a rational diagnosis for children with complex trauma histories. Psychiatric Annals, 35(5), 401-408. https://doi.org/10.3928/00485713-20050501-06

Van der Kolk, B. A. (2015). The body keeps the score: Brain, mind, and body in the healing of trauma. Penguin Books.

Van Leeuwen, B., \& Merry, M. (2018). Should the homeless be forcibly helped? Public Health Ethics, 12(1), 30-43. https://doi.org/10.1093/phe/phy006

Votta, E., \& Manion, I. (2004). Suicide, high-risk behaviors, and coping style in homeless adolescent males' adjustment. Journal of Adolescent Health, 34(3), 237-324. https://doi.org/10.1016/j.jadohealth.2003.06.002

Waters, R. (2020). Despite education reforms, foster students in California lag far behind on multiple measures. EdSource. https://edsource.org/2019/despite-education-reformsfoster-students-in-california-lag-far-behind-on-multiple-measures/611086

Werner, E. (2005). Resilience and recovery: Findings from the Kauai Longitudinal Study. Research, Policy, and Practice in Children's Mental Health, 19(1), 11-14.

Werner, E., \& Smith, R. (1992). Overcoming the odds: High-risk children from birth to adulthood. Cornell University Press.

Werner, E., \& Smith, R. (2001). Journeys from childhood to midlife: Risk, resilience, and recovery. Cornell University Press. 
WestEd. (n.d.). California safe and supportive schools S32 factsheet. https://data.calschls.org/resources/S3factsheet2_participation_20120224.pdf

WestEd. (2011). Measurement analysis of CHKS Core and School Climate Module items. http://surveydata.wested.org/resources/S3_CHKS_FactorAnalysis.pdf

WestEd. (2017, January). California Healthy Kids Survey. http://chks.wested.org/

Wheelan, C. (2013). Naked statistics: Stripping the dread from the data. W.W. Norton \& Company.

Wildeman, C., \& Emanuel, N. (2014). Cumulative risks of foster care placement by age 18 for U.S. children, 2000-2011. PLOS ONE, 9(3), Article e92785. https://doi.org/10.1371/journal.pone.0092785

Wilson, D. (2004). The interface of school climate and school connectedness and relationships with aggression and victimization. Journal of School Health, 74(7), 293-299. https://doi.org/10.1111/j.1746-1561.2004.tb08286.x

Wolpow, R., Johnson, M. M., Hertel, R., \& Kincaid, S. O. (2009). The heart of learning ad teaching: Compassion, resiliency, and academic success. State Office of Superintendent of Public Instruction, Compassionate Schools. https://www.k12.wa.us/sites/default/files/public/compassionateschools/pubdocs/thehearto flearningandteaching.pdf

Wright, M., Masten, A., \& Narayan, A. (2013). Resilience processes in development: Four waves of research on positive adaptation in the context of adversity. In S. Goldstein \& R. B. Brooks (Eds.), Handbook of resilience in children (pp. 15-37). Springer. 
World Health Organization. (2018). Millennium development goals.

https://www.who.int/en/news-room/fact-sheets/detail/millennium-development-goals(mdgs)

Zetlin, A., Macleod, E., \& Kimm, C. (2010). Beginning teacher challenges instructing students who are in foster care. Remedial and Special Education, 33(1), 4-13.

https://doi.org/10.1177/0741932510362506 
APPENDIX

\title{
California Healthy Kids Survey
}

\author{
C A L IFORNIA healthykids SURVE Y \\ Core Module
}

High School Questionnaire

2017-2018

This survey asks about your behavior, experiences, and attitudes related to your school, health, and well-being. It includes questions about use of alcohol, tobacco, and other drugs, and about bullying and violence.

You do not have to answer these questions, but your answers will be very helpful in improving school and health programs. You will be able to answer whether or not you have done or experienced any of these things.

Please do not write your name on this form or the answer sheet. Do not identify yourself in any other way.

Please mark all of your answers on the answer sheet. Fill in the bubbles neatly with a \#2 pencil. Do not write on the questionnaire. Mark only one answer unless told to "Mark All That Apply."

This survey asks about things you may have done during different periods of time, such as during your lifetime (you ever did something), or the past 12 months, or 30 days. Each provides different information. Please pay careful attention to these time periods.

Thank you for taking this survey!

$\sim 1 \sim$




\section{A L I F OR N I healthykids $S$ U R E Y Core Module}

\section{Begin by writing your school's name at the top of the answer sheet.}

1. Fill in the bubble for the letter " $\mathrm{H}$."

2. $\quad$ Fill in the bubble for the letter "K."

\section{Next, we would like some background information about you.}

3. What is your sex?
A) Male

B) Female

4. What grade are you in?
A) 6th grade
F) 11th grade
B) 7th grade
C) 8th grade
D) 9th grade
G) 12th grade
H) Other grade
E) 10th grade
I) Ungraded

5. Are you of Hispanic or Latino origin?
A) $\mathrm{No}$
B) Yes

6. What is your race?
A) American Indian or Alaska Native
D) Native Hawaiian or Pacific Islander
B) Asian
E) White
C) Black or African American
F) Mixed (two or more) races 


\section{A L I F O R N I A healthykids $S$ U R E Y}

\section{Core Module}

7. If you are Asian or Pacific Islander, which groups best describe you? (Mark All That Apply.) If you are not of Asian/Pacific Islander background, mark "A) Does not apply."
A) Does not apply; I am not Asian or
H) Korean
Pacific Islander
I) Laotian
B) Asian Indian
J) Vietnamese
C) Cambodian
D) Chinese
K) Native Hawaiian, Guamanian, Samoan, Tahitian, or other Pacific
E) Filipino Islander
F) Hmong
L) Other Asian

G) Japanese

8. What best describes where you live? A home includes a house, apartment, trailer, or mobile home.
A) A home with one or more parent or
F) Hotel or motel guardian
B) Other relative's home
G) Shelter, car, campground, or other
transitional or temporary housing
C) A home with more than one family
H) Other living arrangement

D) Friend's home
E) Foster home, group care, or waiting placement

9. What is the highest level of education your parents or guardians completed? (Mark the educational level of the parent or guardian who went the furthest in school.)
A) Did not finish high school
B) Graduated from high school
C) Attended college but did not complete four-year degree
D) Graduated from college
E) Don't know

10. Do you receive free or reduced-price lunches at school? (Receiving free or reduced-price lunches means that lunch at school is provided to you for free or you pay less for it.)
A) No
B) Yes
C) Don't know

11. In the past three years, were you part of the Migrant Education Program or did your family move to find seasonal or temporary work in agriculture or fishing?
A) No
B) Yes
C) Don't know 


\section{A L I F OR N I A healthykids $S$ U R E Y}

\section{Core Module}

12. What language is spoken most of the time in your home?
A) English
F) Tagalog
B) Spanish
G) Vietnamese
C) Mandarin
H) Korean
D) Cantonese
I) Other
E) Taiwanese

How well do you understand, speak, read, and write English?

13. Understand English

14. Speak English

15. Read English

16. Write English

\begin{tabular}{|c|c|c|c|}
\hline $\begin{array}{l}\text { Very } \\
\text { Well }\end{array}$ & Well & $\begin{array}{l}\text { Not } \\
\text { Well }\end{array}$ & $\begin{array}{c}\text { Not } \\
\text { At All }\end{array}$ \\
\hline A & B & C & D \\
\hline A & B & C & D \\
\hline A & B & C & D \\
\hline A & B & $\mathrm{C}$ & D \\
\hline
\end{tabular}

17. How many days a week do you usually go to your school's after school program?
A) 0 days
E) 4 days
B) 1 day
F) 5 days
C) 2 days
D) 3 days

18. During the past 12 months, how would you describe the grades you mostly received in school?
A) Mostly A's
E) Mostly C's
B) A's and B's
F) C's and D's
C) Mostly B's
D) B's and C's
G) Mostly D's
H) Mostly F's

19. In the past 30 days, how often did you miss an entire day of school for any reason?
A) I did not miss any days of school in
C) 2 days the past 30 days
D) 3 or more days
B) 1 day 


\section{A L IFORNIA healthykids SURVEY Core Module}

\section{Please mark on your answer sheet how TRUE you feel each of the following statements is about your SCHOOL and things you might do there.}

At my school, there is a teacher or some other adult ...

35. who really cares about me.

36. who tells me when I do a good job.

37. who notices when I'm not there.

38. who always wants me to do my best.

39. who listens to me when I have something to say.

40. who believes that I will be a success.

\begin{tabular}{|c|c|c|c|}
\hline $\begin{array}{l}\text { Not At All } \\
\text { True }\end{array}$ & $\begin{array}{c}\text { A Little } \\
\text { True }\end{array}$ & $\begin{array}{c}\text { Pretty Much } \\
\text { True } \\
\end{array}$ & $\begin{array}{c}\text { Very Much } \\
\text { True }\end{array}$ \\
\hline A & B & C & $\mathrm{D}$ \\
\hline A & B & $\mathrm{C}$ & D \\
\hline A & B & C & $\mathrm{D}$ \\
\hline A & B & $\mathrm{C}$ & D \\
\hline A & B & C & D \\
\hline A & B & $\mathrm{C}$ & D \\
\hline
\end{tabular}

Atschool, ...

41. I do interesting activities.

42. I help decide things like class activities or rules.

43. I do things that make a difference.

44. I have a say in how things work.

45. I help decide school activities or rules.

\begin{tabular}{|c|c|c|c|}
\hline $\begin{array}{l}\text { Not At All } \\
\text { True } \\
\end{array}$ & $\begin{array}{c}\text { A Little } \\
\text { True }\end{array}$ & $\begin{array}{l}\text { Pretty Much } \\
\text { True } \\
\end{array}$ & $\begin{array}{c}\text { Very Much } \\
\text { True }\end{array}$ \\
\hline A & B & C & D \\
\hline A & B & C & D \\
\hline A & B & C & D \\
\hline A & B & C & $\mathrm{D}$ \\
\hline A & B & C & D \\
\hline
\end{tabular}

The next questions ask about the use of alcohol, tobacco, marijuana, and other drugs, including pills or medications, to get "high" or for reasons other than medical, as ordered or prescribed by a doctor.

\section{Keep the following definitions in mind:}

- One drink of ALCOHOL, or alcoholic drink (beverage), means one regular size can/bottle of beer or wine cooler, one glass of wine, one mixed drink, or one shot glass of liquor.

- Questions about alcohol do not include drinking a few sips of wine for religious purposes.

- DRUG means any substance other than alcohol or tobacco, including pills and medications, used to get "high" ("loaded", "stoned", or "wasted") or for purposes other than prescribed by a doctor. 


\section{A L I F OR N I A healthykids S U R V E \\ Core Module}

20. In the past $\mathbf{3 0}$ days, did you miss a day of school for any of the following reasons? (Mark All That Apply.)
A) Does not apply; I didn't miss any school
G) Had to take care of or help a family member or friend
B) Illness (feeling physically sick), including problems with breathing or your teeth
C) Were being bullied or mistreated at school
H) Wanted to spend time with friends
I) Use alcohol or drugs
J) Were behind in schoolwork or weren't prepared for a test or class assignment
D) Felt very sad, hopeless, anxious, stressed, or angry
K) Were bored or uninterested in school
E) Didn't get enough sleep
L) Had no transportation to school
M) Other reason
F) Didn't feel safe at school or going to and from school

21. During the past 12 months, about how many times did you skip school or cut classes?
A) 0 times
E) Twice a month
B) 1-2 times
F) Once a week
C) A few times
G) More than once a week
D) Once a month

How strongly do you agree or disagree with the following statements?

\begin{tabular}{|c|c|c|c|c|}
\hline & & $\begin{array}{l}\text { Neither } \\
\text { Disagree }\end{array}$ & & \\
\hline trong & & Nor & & Strongly \\
\hline Disagree & Disagree & Agree & Agree & Agree \\
\hline
\end{tabular}

22. I feel close to people at this school.

23. I am happy to be at this school.

24. I feel like I am part of this school.

25. The teachers at this school treat students fairly.

26. I feel safe in my school.

27. My school is usually clean and tidy.

28. Teachers at this school communicate with parents about what students are expected to learn in class.

$\begin{array}{lllll}\text { A } & \text { B } & \text { C } & \text { D } & \text { E }\end{array}$

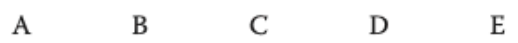

$\begin{array}{lllll}\text { A } & \text { B } & \text { C } & \text { D } & \text { E } \\ \text { A } & \text { B } & \text { C } & \text { D } & \text { E }\end{array}$

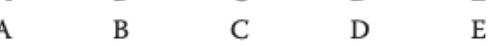

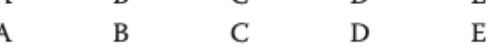

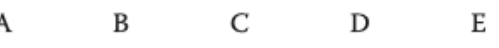

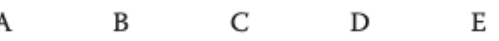

29. Parents feel welcome to participate at this school.

30. School staff takes parent concerns seriously.

31. I try hard to make sure that I am good at my schoolwork.

32. I try hard at school because I am interested in my work.

33. I work hard to try to understand new things at school.

$\begin{array}{lllll}\text { A } & \text { B } & \text { C } & \text { D } & \text { E } \\ \text { A } & \text { B } & \text { C } & \text { D } & \text { E } \\ \text { A } & \text { B } & \text { C } & \text { D } & \text { E }\end{array}$

34. I am always trying to do better in my schoolwork.

$\begin{array}{lllll}\text { A } & \text { B } & \text { C } & \text { D } & \text { E } \\ \text { A } & \text { B } & \text { C } & \text { D } & \text { E }\end{array}$




\section{A L I F OR N I A healthykids S U R V E Y}

\section{Core Module}

During your life, how many times have you used the following?

46. A whole cigarette

47. Smokeless tobacco (dip, chew, or snuff)

48. Electronic cigarettes, e-cigarettes, or other vaping device such as e-hookah, hookah pens, or vape pens

49. One full drink of alcohol (such as a can of beer, glass of wine, wine cooler, or shot of liquor)

50. Marijuana (smoke, vape, eat, or drink)

51. Inhalants (things you sniff, huff, or breathe to get "high" such as glue, paint, aerosol sprays, gasoline, poppers, gases)

52. Cocaine, Methamphetamine, or any amphetamines (meth, speed, crystal, crank, ice)

53. Derbisol

54. Heroin

55. Ecstasy, LSD, or other psychedelics (acid, mescaline, peyote, mushrooms)

56. Prescription pain medication or opioids (Vicodin ${ }^{\mathrm{m}}$, OxyContin" ${ }^{\mathrm{m}}$, Percodan ${ }^{\mathrm{mw}}$, Lortab ${ }^{\mathrm{m}}$ ), tranquilizers, or sedatives (Xanax ${ }^{\mathrm{mw}}$, Ativan ${ }^{\mathrm{w}}$ )

57. Diet Pills (Didrex, Dexedrine, Zinadrine, Skittles, M\&M's)

58. Ritalin ${ }^{\mathrm{m} *}$ or Adderall ${ }^{\mathrm{Tw}}$ or other prescription stimulant

59. Cold/Cough Medicines or other over-thecounter medicines to get "high"

60. Any other drug, pill, or medicine to get "high" or for reasons other than medical

Number of Times

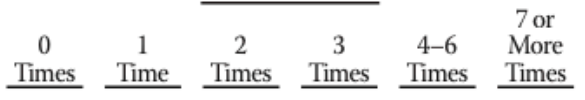

$\begin{array}{llllll}\text { A } & \text { B } & \text { C } & \text { D } & \text { E } & \text { F } \\ \text { A } & \text { B } & \text { C } & \text { D } & \text { E } & \text { F } \\ \text { A } & \text { B } & \text { C } & \text { D } & \text { E } & \text { F }\end{array}$

$\begin{array}{llllll}\text { A } & \text { B } & \text { C } & \text { D } & \text { E } & \text { F } \\ & & & & & \\ \text { A } & \text { B } & \text { C } & \text { D } & \text { E } & \text { F } \\ \text { A } & \text { B } & \text { C } & \text { D } & \text { E } & \text { F }\end{array}$

A $\quad$ B $\quad$ C $\quad$ D $\quad$ E $\quad$ F

$\begin{array}{llllll}\text { A } & \text { B } & \text { C } & \text { D } & \text { E } & \text { F }\end{array}$

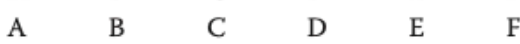

$\begin{array}{llllll}\text { A } & \text { B } & \text { C } & \text { D } & \text { E } & \text { F }\end{array}$

$\begin{array}{lllllll}\text { A } & \text { B } & \text { C } & \text { D } & \text { E } & \text { F }\end{array}$

$\begin{array}{llllll}\text { A } & \text { B } & \text { C } & \text { D } & \text { E } & \text { F }\end{array}$

$\begin{array}{lllllll}\text { A } & \text { B } & \text { C } & \text { D } & \text { E } & \text { F }\end{array}$

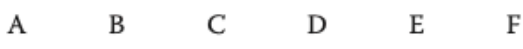

$\begin{array}{llllll}\text { A } & \text { B } & \text { C } & \text { D } & \text { E } & \text { F }\end{array}$ 


\section{A L I F OR N I A healthykids $S U R V E Y$ Core Module}

During your life, how many times have you been ...

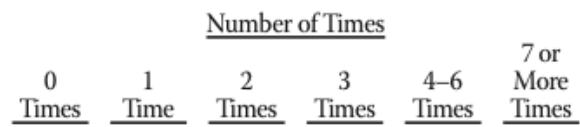

61. very drunk or sick after drinking alcohol?

62. "high" (loaded, stoned, or wasted) from using

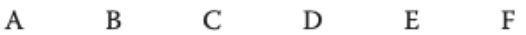
drugs?

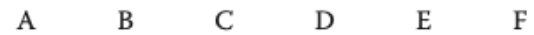

63. drunk on alcohol or "high" on drugs on school property?

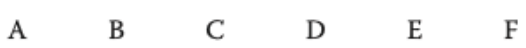

During your life, how many times have you used marijuana in any of the following ways:

Number of Times

\begin{tabular}{|c|c|c|c|c|c|}
\hline \multirow[b]{2}{*}{0} & \multirow[b]{2}{*}{1} & & \multirow{2}{*}{\multicolumn{2}{|c|}{$\begin{array}{l}7 \text { or } \\
\text { More }\end{array}$}} \\
\hline & & 2 & 3 & & \\
\hline Times & Time & Times & Times & Times & Times \\
\hline
\end{tabular}

64. Smoke it?

65. In an electronic or e-cigarette or other vaping device?

66. Eat or drink it in products made with marijuana?

$\begin{array}{llllll}\text { A } & \text { B } & \text { C } & \text { D } & \text { E } & \text { F } \\ \text { A } & \text { B } & \text { C } & \text { D } & \text { E } & \text { F } \\ & & & & & \\ \text { A } & \text { B } & \text { C } & \text { D } & \text { E } & \text { F }\end{array}$




\section{A L I F OR N I A healthykids $S$ U V E Y}

\section{Core Module}

During the past 30 days, on how many days did you use ...

67. cigarettes?

68. smokeless tobacco (dip, chew, or snuff)?

69. electronic cigarettes, e-cigarettes, or other vaping device such as e-hookah, hookah pens, or vape pens?

70. one or more drinks of alcohol?

71. five or more drinks of alcohol in a row, that is, within a couple of hours?

72. marijuana (smoke, vape, eat, or drink)?

73. inhalants (things you sniff, huff, or breathe to get "high")?

74. prescription drugs to get "high" or for reasons other than prescribed?

75. any other drug, pill, or medicine to get "high" or for reasons other than medical?

76. two or more substances at the same time (for example, alcohol with marijuana, ecstasy with mushrooms)?

\begin{tabular}{|c|c|c|c|c|c|}
\hline $\begin{array}{c}0 \\
\text { Days }\end{array}$ & $\begin{array}{c}1 \\
\text { Day }\end{array}$ & $\begin{array}{c}2 \\
\text { Days }\end{array}$ & $\begin{array}{l}3-9 \\
\text { Days }\end{array}$ & $\begin{array}{c}10-19 \\
\text { Days } \\
\end{array}$ & $\begin{array}{c}20-30 \\
\text { Days } \\
\end{array}$ \\
\hline A & B & C & D & $\mathrm{E}$ & $\mathrm{F}$ \\
\hline A & B & C & D & $\mathrm{E}$ & F \\
\hline A & B & C & D & $E$ & F \\
\hline
\end{tabular}

$\begin{array}{llllll}\text { A } & \text { B } & \text { C } & \text { D } & \text { E } & \text { F }\end{array}$

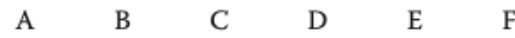

$\begin{array}{lllllll}\text { A } & \text { B } & \text { C } & \text { D } & \text { E } & \text { F }\end{array}$

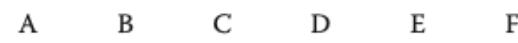

A $\quad$ B $\quad$ C $\quad$ D $\quad$ E $\quad$ F

$\begin{array}{llllllllllllllllllll}\text { A } & \text { B } & \text { C } & \text { D } & \text { E } & \text { F }\end{array}$

$\begin{array}{llllll}\text { A } & \text { B } & \text { C } & \text { D } & \text { E } & \text { F }\end{array}$ 


\section{A L I F OR N I A healthykids S U R V E}

\section{Core Module}

During the past 30 days, on how many days on school property did you use ...

cigarettes?

78. smokeless tobacco (dip, chew, or snuff)?

79. electronic cigarettes, e-cigarettes, or other vaping device such as e-hookah, hookah pens, or vape pens?

\begin{tabular}{|c|c|c|c|c|c|}
\hline $\begin{array}{c}0 \\
\text { Days }\end{array}$ & $\begin{array}{c}1 \\
\text { Day }\end{array}$ & $\begin{array}{c}2 \\
\text { Days } \\
\end{array}$ & $\begin{array}{l}3-9 \\
\text { Days }\end{array}$ & $\begin{array}{c}10-19 \\
\text { Days } \\
\end{array}$ & $\begin{array}{c}20-30 \\
\text { Days }\end{array}$ \\
\hline A & B & C & D & $\mathrm{E}$ & F \\
\hline A & B & C & D & $\mathrm{E}$ & $\mathrm{F}$ \\
\hline A & B & C & $\mathrm{D}$ & $\mathrm{E}$ & F \\
\hline A & B & $\mathrm{C}$ & $\mathrm{D}$ & $\mathrm{E}$ & $\mathrm{F}$ \\
\hline A & B & C & $\mathrm{D}$ & $\mathrm{E}$ & $\mathrm{F}$ \\
\hline A & B & $\mathrm{C}$ & D & E & F \\
\hline
\end{tabular}

How much do people risk harming themselves physically and in other ways when they do the following?

83. Smoke cigarettes occasionally

84. Smoke 1 or more packs of cigarettes each day

85. Use e-cigarettes (electronic) or vaping device occasionally compared to smoking cigarettes

How Much Risk or Harm

\begin{tabular}{|c|c|c|c|}
\hline Great & Moderate & $\begin{array}{l}\text { Risk or } \\
\text { Slight }\end{array}$ & None \\
\hline A & B & C & $\mathrm{D}$ \\
\hline A & B & C & D \\
\hline A & B & C & D \\
\hline A & B & C & D \\
\hline A & B & C & $\mathrm{D}$ \\
\hline A & B & C & $\mathrm{D}$ \\
\hline A & B & C & D \\
\hline A & B & C & $\mathrm{D}$ \\
\hline
\end{tabular}

90. Use marijuana daily

How difficult is it for students in your grade to get any of the following if they really want them?

91. Cigarettes

92. E-cigarettes (electronic) or vaping device

93. Alcohol

94. Marijuana

\begin{tabular}{|c|c|c|c|c|}
\hline $\begin{array}{c}\text { Very } \\
\text { Difficult }\end{array}$ & $\begin{array}{c}\text { Fairly } \\
\text { Difficult } \\
\end{array}$ & $\begin{array}{r}\text { Fairly } \\
\text { Easy }\end{array}$ & $\begin{array}{l}\text { Very } \\
\text { Easy }\end{array}$ & $\begin{array}{l}\text { Don't } \\
\text { Know }\end{array}$ \\
\hline A & B & C & D & $\mathrm{E}$ \\
\hline A & B & C & D & $E$ \\
\hline A & B & C & D & $\mathrm{E}$ \\
\hline A & B & C & D & $\mathrm{E}$ \\
\hline
\end{tabular}

How many times have you tried to quit or stop using...

$\begin{array}{ll}\text { 95. } & \text { cigarettes? } \\ \text { 96. } & \text { alcohol? } \\ \text { 97. } & \text { marijuana? }\end{array}$

\begin{tabular}{|c|c|c|c|c|}
\hline $\begin{array}{c}\text { Does Not } \\
\text { Apply, } \\
\text { Don't Use }\end{array}$ & 0 Times & 1Time & $\begin{array}{c}2-3 \\
\text { Times }\end{array}$ & $\begin{array}{l}\text { 4 or } \\
\text { More } \\
\text { Times }\end{array}$ \\
\hline A & B & C & D & E \\
\hline A & B & C & D & $\mathrm{E}$ \\
\hline A & B & C & D & E \\
\hline
\end{tabular}

California Healthy Kids Survey C2017 CA Dept. of Ed.

High School Questionnaire

Version H21 - Fall 2017-Spring 2018

core Module 


\section{A L I F OR N I healthykids $S$ U R V Y \\ Core Module}

98. During your life, how many times have you ever driven a car when you had been using alcohol or drugs, or been in a car driven by a friend when he or she had been using?
A) Never
B) 1 time
C) 2 times
D) 3 to 6 times
E) 7 or more times

\section{Next are questions about violence, safety, harassment, \& bullying on school property.}

99. How safe do you feel when you are at school?
A) Very safe
B) Safe
C) Neither safe nor unsafe
D) Unsafe
E) Very unsafe

During the past 12 months, how many times on school property have you...

\section{0. been pushed, shoved, slapped, hit, or kicked by someone who wasn't just kidding around? \\ 101. been afraid of being beaten up? \\ 102. been in a physical fight? \\ 103. had mean rumors or lies spread about you? \\ 104. had sexual jokes, comments, or gestures made to you?}

105. been made fun of because of your looks or the way you talk?

106. had your property stolen or deliberately damaged, such as your car, clothing, or books?

107. been offered, sold, or given an illegal drug?

108. damaged school property on purpose?

109. carried a gun?

110. carried any other weapon (such as a knife or club)?

111. been threatened or injured with a weapon (gun, knife, club, etc.)?

112. seen someone carrying a gun, knife, or other weapon?

113. been threatened with harm or injury?

114. been made fun of, insulted, or called names?
Happened on School Property

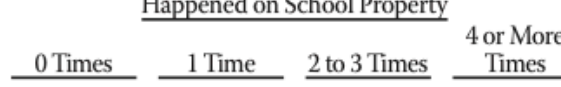

\begin{tabular}{|c|c|c|c|}
\hline A & B & C & D \\
\hline A & B & C & D \\
\hline A & B & C & D \\
\hline A & B & C & D \\
\hline A & B & C & D \\
\hline A & B & C & D \\
\hline $\mathrm{A}$ & B & C & D \\
\hline A & B & C & D \\
\hline A & B & C & D \\
\hline A & B & C & D \\
\hline A & B & C & D \\
\hline A & B & C & D \\
\hline A & B & C & D \\
\hline A & B & C & D \\
\hline A & B & C & D \\
\hline
\end{tabular}




\section{A L I F OR N I A healthykids S U R V Y}

\section{Core Module}

During the past 12 months, how many times on school property were you harassed or bullied for any of the following reasons? [You were bullied if you were shoved, hit, threatened, called mean names, teased, or had other unpleasant physical or verbal things done to you repeatedly or in a severe way. It is not bullying when two students of about the same strength or power quarrel or fight.]

115. Your race, ethnicity, or national origin

\begin{tabular}{|c|c|c|c|}
\hline 0 Times & 1 Time & 2 to 3 Times & $\begin{array}{c}4 \text { or More } \\
\text { Times }\end{array}$ \\
\hline A & B & C & D \\
\hline A & B & $\mathrm{C}$ & D \\
\hline A & B & C & D \\
\hline A & B & C & D \\
\hline
\end{tabular}

Your religion

117. Your gender

118. Because you are gay or lesbian or someone thought you were

119. A physical or mental disability

120. You are an immigrant or someone thought you were

A $\quad$ B $\quad$ C $\quad$ D

121. Any other reason

A

B $\quad$ C $\quad$ D

122. During the past 12 months, how many times did other students spread mean rumors or lies, or hurtful pictures, about you online, on social media, or on a cell phone?
A) 0 times (never)
B) 1 time
C) 2-3 times
D) 4 or more times

123. Do you consider yourself a member of a gang?
A) No
B) Yes

124. During the past 12 months, did you ever feel so sad or hopeless almost everyday for two weeks or more that you stopped doing some usual activities?
A) No
B) Yes

125. During the past 12 months, did you ever seriously consider attempting suicide?
A) No
B) Yes

126. Did you eat breakfast today?
A) No
B) Yes 


\section{A L I F OR N I A healthykids $S$ U V E Y}

\section{Core Module}

127. How many questions in this survey did you answer honestly?
A) All of them
B) Most of them
C) Only some of them
D) Hardly any

128. Is your father, mother, or guardian currently in the military (Army, Navy, Marines, Air Force, National Guard, or Reserves)?
A) No
B) Yes
C) Don't know

129. Which of the following best describes you?
A) Straight (not gay)
B) Gay or Lesbian
C) Bisexual
D) I am not sure yet
E) Something else
F) Decline to respond

130. Some people describe themselves as transgender when their sex at birth does not match the way they think or feel about their gender. Are you transgender?
A) No, I am not transgender
B) Yes, I am transgender
C) I am not sure if I am transgender
D) Decline to respond 


\section{CALIFORNIA healthykids SUR VEY Core Module}

\section{High School Questionnaire}

2018-2019

This survey asks about your behavior, experiences, and attitudes related to your school, health, and well-being. It includes questions about use of alcohol, tobacco, and other drugs, and about bullying and violence.

You do not have to answer these questions, but your answers will be very helpful in improving school and health programs. You will be able to answer whether or not you have done or experienced any of these things.

Please do not write your name on this form or the answer sheet. Do not identify yourself in any other way.

Please mark all of your answers on the answer sheet. Fill in the bubbles neatly with a \#2 pencil. Do not write on the questionnaire. Mark only one answer unless told to "Mark All That Apply."

This survey asks about things you may have done during different periods of time, such as during your lifetime (you ever did something), or the past 12 months, or 30 days. Each provides different information. Please pay careful attention to these time periods.

\section{Thank you for taking this survey!}




\section{A L I FOR N I A healthykids SURVE Core Module}

Begin by writing your school's name at the top of the answer sheet.

1. Fill in the bubble for the letter "H."

2. Fill in the bubble for the letter "L."

\section{Next, we would like some background information about you.}

3. What is your sex?

A) Male

B) Female

4. What grade are you in?
A) 6th grade
F) 11th grade
B) 7 th grade
G) 12th grade
C) 8 th grade
D) 9 th grade
H) Other grade
I) Ungraded

E) 10th grade

5. Are you of Hispanic or Latino origin?
A) No
B) Yes

6. What is your race?
A) American Indian or A laska Native
D) Native Hawaiian or Pacific Islander
B) Asian
E) White
C) Black or African Americ an
F) Mixed (two or more) races 


\section{A L I FOR N A healthykids SUR V E Y Core Module}

7. If you are Asian or Pacific Islander, which groups best describe you? (Mark All That Apply.) If y ou are not of Asian/Pacific Islander background, mark "A) Does not apply."
A) Does not apply; I am not Asian or
H) Korean Pacific Islander
I) Laotian
B) Asian Indian
J) Vietnamese
C) Cambodian
K) Native Hawaiian, Guamanian,
D) Chinese
E) Filipino Samoan, Tahitian, or other
F) Hmong Pacific Islander
G) Japanese
L) Other Asian

8. What best describes where you live? A home includes a house, apartment, trailer, or mobile home.
A) A home with one or more parent or guardian
E) Foster home, group care, or waiting placement
B) Other relative's home
C) A home with more than one family
D) Friend's home
F) Hotel or motel
G) Shelter, car, campground, or other transitional or temporary housing
H) Other living arrangement

9. What is the highest level of education your parents or guardians completed? (Mork the educational level of the parent or guardian who went the furthest in school.)
A) Did not finish high school
B) Graduated from high school
C) Attended college but did not complete four-year degree
D) Graduated from college
E) Don't know

10. Do you receive free or reduced-price lunches at school? (Receiving free or reduced-price lunches means that lunch at school is provided to you for free or you pay less for it.)
A) No
B) Yes
C) Don't know

11. In the past three years, were you part of the Migrant Education Program or did your family move to find seasonal or temporary work in agriculture or fishing?
A) No
B) Yes
C) Don't know 


\section{A L I FOR N A healthykids SUR V E Y Core Module}

12. What language is spoken most of the time in your home?
A) English
F) Tagalog
B) Spanish
G) Vietnamese
C) Mandarin
H) Korean
D) Cantonese
I) Other

E) Taiwanese

How well do you understand, speak, read, and write English?

13. Understand English

\begin{tabular}{|c|c|c|c|}
\hline $\begin{array}{l}\text { Very } \\
\text { Well }\end{array}$ & Well & $\begin{array}{l}\text { Not } \\
\text { Well }\end{array}$ & $\begin{array}{l}\text { Not } \\
\text { At All }\end{array}$ \\
\hline $\mathrm{A}$ & B & $\mathrm{C}$ & D \\
\hline $\mathrm{A}$ & B & C & D \\
\hline $\mathrm{A}$ & B & $\mathrm{C}$ & D \\
\hline A & B & $\mathrm{C}$ & D \\
\hline
\end{tabular}

17. How many days a week do you usually go to your school's afterschool program?
A) 0 days
E) 4 days
B) 1 day
F) 5 days
C) 2 days
D) 3 days

18. During the past 12 months, how would you describe the grades you mostly received in school?
A) Mostly A's
E) Mostly C's
B) A's and B's
F) C's and D's
C) Mostly B's
G) Mostly D's
D) B's and C's
H) Mostly F's

19. In the past 30 days, how often did you miss an entire day of school for any reason?
A) I did not miss any days of school
C) 2 days in the past 30 days
D) 3 or more days
B) 1 day 


\section{A L I FOR N I A healthykids SUR V E Y Core Module}

20. In the past 30 days, did you miss a day of school for any of the following reasons? (Mark All That Apply.)

A) Does not apply; I didn't miss any school

G) Had to take care of or help a family member or friend

B) Illness (feeling physically sick), including problems with breathing or your teeth

C) Were being bullied or mistreated at school

H) Wanted to spend time with friends

I) Used alcohol or drugs

J) Were behind in schoolwork or weren't prepared for a test or class assignment

D) Felt very sad, hopeless, anxious, stressed, or angry

K) Were bored or uninterested in school

E) Didn't get enough sleep

L) Had no transportation to school

F) Didn't feel safe at school or going

M) Other reason to and from school

21. During the past 12 months, about how many times did you skip school or cut classes?
A) 0 times
E) Twice a month
B) 1-2 times
F) Once a week
C) A few times
G) More than once a week
D) Once a month

How strongly do you agree or disagree with the following statements?

22. I feel close to people at this school. $\begin{array}{lcc}\text { Strongly } & \begin{array}{c}\text { Disagree } \\ \text { Disagree }\end{array} \text { Disagree } & \text { Nor Agree } \\ \text { Agree } & \begin{array}{c}\text { Strongly } \\ \text { Agree }\end{array}\end{array}$

23. I am happy to be at this school.

A

B

C

A $\quad$ B

C

D

E

24. I feel like I am part of this school.

25. The teachers at this school treat students fairly.

A $\quad$ B

26. I feel safe in my school.

27. My school is usually clean and tidy.

28. Teachers at this school communic ate with parents about what students are expected to learn in class.

29. Parents feel welcome to participate at this school.

30. School staff take parent concerns seriously.

31. I try hard to make sure that I am good at my schoolwork.

32. I try hard at school because I am interested in my work.

33. I work hard to try to understand new things at school.

34. I am always trying to do better in my schoolwork.

A B

C D E 


\section{A L I FOR N I A healthy kids SUR V E Y Core Module}

Please mark on your answer sheet how TRUE you feel each of the following statements is about your SCHOOL and things you might do there.

At my school, there is a teacher or some other adult..

35. who really cares about me.

Not At All A Little PrettyMuch Very Much

36. who tells me when I do a good job.

True
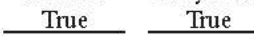
True

37. who notices when I'm not there.

38. who always wants me to do my best.

39. who listens to me when I have something to say.

40. who believes that I will be a success.

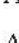

A

$\mathrm{C}$

D

Atschool,..

41. I do interesting activities.

\begin{tabular}{|c|c|c|c|}
\hline $\begin{array}{c}\text { Not At All } \\
\text { True }\end{array}$ & $\begin{array}{c}\text { A Little } \\
\text { True }\end{array}$ & $\begin{array}{l}\text { Pretty Much } \\
\text { True }\end{array}$ & $\begin{array}{c}\text { Very Much } \\
\text { True }\end{array}$ \\
\hline $\mathrm{A}$ & B & $\mathrm{C}$ & D \\
\hline $\mathrm{A}$ & B & $\mathrm{C}$ & D \\
\hline $\mathrm{A}$ & B & $\mathrm{C}$ & D \\
\hline $\mathrm{A}$ & B & $\mathrm{C}$ & $\mathrm{D}$ \\
\hline A & B & $\mathrm{C}$ & D \\
\hline
\end{tabular}

42. I help decide things like class activities or rules.

43. I do things that make a difference.

44. I have a say in how things work.

45. I help decide school activities or rules.

\section{A}

A

A

A

A

B $\quad$ C $\quad$ D

B $\quad$ C $\quad$ D

B $\quad$ C $\quad$ D

B C D

B $\quad$ C $\quad$ D

The next questions ask about the use of alcohol, tobacco, marijuana, and other drugs, including pills or medications, to get "high" or for reasons other than medical, as ordered or prescribed by a doctor.

\section{Keep the following definitions in mind:}

- One drink of ALCOHOL, or alcoholic drink (beverage), means one regular size can/bottle of beer or wine cooler, one glass of wine, one mixed drink, or one shot glass of liquor.

- Questions about alcohol do not include drinking a few sips of wine for religious purposes.

- DRUG means any substance other than alcohol or tobacco, including pills and medications, used to get "high" ("loaded," "stoned," or "wasted") or for purposes other than prescribed by a doctor. 


\section{A L I FOR N I A healthy kids SUR V E Y Core Module}

During your life how many times have you used the following?

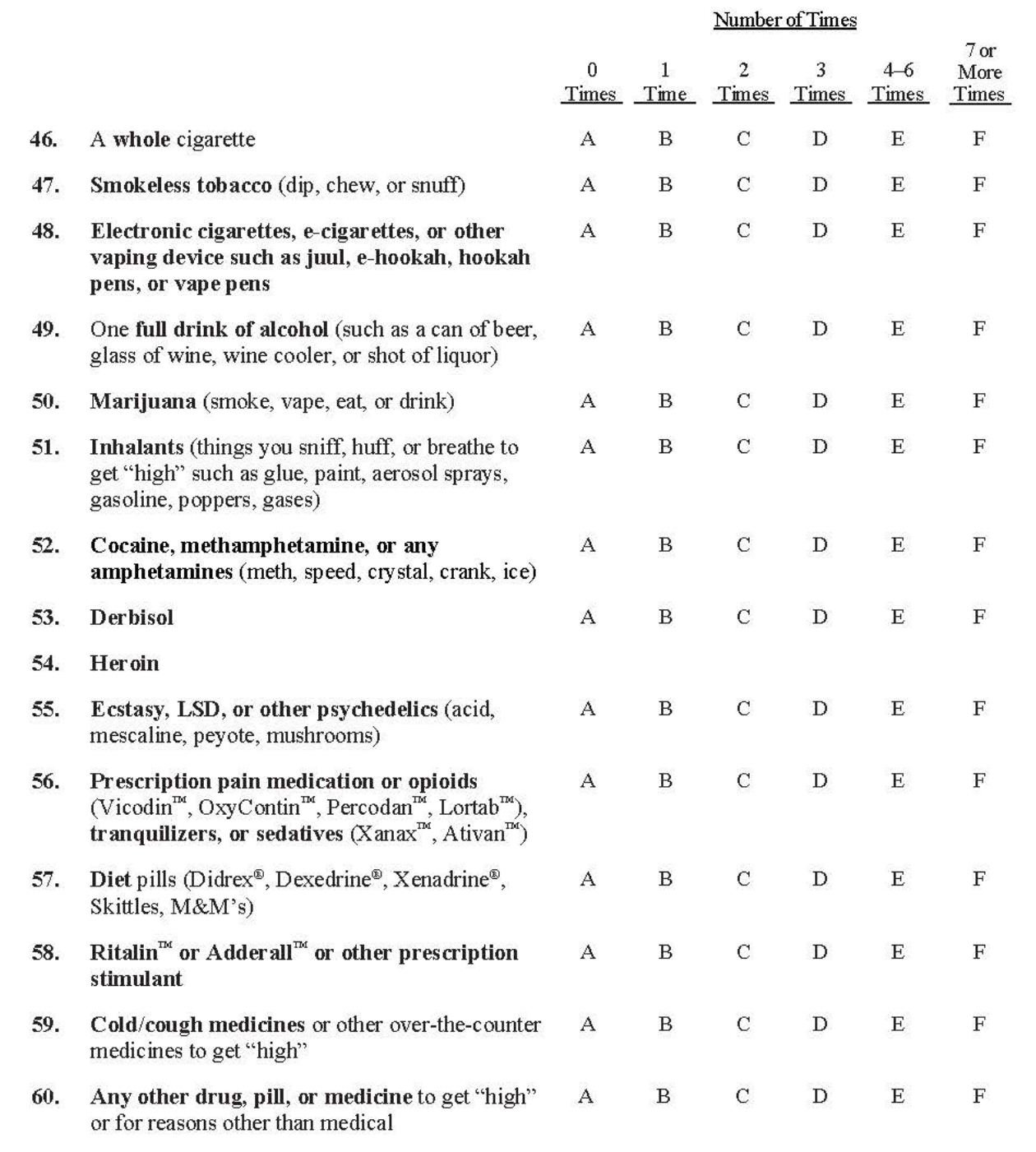




\section{A L I FOR N I A healthykids SUR V E Y Core Module}

During your life, how many times have you been...

\section{Number of Times}

$\begin{array}{llllllll}0 & 1 & 2 & 3 & 4 & & \end{array}$
Times Time Times Times Times Times

61. very drunk or sick after drinking alcohol?

$\begin{array}{llllll}A & B & C & D & E & F\end{array}$

62. "high" (loaded, stoned, or wasted) from using

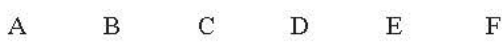
drugs?

63. drunk on alc ohol or "high" on drugs on school property?

$\begin{array}{llllll}\text { A } & \text { B } & \text { C } & \text { D } & \text { E } & \text { F }\end{array}$

During your life, how many times have you used marijuana in any of the following ways:

64. Smoke it?

65. In an electronic or e-cigarette or other vaping device?

66. Eat or drink it in products made with marijuana?

\section{Number of Times}

\begin{tabular}{|c|c|c|c|c|c|}
\hline 0 & 1 & 2 & 3 & $4-6$ & $\begin{array}{l}7 \text { or } \\
\text { More }\end{array}$ \\
\hline Times & Time & Times & Times & Times & Times \\
\hline
\end{tabular}

$\begin{array}{lllllll}\text { A } & B & C & D & E & F\end{array}$

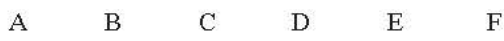

A $\quad$ B $\quad$ C $\quad$ D $\quad$ E $\quad$ F 


\section{A L I FOR N I A healthy kids SUR V E Y \\ Core Module}

During the past $\underline{30 \text { daws }}$, on how many days did you use...

67. cigarettes?

68. smokeless tobacco (dip, chew, or snuff)?

69. electr onic cigarettes, e-cigar ettes, or other vaping device such as juul, e-hookah, hookah pens, or vape pens?

70. one or more drinks of alcohol?

71. five or more drinks of alcohol in a row, that is, within a couple of hours?

72. marijuana (smoke, vape, eat, or drink)?

73. inhalants (things you sniff, huff, or breathe to get "high")?

74. prescription drugs to get "high" or for reasons other than prescribed?

75. any other drug, pill, or medicine to get "high" or for reasons other than medical?

76. two or more substances at the same time (for example, alcohol with marijuana, ecstasy with mushrooms)?

\begin{tabular}{|c|c|c|c|c|c|}
\hline $\begin{array}{c}0 \\
\text { Days }\end{array}$ & $\begin{array}{c}1 \\
\text { Day }\end{array}$ & $\begin{array}{c}2 \\
\text { Days } \\
\end{array}$ & $\begin{array}{c}3-9 \\
\text { Days }\end{array}$ & $\begin{array}{l}10-19 \\
\text { Days }\end{array}$ & $\begin{array}{r}20-30 \\
\text { Days } \\
\end{array}$ \\
\hline A & B & C & D & $\mathrm{E}$ & $\mathrm{F}$ \\
\hline A & B & C & D & $\mathrm{E}$ & $\mathrm{F}$ \\
\hline A & B & C & D & $\mathrm{E}$ & $\mathrm{F}$ \\
\hline A & B & $\mathrm{C}$ & D & $\mathrm{E}$ & $\mathrm{F}$ \\
\hline A & B & C & D & $\mathrm{E}$ & $\mathrm{F}$ \\
\hline A & B & $\mathrm{C}$ & D & $\mathrm{E}$ & $\mathrm{F}$ \\
\hline $\mathrm{A}$ & B & C & D & $\mathrm{E}$ & $\mathrm{F}$ \\
\hline $\mathrm{A}$ & B & C & D & $\mathrm{E}$ & $\mathrm{F}$ \\
\hline A & B & C & D & $\mathrm{E}$ & $\mathrm{F}$ \\
\hline $\mathrm{A}$ & B & $\mathrm{C}$ & D & $\mathrm{E}$ & $F$ \\
\hline
\end{tabular}




\section{A L I FOR N I A healthykids SUR V E Y \\ Core Module}

During the past $\underline{30 \text { davs }}$, on how many days on school property did you use...

78. smokeless tobacco (dip, chew, or snuff)?

79. electronic cigarettes, e-cigar ettes, or other vaping device such as juul, e-hookah, hookah

\begin{tabular}{|c|c|c|c|c|}
\hline 0 & 1 & 2 & 3-9 & $10-19$ \\
\hline A & $B$ & $\mathrm{C}$ & D & $F$ \\
\hline$A$ & $B$ & $\mathrm{C}$ & $D$ & $\mathrm{E}$ \\
\hline $\mathrm{A}$ & $B$ & $\mathrm{C}$ & $D$ & $\mathrm{E}$ \\
\hline
\end{tabular}
pens, or vape pens?

80. at least one drink of alcohol?

81. marijuana (smoke, vape, eat, or drink)?
82. any other drug, pill, or medicine to get "high" or for reasons other than medical?

How much do people risk harming themselves physically and in other ways when they do the following?

83. Smoke cigarettes occasionally

84. Smoke 1 or more packs of cigarettes each day

85. Use e-cigarettes (electronic) or vaping device occasionally

86. Use e-cigarettes or vaping devices several times a day (100 puffs or more)

87. Drink alcohol (beer, wine, liquor) occasionally

88. Have five or more drinks of alcohol once or twice a week

89. Use marijuana occasionally (smoke, vape, eat, or drink)

90. Use marijuana daily

How Much Risk or Harm

\begin{tabular}{|c|c|c|c|}
\hline Great & $\frac{\text { Moderate }}{\mathrm{D}}$ & Slight & None \\
\hline A & B & C & D \\
\hline A & B & C & D \\
\hline A & B & C & D \\
\hline A & B & C & D \\
\hline A & B & C & D \\
\hline A & B & C & D \\
\hline A & B & $\mathrm{C}$ & D \\
\hline A & B & C & D \\
\hline
\end{tabular}

How difficult is it for students in your grade to get any of the following if they really want them?

\begin{tabular}{|c|c|c|c|}
\hline Very & Fairly & Fairly & Very \\
\hline & & & \\
\hline
\end{tabular}

91. Cigarettes

92. E-cigarettes (electronic) or vaping device

93. Alcohol

94. Marijuana

$\begin{array}{llllll}\text { A } & \text { B } & \text { C } & \text { D } & \text { E } \\ \text { A } & \text { B } & \text { C } & \text { D } & \text { E } \\ \text { A } & \text { B } & \text { C } & \text { D } & \text { E } \\ \mathrm{A} & \text { B } & \text { C } & \text { D } & \text { E }\end{array}$

How many times have you tried to quit or stop using...

95. cigarettes?
96. alcohol?
97. marijuana?

\begin{tabular}{ccccc}
$\begin{array}{c}\text { Does Not } \\
\text { Apply, } \\
\text { Don?t Use }\end{array}$ & $\begin{array}{c}0 \\
\text { Times }\end{array}$ & $\begin{array}{c}1 \\
\text { Time }\end{array}$ & $\begin{array}{c}2-3 \\
\text { Times }\end{array}$ & $\begin{array}{c}\text { 4or More } \\
\text { Times }\end{array}$ \\
\hline A & B & C & D & E \\
A & B & C & D & E \\
A & B & C & D & E
\end{tabular}




\section{A L I FOR N I A healthykids SURVE Core Module}

98. During your life, how many times have you ever driven a car when you had been using alcohol or drugs, or been in a car driven by a friend when he or she had been using?
A) Never
B) 1 time
C) 2 times
D) 3 to 6 times
E) 7 or more times

\section{Next are questions about violence, safety, harassment, $\&$ bullying on school property.}

99. How safe do you feel when you are at school?
A) Very safe
B) Safe
C) Neither safe nor unsafe
D) Unsafe
E) Very unsafe

During the past $\underline{12 \text { months }}$, how many times on school property have you...

Happened on School Property

100. been pushed, shoved, slapped, hit, or kicked by someone who wasn't just kidding around?

101. been afraid of being beaten up?

102. been in a physical fight?

103. had mean rumors or lies spread about you?

104. had sexual jokes, comments, or gestures made to you?

105. been made fun of because of your looks or the way you talk?

106. had your property stolen or deliberately damaged, such as your car, clothing, or books?

107. been offered, sold, or given an illegal drug?

108. damaged school property on purpose?

109. carried a gun?

110. carried any other weapon (such as a knife or club)?

111. been threatened or injured with a weapon (gun, knife, club, etc.)?

112. seen someone carrying a gun, knife, or other weapon?

113. been threatened with harm or injury?

114. been made fun of, insulted, or called names?

\begin{tabular}{|c|c|c|c|}
\hline 0 Times & 1 Time & $\begin{array}{l}2 \text { to } 3 \\
\text { Times } \\
\end{array}$ & $\begin{array}{c}4 \text { or More } \\
\text { Times }\end{array}$ \\
\hline A & B & C & D \\
\hline $\mathrm{A}$ & B & $\mathrm{C}$ & D \\
\hline A & B & $\mathrm{C}$ & D \\
\hline A & B & C & D \\
\hline A & B & $\mathrm{C}$ & D \\
\hline A & B & C & D \\
\hline A & B & C & D \\
\hline A & B & $\mathrm{C}$ & D \\
\hline A & B & C & D \\
\hline A & B & C & D \\
\hline A & B & C & D \\
\hline A & B & C & D \\
\hline A & B & $\mathrm{C}$ & D \\
\hline $\mathrm{A}$ & B & C & D \\
\hline A & B & C & D \\
\hline
\end{tabular}




\section{A L I FOR N A healthykids SUR VEY Core Module}

127. On an average school night, how many hours of sleep do you get?
A) 4 or less hours
B) 5 hours
C) 6 hours
D) 7 hours
E) 8 hours
F) 9 hours
G) 10 or more hours

128. How many questions in this survey did you answer honestly?
A) All of them
B) Most of them
C) Only some of them
D) Hardly any

129. Is y our father, mother, or guardian currently in the military (Army, Navy, Marines, Air Force, National Guard, or Reserves)?
A) No
B) Yes
C) Don't know

130. Which of the following best describes you?
A) Straight (not gay)
B) Gay or Lesbian
C) Bisexual
D) I am not sure yet
E) Something else
F) Decline to respond

131. Some people describe themselves as transgender when their sex at birth does not match the way they think or feel about their gender. Are you transgender?
A) No, I am not transgender
B) Yes, I am transgender
C) I am not sure if I am transgender
D) Decline to respond 


\section{A L I FOR N I A healthykids S U R V E Y Core Module}

During the past 12 months, how many times on school property were you harassed or bullied for any of the following reasons? [You were bullied if you were shoved, hit, threatened, called mean names, teased, or had other unpleasant physical or verbal things done to you repeatedly or in a severe way. It is not bullying when two students of about the same strength or power quarrel or fight.]

115. Your race, ethnicity, or national origin

116. Your religion

117. Your gender

118. Because you are gay or lesbian or someone thought you were

119. A physical or mental disability

120. You are an immigrant or someone thought you were

121. Any other reason

\begin{tabular}{ccccc}
\multicolumn{4}{c}{ Happened on School Property } \\
0 Times & $\frac{1 \text { Time }}{2}$ & & $\begin{array}{c}2 \text { to } 3 \\
\text { Times }\end{array}$ & $\begin{array}{c}4 \text { or More } \\
\text { Times }\end{array}$ \\
A & B & C & & D \\
A & B & C & D \\
A & B & C & D \\
A & B & C & D \\
A & B & C & D \\
A & B & C & D \\
A & B & C & D
\end{tabular}

122. During the past 12 months, how many times did other students spread mean rumors or lies, or hurtful pictures, about you online, on social media, or on a cell phone?
A) 0 times (never)
B) 1 time
C) 2-3 times
D) 4 or more times

123. Do you consider yourself a member of a gang?
A) No
B) Yes

124. During the past 12 months, did you ever feel so sad or hopeless almost every day for two weeks or more that you stopped doing some usual activities?

A) $\mathrm{No}$

B) Yes

125. During the past 12 months, did you ever seriously consider attempting suicide?
A) No

B) Yes

126. Did you eat breakfast today?
A) No
B) Yes 